\title{
IN-DEPTH SURVEY REPORT OF CARBON MONOXIDE EMISSIONS AND EXPOSURES ON EXPRESS CRUISERS UNDER VARIOUS OPERATING CONDITIONS
}

\section{REPORT WRITTEN BY:}

Alberto Garcia, M.S.

Bryan Beamer, Ph.D., P.E., C.S.P.

G. Scott Earnest, Ph.D., P.E., C.S.P.

\section{REPORT DATE:}

January 2006

\section{REPORT NO:}

EPHB 289-11a

U.S. Department of Health and Human Services Centers for Disease Control and Prevention National Institute for Occupational Safety and Health

Division of Applied Research and Technology Engineering and Physical Hazards Branch 4676 Columbia Parkway, MS - R5

Cincinnati, Ohio 45226 
SITES SURVEYED:

SIC CODE:

SURVEY DATE:

SURVEY CONDUCTED BY:

EMPLOYEE REPRESENTATIVE

CONTACTED:
Florida, North Carolina and New Jersey

N/A

July 7 - December 15, 2005

Alberto Garcia, NIOSH

G. Scott Earnest, NIOSH

Bryan Beamer, UW-Stout

Dan Almaguer, NIOSH

NONE 


\section{DISCLAIMER}

Mention of any company or product does not constitute endorsement by the Centers for Disease Control and Prevention (CDC), National Institute for Occupational Safety and Health (NIOSH).

The findings and conclusions in this report are those of the authors and do not necessarily represent the views of the National Institute for Occupational Safety and Health. 


\section{EXECUTIVE SUMMARY}

Under an interagency agreement with the United States Coast Guard, working in collaboration with an industry consultant, National Institute for Occupational Safety and Health (NIOSH) researchers evaluated carbon monoxide (CO) exposures on ten express cruiser boats from several manufacturers. The evaluated boats were new and included several different models. These boats had gasoline-powered propulsion engines and used gasoline-powered generators to provide electricity for onboard appliances.

This study was performed for the U.S. Coast Guard to better understand how CO poisonings may occur on express cruisers, identify the most hazardous conditions, and begin the process of identify controls to prevent/reduce $\mathrm{CO}$ exposures. Boats were evaluated while stationary and at multiple speeds, ranging from 5 to 25 miles per hour. $\mathrm{CO}$ concentrations were measured by multiple real-time instruments, which were placed at different locations on the boats with overhead, enclosing canopies set at various configurations.

Many of the evaluated boats generated hazardous $\mathrm{CO}$ concentrations: peak CO concentrations often exceeded 1,100 parts per million (ppm), while average CO concentrations were well over $100 \mathrm{ppm}$ at the stern (rear). Two boats with a combined exhaust system (exhausting at the sides and underwater) had dramatically lower CO concentrations than any of the other evaluated boats (about $40 \%$ lower). Based on the results and observations made in this report, the following major findings are summarized below:

- When the canvas is deployed and boat is underway, CO concentrations exceeded the immediately dangerous to life and health (IDLH) level near the swim platform for many of the evaluated boats.

- The combination of travel at low speeds into the wind with the canvas fully deployed and no forward hatches, windows or front panels opened maximized the station wagon effect, pulling significant amounts of $\mathrm{CO}$ into the cockpit.

- Different exhaust configurations have a major impact on how CO concentrations are entrained into the cockpit and other occupied areas. Accordingly, boats equipped with underwater exhaust exhibited significantly lower CO concentrations than vessels equipped with other exhaust designs.

- CO concentrations are typically higher at the stern of the boat and become gradually lower toward the front of the boat.

- Stationary smoke tests in the engine compartment showed satisfactory sealing of the bulkhead between the engine and adjacent compartments on all boats.

Based on the preceding findings, the following recommendations are made to reduce $\mathrm{CO}$ concentrations on express cruisers: 
- Boat manufacturers should consider underwater exhaust that will significantly reduce $\mathrm{CO}$ concentrations inside the cockpit and other occupied areas compared to surface exhaust.

- Because of the station wagon effect, some canvas configurations should not be used while boat is moving or propulsion and/or generator engines are running.

- The possibility of adding force draft blowers into the cabin, creating a positive pressure to minimize potential CO intrusions, should be studied. Auxiliary blowers can be fitted and routed to ventilate the cockpit and swim platform areas in order to minimize negative pressure areas throughout the vessel.

- Since properly sealed cabin doors directly influenced the CO concentration in the cabin area, door suppliers should be encouraged to develop better sealing methods and designs.

- Windshield manufacturers should be encouraged to study the possibility of maximizing ventilation of occupied areas by improving the design of the center and side wings of the windshield.

- Due care should be exercised when designing the powered ventilation system on the engine compartment, locating the air intake on the opposite side of the generator exhaust. Also, potentially moving the intake much farther forward on the vessel would help minimize the intake of $\mathrm{CO}$ exhaust into the engine compartment.

- The development of cleaner burning engines (propulsion and generators) with catalytic converters should continue since they have the potential to greatly reduce $\mathrm{CO}$ concentrations to safer levels.

- The American Boat and Yacht Council (ABYC) should examine their standards and emphasize ventilation problems that can lead to $\mathrm{CO}$ intrusions, taking a strong position against surface exhaust designs for propulsion engines. 


\section{BACKGROUND}

On July 6 through December 14, 2005, researchers from the National Institute for Occupational Safety and Health (NIOSH) working with the U.S. Coast Guard and industry consultant evaluated carbon monoxide (CO) emissions and exposures on a variety of express cruisers at various locations in Florida, North Carolina and New Jersey. This evaluation was conducted under an interagency agreement between the U.S. Coast Guard's Office of Boating Safety and NIOSH to become more fully aware of the types of $\mathrm{CO}$ emissions and exposures that are occurring on express cruisers used in the United States today. Similar NIOSH surveys regarding houseboats and other types of recreational boats have been conducted and are described in separate reports. Each of the evaluated boats was propelled by gasoline-powered engines and had a gasolinepowered generator to provide electrical power for onboard appliances. This report provides background information and describes the study methods, results, discussion, conclusions, and recommendations.

A great deal of work has already been performed to evaluate $\mathrm{CO}$ exposures and controls on houseboats, but less effort has been given to understanding the extent of the $\mathrm{CO}$ hazard on other types of recreational boats. Overall, as many as $185 \mathrm{CO}$ poisonings are known to have occurred on or near recreational boats (non-houseboats) [DOI, 2004]. The current study was intended to provide a better understanding of the CO exposures that occur on express cruiser boats, to identify the most hazardous conditions, and begin the process of identify controls to prevent/reduce CO exposures. Collection of environmental data was vital to this effort, by testing the variability between different kinds of boats, engines, and design features.

\section{CO Poisonings on Recreational Boats (Non-Houseboats)}

A sampling of cases in which $\mathrm{CO}$ is known to have played a role in creating injuries or fatalities on recreational boats is provided below. These cases come from the document "Boat-Related Carbon Monoxide (CO) Poisonings" available at the Department of the Interior and available at http://safetynet.smis.doi.gov/thelistbystate10-19-04.pdf [DOI, 2004] website.

\section{Nevada - Lake Powell}

Since 1990, 19 people have been poisoned while in the cabin or within a canopy of a pleasure craft (other than houseboat) on Lake Powell. Six of the 19 people were poisoned by generator exhaust while inside a cabin cruiser boat during a single incident. The remaining 13 people were poisoned by propulsion engine exhaust. Eight of the 19 people lost consciousness as a result of their exposure. (Source: Review of NSP EMS Records, Glen Canyon National Recreation Area.) 


\section{California - Unspecified water body}

In 1998, 4 people were poisoned while occupying the cabin of a cabin cruiser boat powered by an inboard engine. Three people were above deck and four were below deck. There appeared to have been a ventilation system failure that caused CO to enter the cabin area, sickening all four people below deck. The two most seriously affected were a 7-year-old female and a 4-year-old male. All received medical attention and recovered. (Source: US Coast Guard Database.)

\section{Florida - Intercostals Waterway near Jacksonville}

In 1991, a woman died while occupying the cabin of a moving 42' cabin cruiser piloted by her husband. She was seated at the table, and her sister was seated near the door. The sea was very rough. When the husband went to the cabin at one point, his wife was ill. They assumed it was sea-sickness due to the rough ride. He returned to the helm. After many miles of returning to the calmer waters of the Intracoastal Waterway, the sister asked him to return to the cabin. He found his wife on the floor beneath the table, dead. The resulting investigation determined that she died of $\mathrm{CO}$ poisoning from the propulsion engines exhaust. (Source: personal communication with the husband, United States District Court Middle District of Florida Jacksonville Division records.)

\section{Florida - Ocean near Clearwater}

In June 2004, three passengers were overcome by CO while traveling in the air conditioned cabin of a 40-foot cabin cruiser. The boat, with nine passengers aboard, left Island Estates at about 7:00 a.m. for a fishing trip. When the boat returned shortly after noon, one member of the group went into the cabin to wake three people who had decided to take a nap. The sleeping boaters could not be awakened. Rescue crews determined that the passengers had suffered $\mathrm{CO}$ poisoning. They were transported to the local hospital, and then on to a hospital where they could be treated in a hyperbaric oxygen chamber. One of the three remained hospitalized for several days. (Source: Tampa Tribune newspaper.)

\section{Florida - Unspecified water body}

In 1998, 4 people (ages 6, 9, 10, and 38) survived poisoning aboard a cabin cruiser with an inboard stern drive propulsion engine. The database states that exhaust fumes drifted into the cabin. (Source: US Coast Guard Database.)

\section{Maryland - Broad Creek}

In 2000, 3 children survived poisoning aboard a cabin cruiser that was rafted with several others. All of the boats were operating their generators for electrical power. There were 3 juveniles asleep in the cabin of one of the vessels with the windows and doors closed. CO had collected in the cabin. When the juveniles were awakened, they were sluggish, unresponsive, and nauseous. (Source: US Coast Guard Database.) 


\section{Maryland - Main Bay Area}

In 2000, the operator of a cabin cruiser with an inboard propulsion engine was poisoned. The operator stated that he had the canopy of his vessel closed.

There was no wind, and it believed that the exhaust from the engine collected inside. When the operator began to feel ill, he called for help suspecting CO poisoning. (Source: US Coast Guard Database.)

\section{Maryland - Unspecified water body}

In May 2001, 2 people (the operator and a passenger) were poisoned aboard a cabin cruiser with an inboard propulsion engine. The cockpit was enclosed by side and back curtains, and a back door was open. A "station wagon effect" caused exhaust to be drawn into the vessel. The passenger went into the cabin and was overcome by $\mathrm{CO}$ that had apparently accumulated in the lower areas. Both were treated for CO poisoning and released. (Source: US Coast Guard Database.)

\section{Carbon Monoxide Symptoms and Exposure Limits}

$\mathrm{CO}$ is a lethal poison, produced when fuels such as gasoline or propane are burned. It is one of many chemicals found in engine exhaust, which results from incomplete combustion. Because CO is a colorless, odorless, and tasteless gas, it may overcome the exposed person without warning. The initial symptoms of CO poisoning may include headache, dizziness, drowsiness, or nausea. Symptoms may advance to vomiting, loss of consciousness, and collapse if prolonged or high exposures are encountered. If the exposure level is high, loss of consciousness can occur without other symptoms. Coma or death can occur if high exposures continue [NIOSH 1972; NIOSH 1977; NIOSH 1979]. The display of symptoms varies widely from individual to individual, and may occur sooner in susceptible individuals, such as young or aged people, people with preexisting lung or heart disease, or those living at high altitudes [Proctor, Hughes, et al. 1988; ACGIH 1996; NIOSH 2000].

Exposure to CO limits the ability of blood to carry oxygen to tissues because it binds with the hemoglobin to form COHb. Blood has an estimated 210-250 times greater affinity for $\mathrm{CO}$ than oxygen; thus, the presence of $\mathrm{CO}$ in the blood interferes with oxygen uptake and delivery to the body [Forbes, Sargent, et al. 1945].

Although NIOSH typically focuses on occupational safety and health issues, the Institute is a public health agency and cannot ignore the overlapping exposure concerns between marine workers and boat passengers in this type of setting. NIOSH researchers have done a considerable amount of work related to controlling CO exposures in the past [Ehlers, McCammon, et al. 1996; Earnest, Mickelsen, et al. 1997; Kovein, Earnest, et al. 1998]. 


\section{Exposure Criteria}

Occupational criteria for CO exposure are applicable to U.S. National Park Service (USNPS) and concessionaire employees who have been shown to be at risk of boatrelated CO poisoning. The occupational exposure limits noted below should not be used for interpreting general population exposures (such as visitors engaged in boating activities). Occupational standards do not provide the same degree of protection for the general population as they do for healthy workers; the effects of $\mathrm{CO}$ are more pronounced in a shorter time if the person is physically active, very young, very old, or has preexisting health conditions such as lung or heart disease. Persons at extremes of age and persons with underlying health conditions may have marked symptoms and may suffer serious complications at lower levels of carboxyhemoglobin. Standards relevant to the general population take these factors into consideration, and are listed following the occupational criteria. The NIOSH Recommended Exposure Limit (REL) for occupational exposures to CO gas in air is 35 ppm for a full shift time-weighted average (TWA) exposure, and a ceiling limit of 200 ppm, which should never be exceeded [CDC 1988; CFR 1997]. The NIOSH REL of 35 ppm is designed to protect workers from health effects associated with COHb levels in excess of 5\% [Kales 1993]. NIOSH has established the immediately dangerous to life and health (IDLH) value for CO as 1,200 ppm [NIOSH 2000]. The American Conference of Governmental Industrial Hygienists' $\left(\right.$ ACGIH $\left.^{\circledR}\right)$ recommends an 8-hour TWA threshold limit value (TLV ${ }^{\circledR}$ ) for occupational exposures of 25 ppm [ACGIH 1996] and discourages exposures above 125 ppm for more than 30 minutes during a workday. The Occupational Safety and Health Administration (OSHA) permissible exposure limit (PEL) for CO is $50 \mathrm{ppm}$ for an 8hour TWA exposure (CFR 1997).

\section{Health Criteria Relevant to the General Public}

The U.S. Environmental Protection Agency (EPA) has promulgated a National Ambient Air Quality Standard (NAAQS) for CO. This standard requires that ambient air contain no more than 9 ppm CO for an 8-hour TWA, and 35 ppm for a 1-hour average [EPA 1991]. The NAAQS for CO was established to protect "the most sensitive members of the general population” by maintaining increases in carboxyhemoglobin to less than $2.1 \%$.

The World Health Organization (WHO) has recommended guideline values and periods of time-weighted average exposures related to $\mathrm{CO}$ exposure in the general population [WHO 1999]. WHO guidelines are intended to ensure that COHb levels not exceed $2.5 \%$ when a normal subject engages in light or moderate exercise. Those guidelines are:

$100 \mathrm{mg} / \mathrm{m}^{3}$ (87 ppm) for 15 minutes

$60 \mathrm{mg} / \mathrm{m}^{3}$ (52 ppm) for 30 minutes

$30 \mathrm{mg} / \mathrm{m}^{3}$ (26 ppm) for 1 hour

$10 \mathrm{mg} / \mathrm{m}^{3}$ (9 ppm) for 8 hours 


\section{METHODS}

Air sampling for CO, ventilation, and wind-velocity measurements were collected on 10 different express cruisers built by various manufacturers. The evaluated boats had new drive engines and generator sets, tuned to manufacturer's specifications. Drive engines used on the evaluated boats were manufactured by Volvo Penta, Crusader Marine and Mercury Marine and generators were all manufactured by Kohler. Data was collected to evaluate the $\mathrm{CO}$ emissions of gasoline-powered engines and $\mathrm{CO}$ exposures on and near the boats, operating under various conditions.

A description of the boats, the drive engines, and generator set is provided below. All boats had inboard engines, and most of them were stern drive units, with the exception of three that had straight inboard units. On inboard engines, the engine and drive train are permanently mounted near the center of the boat's hull, and the propeller shaft penetrates beneath the hull. Stern drives are located near the back of the boat. Stern drives have permanently mounted engines, however, the drive train penetrates the transom of the vessel.

\section{Description of the Evaluated Recreational Boats}

\section{Boats evaluated}

\section{Boat 1 (33')}

- Engines: Twin Volvo Penta 5.7L

- Generator: Gas 120 v 5.0 KW Kohler

- Approximate dimensions of boat:

o Length: 34'8"

o Beam: 11' 4"

- Exhaust Configuration: Exhaust through hub

Boat 2 (30')

- Engines: Twin Mercruiser 5.0L

- Generator: Gas 120 v 5.0 KW Kohler

- Approximate dimensions of boat:

o Length: 30'10"

o Beam: 10' 6"

- Exhaust Configuration: Exhaust through hub

Boat 3 (31')

- Engines: Twin Volvo Penta 8.1L

- Generator: Gas 120 v 7.3 KW Kohler

- Approximate dimensions of boat:

o Length: 33'1"

o Beam: 11'0" 
- Exhaust Configuration: Exhaust through hub

Boat 4 (37')

- Engines: Twin Mercruiser 8.1L

- Generator: Gas 120 v 7.3 KW Kohler

- Approximate dimensions of boat:

o Length: 38'4"

o Beam: 10' 6"

- Exhaust Configuration: Equipped with both through transom and through hub (underwater) selectable by operator.

Boat 5 (36')

- Engines: Twin Mercruiser 8.1L

- Generator: Gas 120 v $7.3 \mathrm{KW}$ Kohler

- Approximate dimensions of boat:

o Length: 39'0"

o Beam: 12'6"

- Exhaust Configuration: Combined Exhaust Through the Sides and Underwater

Boat 6 (40')

- Engines: Twin Mercruiser 8.1L

- Generator: Gas 120 v 7.3 kW Kohler

- Approximate dimensions of boat:

o Length: 45'0"

o Beam: 14'0"

- Exhaust Configuration: Combined Exhaust Through the Sides and Underwater

Boat 7 (41')

- Engines: Twin Mercruiser 8.1L

- Generator: Gas 120 v 7.3 KW Kohler

- Approximate dimensions of boat:

o Length: 42'6"

o Beam: 13'8"

- Exhaust Configuration: Combined Exhaust Through the Sides and Underwater

Boat 8 (34')

- Engines: Twin Mercruiser 8.1L

- Generator: Gas 120 v 7.3 kW Kohler

- Approximate dimensions of boat:

o Length: 36'6"

o Beam: 11'8"

- Exhaust Configuration: Side Exhaust only

Boat 9 (38')

- Engines: Twin Crusader 8.1L

- Generator: Gas 120 v 8.0 KW Kohler 


\section{- Approximate dimensions of boat:}

o Length: 38'11"

o Beam: 14'4"

- Exhaust Configuration: Underwater Exhaust

\section{Boat 10 (35')}

- Engines: Twin Crusader 8.1L

- Generator: Gas 120 v 8.0 KW Kohler

- Approximate dimensions of boat:

o Length: 35'2"

o Beam: 13'4"

- Exhaust Configuration: Underwater Exhaust

\section{Exhaust Configurations Evaluated}

The following notes refer to the different exhaust configurations evaluated:

- Through-Hub Exhaust: Through-hub exhaust and over-hub exhaust propellers are used on boats where the exhaust passes out through the rear of the "torpedo" on the lower unit, around the propeller shaft. Most outboards utilize this type of exhaust.

- Through Transom Exhaust: The exhaust is directed through openings located on the transom (stern) of the vessel, usually above water line.

- Side Exhaust: The exhaust is directed through openings located on the sides of the boat near the transom of the vessel, usually above water line.

- Underwater Exhaust: The exhaust is directed through openings located on the transom (stern) of the vessel, and then released through an elbow shaped fiberglass structure about $1.5 \mathrm{ft}$ below the water line.

- Combined Exhaust through Sides and Underwater: The system is engineered to release all the exhaust at the surface through the sides of the vessel when the engine is idling or the rpm has not exceeded $1500 \mathrm{rpm}$. When the engine exceeds $1500 \mathrm{rpm}$, a pressure release mechanism is activated releasing most of the exhaust underwater, a foot away from the transom, on the lower part of the vessel hull.

There are several differences between automobile engines and marine engines used on recreational boats relate to the cooling and exhaust systems. The cooling system in an automobile engine is closed-loop having air-to-water radiators. In contrast, marine engines are open-loop drawing sea or lake water into the engine's water pump. The second big difference between auto and marine engines is that marine engines use watercooled exhaust manifolds to mix water with exhaust gases for cooling. The objective is 
to keep all surface temperatures within the boat below $200^{\circ} \mathrm{F}$. In contrast, automobile engines do not add water into the engine exhaust. A third difference relates to the treatment of the exhaust gases before releasing them to the atmosphere. In automobile engines, the exhaust passes through a catalytic converter which removes many of the air pollutants, including CO. In contrast, exhausts from marine engines are directly released into the environment without passing through a catalyst.

The hot exhaust gases produced by the generators were injected with water, near the end of the exhaust manifold, in a process commonly called "water-jacketing." Waterjacketing is used for exhaust cooling and noise reduction. All generators in this study exhausted on one side of the boat, close to the transom of the vessel above the water line.

\section{Description of the Evaluation Equipment}

- Biometrics Inc., ToxiUltra Atmospheric Monitors equipped with CO sensors

- $\quad$ TSI Inc., Q-trak equipped with CO sensor

- Sensidyne handheld smoke tubes

- $\quad$ TSI Inc., Velocicalc Plus Model 8360 air velocity meter with micro manometer

- Draeger Accuro Handheld colorimetric detector tubes

- Rosco Fog Machine

- Mine Safety and Health Administration (MSHA) Glass evacuated containers

CO concentrations were measured at various locations on the boat by ToxiUltra Atmospheric Monitors (Biometrics, Inc.), equipped with CO sensors. ToxiUltra CO monitors were calibrated before and after use, according to the manufacturer's recommendations. These monitors are direct-reading instruments, having data logging capabilities. The instruments were operated in the passive diffusion mode, having a 30 second sampling interval. The instruments have a nominal range, from $0 \mathrm{ppm}$ to approximately 999 ppm.

CO concentration data was also collected with colorimetric detector tubes (Draeger A.G. [Lubeck, Germany] CO, CH 29901-range 0.3\% [3,000 ppm] to 7\% [70,000 ppm]) in the areas near the rear swim deck. Having a bellows-type pump, allows air to be drawn through the tube. The resulting length of the stain in the tube (produced by a chemical reaction with the sorbent) is proportional to the concentration of the air contaminant. Grab samples were collected using MSHA 50-mL glass evacuated containers. These samples were collected by snapping open the top of the glass container and allowing the air to enter. Then, containers were sealed with wax-impregnated MSHA caps. The samples were then sent to DataChem laboratories in Salt Lake City, UT, where a Varian 3800 gas chromatography equipped with a methanizer and thermal conductivity, flame ionization and electron capture detectors, was used to analyze them for CO. 
During air sampling, researchers took wind velocity measurements when the boat was stationary or measured air velocity with respect to the boat when it was underway, by using a VelociCalc Plus Model 8360 air velocity meter (TSI Inc., St. Paul, MN). The air velocity meter measured wind speeds based upon the heat transfer to the air from a heated probe. The same instrument was also used as a pressure differential device to compare the pressure between the engine compartment and adjacent cabin space. Boat speed was estimated using Magellan Meridian Marine global positioning system. Smoke tubes and a Rosco fog machine device were used to assess air flow patterns on the moving boat and qualitatively assess whether the engine emissions were being reentrained into the boat under various operating conditions.

\section{Description of Procedures}

Evaluations were conducted on various boats and involved teams of several people. Each team consisted of: 1) a person to steer the boats, start the engines, and provide mechanical assistance when necessary, this person was usually from the collaborating organization; 2) two to three NIOSH researchers to collect data and organize experimentation; 3) an industry consultant; 4) a representative from the USCG to act in an advisory capacity. Following each day of data collection, NIOSH researchers downloaded data and recalibrated instruments. Two boats were typically evaluated per day. Testing took approximately three hours for each boat and included both stationary and underway conditions.

Testing was made with boats' canopies in various configurations. At a minimum, each boat was tested under the following conditions: 1) with canopy enclosing the cockpits fully closed except for the rear flaps open; 2) canopy fully enclosing the cockpit except for the rear and side flaps open; 3) canopy entirely removed except for the top section. Since each boat had a different canopy design, testing between boats was not entirely uniform, although attempts were made to approximate similar conditions from boat to boat. See Tables 1-5 for specifics on testing conditions and canopy configurations. For each canopy configuration, underway boat emissions were evaluated at five different speeds: stationary, 5 miles per hour (mph), $10 \mathrm{mph}, 15 \mathrm{mph}$ and $25 \mathrm{mph}$.

Boat speed was measured by onboard Global Positioning System (GPS) equipment. When possible, researchers conducted testing both into the wind and with the wind; however, this was not possible for testing where boat direction was dictated by channel routes. Temperature and relative humidity were measured every time a new run was initiated. Researchers gathered CO samples at various locations on the boat and in the engine compartment using ToxiUltra monitors (see Figure 1). Monitors were partially wrapped in plastic to protect them from water. All CO monitors and stop watches were synchronized with the computer's clock to accurately correlate each test with downloaded data. Monitors were placed at various locations on the boats, in part, to approximate passenger position during operation. Because $\mathrm{CO}$ emissions originate from engine exhaust near the stern of the boat, multiple CO monitors were placed in this area. 
Through an interactive approach, evaluations were performed to establish how carbon monoxide flows into an express cruiser cabin. First, tests were conducted to determine the presence of $\mathrm{CO}$ within the engine room. Potential sources of CO contamination could result from a propulsion engine leak or induction of exhaust gases into the engine compartment via the blower system. For positive results, additional tests were conducted to determine if leakage from the engine compartment was making its way to the cabin (e.g., unsealed firewall). Pressure differential measurements were collected between the engine compartment and the adjacent cabin. If the pressure within the engine compartment is positive with respect to the cabin, the potential for flow from the engine compartment to the cabin exists. Additional measurements using $\mathrm{CO}$ real-time detectors and smoke generators were used to track the flow of carbon monoxide from the engine compartment to the adjacent cabin area.

In addition to CO sampling and air velocity measurements, all warning labels placed on the boat, as well as those provided in the owner's manual were inspected for each of the evaluated boats. 


\section{RESULTS}

\section{Results of Air Sampling with ToxiUltra CO Monitors}

Summary statistics for the data collected with the ToxiUltra CO monitors are shown in Tables 6 through 15. These tables are organized so that the experiment number is designated along the left-hand column and ToxiUltra number is listed across the top row. For each sample location and condition a CO mean (Tables 6, 8, 10, 12, and 14) and peak concentration (Tables 7, 9, 11, 13, and 15) is reported. Each CO mean and standard deviation is rounded to the nearest whole number. CO concentrations exceeding approximately 1,000 ppm in Tables 6 through 15 indicate that the upper limit of the instrument was reached and the exact $\mathrm{CO}$ concentration and duration is uncertain. Graphs depicting the average CO concentrations in Tables 6 through 15 for selected boats and conditions are shown in Figures 5 through 14.

\section{ToxiUltra CO Samples while the Boat was Underway}

Air sampling data was collected while the boats were underway, resulting in generally lower concentrations than while the boats were stationary. CO concentrations measured on the boats tended to rise near the cockpit and swimming platform as the boats began to move and as speed increased (see graphs in Figures 5-14). Figure 1 details specific locations that $\mathrm{CO}$ concentrations were measured, which include the following:

- On or near the swimming platform (Port, Center and Starboard)

- Inside of the boat (Several locations within the cockpit)

- Inside the cabin (Two locations where beds or sofas are located)

- Inside the engine compartment

In Table 11, the CO concentrations were considerably lower on the swim platform and cockpit of the vessel compared to the other evaluated vessels. The highest mean concentration for a 36' express cruiser was 293 ppm when going underway at $10 \mathrm{mph}$. The highest mean concentration on the cockpit of this unit was 73 ppm when going at 15 mph with partial canvas installed. Figures 9 and 10 represent the average concentration of the data presented in Table 11. The boats in these figures were equipped with a combined exhaust system, which exhausted through the sides and underwater.

Measured CO concentrations were substantially higher in boats exhausting above waterline. That is the case for boat depicted in Figure 8, equipped with Twin Mercruisers exhausting through four openings at the transom of the vessel above waterline. The highest mean concentration was 975 ppm (close to the NIOSH IDLH) on the swim platform of the vessel when going underway at $5 \mathrm{mph}$ with canvas fully installed. CO concentrations in the cockpit of this unit were as high as $630 \mathrm{ppm}$ behind the captain seat when canvas was fully installed and going at $5 \mathrm{mph}$. These results can be observed on Table 9.

In Figure 11, the CO concentration on the center of the swim platform did not followed the same pattern as the other vessels, in where CO concentrations tended to greatly reduce as speed increased. This unit is considered a Motor Yatch which geometric shape 
on the stern of the vessel is very different from a regular express cruiser. Average CO concentrations were around $250 \mathrm{ppm}$ when going at 5, 10 and $15 \mathrm{mph}$. These concentrations dropped to $166 \mathrm{ppm}$ when the boat increased speed to $25 \mathrm{mph}$. This unit was also equipped with a system which exhausted through the sides and underwater.

The data presented in Table 13 from experiment 14 to 29 shows the peak CO concentration for a 34' exhausting solely through the sides. Figure 12 depicts the different conditions with canvas, partial canvas and bimini top only. In this figure, it can be observed that $\mathrm{CO}$ concentrations were reduced by a factor of 10 when no canvas was installed (bimini top only) compared to full canvas conditions.

\section{ToxiUltra CO Samples While the Boats were Stationary}

$\mathrm{CO}$ concentrations measured on stationary boats were generally medium to high. Peak CO concentrations ranged from single digit numbers to approximately $950 \mathrm{ppm}$.

Stationary conditions usually displayed higher CO concentrations than when the boat is moving for all of the evaluated vessels. For most cases, when testing boats on stationary conditions, virtually no air circulation other than environmental wind was sweeping the $\mathrm{CO}$ away from the vessel.

\section{Detector Tubes and Evacuated Container Results}

Colorimetric detector tubes, and glass evacuated containers were primarily used to characterize CO concentrations at the rear of the vessel. These instruments were used because they are capable of reading higher $\mathrm{CO}$ concentrations than the ToxiUltra CO monitors, which have an upper limit of approximately 1,000 ppm.

Summaries of the detector tube and evacuated container air sampling results are shown in Tables 16 through 25. In general, detector tube and evacuated container air sampling results support measurements made with the ToxiUltra instruments. Any variations in readings among different $\mathrm{CO}$ detection instruments for a particular experiment can be explained by one of several, expected reasons: 1) readings for ToxiUltra CO monitors have an upper limit of approximately 1000 ppm so that any readings above this level may be skewed; 2) although colorimetric detector tubes' accuracy is well established, this method makes a less precise measurement than other instruments used (typically within $+/-10 \%)$; and 3) measurements for any instrument will vary depending on the localized conditions at that instant.

\section{Relative Wind Velocity Measurements}

On the whole, wind velocity measurements were taken to be used as a reference to further investigate unexpected trends in CO concentrations. Wind velocity measurements were collected using a hot wire anemometer. Tables 26 to 29 provide relative wind velocities for various boats and test conditions. As expected, wind velocities varied relative to boat speed depending upon whether the boat was traveling into the wind or with the wind. It should be noted that relative wind velocities were not measured for boats evaluated in 
Millville, NJ since the tests were conducted on an S-shaped river which produced constantly changing wind directions.

\section{Smoke and Pressure Differential Tests}

When underway, smoke tests revealed several trends on all the evaluated boats. When traveling at 5 - $10 \mathrm{mph}$ with the canvas fully installed, the recirculation patterns were observed to be as high as $4 \mathrm{ft}$ measured from the cockpit floor. When traveling at $15 \mathrm{mph}$ with canvas fully installed, this height was reduced to $3 \mathrm{ft}$ from the cockpit floor. Finally when traveling at $25 \mathrm{mph}$ the recirculation pattern was observed to be shifted to two feet measured from the cockpit floor. Figures 2, 3 and 4 provide an illustration of this scenario.

Smoke tests into the engine compartment of all of the evaluated vessels revealed satisfactory sealing of the bulkhead between the engine room and adjacent compartments. Virtually no migration was observed to adjacent rooms or cabin area when releasing smoke in the engine room. This test was performed without the operation of the powered ventilation of the engine compartment. When energizing the powered ventilation of the engine compartment, a good configuration of the intake and exhaust opening was observed for all of the evaluated vessels.

When underway, pressure differential measures revealed a slightly negative pressure in the cabin room compared to the cockpit area for some of the evaluated express cruisers. 


\section{DISCUSSION}

\section{Description of Trends for Individual Boats}

\section{Boat 1: 33' Twin Volvo Penta 5.7L Exhausting Through the Hub.}

This boat exhibited CO levels exceeding 1000 ppm near the center of the stern for 10 and $15 \mathrm{mph}$ into the wind and with the wind (with canvas fully installed). Fairly high concentrations were observed in the engine compartment when no canvas was installed (Bimini top only) at speeds of 15 and $25 \mathrm{mph}$. Potential CO leakage from the engine compartment was possible since the boat's drive engines and generator set were brand new.

CO levels inside the cabin ranged from $0 \mathrm{ppm}$ to $170 \mathrm{ppm}$. This can partially be explained by continuous opening and closing of the cabin sliding door. CO levels varied within the vessel even at similar locations, a phenomenon that can be explained by wind factors and aerodynamics of the vessel. In general, $\mathrm{CO}$ distributions were higher at the stern of the boat (near source) and tended to decline toward the front of the vessel. Refer to Tables 6 and 7 and the graphs in Figure 5 for more details.

\section{Boat 2: 30' Twin Mercruiser 5.0L Exhausting Through the Hub.}

This boat exhibited CO concentrations that not only exceeded $1000 \mathrm{ppm}$ but also approached the $1200 \mathrm{ppm}$ NIOSH IDLH limit on the center of the stern, with and without canvas. The engine compartment on this vessel experienced $\mathrm{CO}$ concentrations approaching the NIOSH IDLH when canvas was installed and close to $1000 \mathrm{ppm}$ when canvas was fully removed (bimini top only). The cockpit of this unit was usually cleared by fresh air, with the exception of $15 \mathrm{mph}$ and no canvas installed. This fact can be attributed to weather conditions since no wind was present during that particular experiment. Cabin concentrations ranged from 0 to $180 \mathrm{ppm}$. Several attendees entered the cabin on different occasions allowing contaminated air to migrate from the cockpit to the cabin.

Exhibiting a trend seen on other tested boats, $\mathrm{CO}$ concentrations were higher on the stern of the vessel (near source), and tended to decrease toward the front of the vessel. The engine compartment consistently exhibited CO concentrations above $150 \mathrm{ppm}$, with a couple peaks at $1100 \mathrm{ppm}$; this might be indicative of a problem with the powered ventilation of this compartment. More details about this particular boat can be found in Tables 6 and 7 and the graphs in Figure 6.

\section{Boat 3: 31' Twin Volvo Penta 8.1L Exhausting Through the Hub.}

Peak concentration on this vessel exceeded $650 \mathrm{ppm}$ at the stern of the boat when the canvas was fully installed. CO concentrations in the cockpit were below the NIOSH ceiling of $200 \mathrm{ppm}$ at all times, and considerably lower when the canvas was fully removed (bimini top only). Inside the cabin CO concentrations never exceeded $60 \mathrm{ppm}$ with an average concentration of $27 \mathrm{ppm}$. Engine compartment concentrations were well below $120 \mathrm{ppm}$ when canvas was fully installed and below $45 \mathrm{ppm}$ when canvas was fully removed. As with the other vessels, $\mathrm{CO}$ concentrations were consistently higher at 
the stern of the boat, and gradually reduced toward the front of the vessel. Tables 8 and 9 and the graphs in Figure 7 contain additional information for this vessel.

\section{Boat 4: 37' Twin Mercruiser 8.1L Exhausting Through the Transom.}

This vessel was equipped with an adjustable exhaust system that allowed the operator to choose an exhaust configuration: through the transom above waterline or though the hub. For all experiments, the exhaust was routed through the transom. CO concentrations were consistently higher near the stern of the boat and reduced gradually toward the front of the vessel. CO concentrations ranged between 24 and 658 ppm at the stern of the boat. Inside the cabin, concentrations ranged from 3 to $166 \mathrm{ppm}$. The cabin door was closed at all times except when occupants visited the cabin. Overall, the engine compartment had low CO concentrations ranging from 17 to $100 \mathrm{ppm}$; however with the canvas fully installed, CO levels did rise to between 237 and 297 ppm. Cockpit concentrations tended to be higher when canvas was installed with an average of 200 ppm compared to $20-70$ ppm when canvas was fully removed. Refer to Tables 8 and 9 and the graphs in Figure 8 for more details.

\section{Boat 5: 36' Twin Mercruiser 8.1L Combined Exhaust Through the Sides and Underwater.}

In terms of onboard $\mathrm{CO}$ concentrations, this boat performed remarkably better than other evaluated boats. The main reason for this is that the vessel was equipped with a combined exhaust configuration - the exhaust was directed not only through the sides of the vessel but also underneath the hull of the boat under certain conditions. As long as the engine was idling or the rpm had not exceeded $1500 \mathrm{rpm}$, the exhaust was directed through the sides of the vessel only. However when the engine built enough pressure on the exhaust to overcome the pressure below the hull, $85 \%$ of the exhaust was directed underwater and the remaining 15\% exhausted through the sides of the vessel.

CO concentrations at the stern of the unit were consistently below the NIOSH ceiling limit of $200 \mathrm{ppm}$ with the canvas fully installed and below $50 \mathrm{ppm}$ when the canvas was fully removed. The engine compartment was completely clear of CO contamination indicating a good design and operation of the powered ventilation system on the engine compartment. CO concentrations in the cabin never exceeded $18 \mathrm{ppm}$ when the canvas was fully installed and $10 \mathrm{ppm}$ when the canvas was fully removed. Cockpit concentrations were consistently below 90 ppm at all times when the canvas was fully installed and below $12 \mathrm{ppm}$ when the canvas was removed. More details about this particular boat can be found in Tables 10 and 11 and the graphs in Figure 9.

\section{Boat 6: 40' Twin Mercruiser 8.1L Combined Exhaust Through the Sides and Underwater.}

This boat was equipped with the combined exhaust configuration described above - the exhaust was directed not only through the sides of the vessel but also underneath the hull of the boat under certain conditions. As long as the engine was idling or the rpm had not exceeded $1500 \mathrm{rpm}$, the exhaust was directed through the sides of the vessel only. However when the engine built enough pressure on the exhaust to overcome the pressure below the hull, $85 \%$ of the exhaust was directed underwater and the remaining $15 \%$ 
exhausted through the sides of the vessel. Although this vessel performed better than other boats evaluated, it still exhibited higher concentrations at the stern of the vessel than boats equipped with the same exhaust configuration.

CO concentrations at the stern of the vessel ranged from 30 to $430 \mathrm{ppm}$ when the canvas was fully installed and between 0 and $67 \mathrm{ppm}$ when the canvas was fully removed. The engine compartment was completely clear of $\mathrm{CO}$ contamination indicating a good design and operation of the powered ventilation system. Cockpit concentrations never exceeded 75 ppm when the canvas was fully installed and 25 ppm without the canvas.

Concentrations in the cabin never exceeded $20 \mathrm{ppm}$ even with the canvas fully installed. This indicates a good sealing of the cabin sliding door. Tables 10 and 11 and the graphs in Figure 10 contain additional information for this vessel.

\section{Boat 7: 41' Motor Yatch Twin Mercruiser 8.1L Combined Exhaust Through the Sides and Underwater.}

This unit was slightly different from the other tested boats, since the cockpit was located much higher from the water level than for other express cruisers. CO concentrations at the stern of the vessel were consistently above $300 \mathrm{ppm}$ with or without the canvas installed. ToxiUltra CO monitors were placed on the stern of the unit where the canvas configuration recessed a few inches higher than the sensor locations. The "station wagon" effect caused by exhaust being drawn into the vessel at this location might be an explanation of why levels remained high throughout all experiments despite the installation of rear and side curtains.

The cabin door was kept closed at all times, and inside levels never exceeded $17 \mathrm{ppm}$. This indicates a good sealing of the sliding cabin door and adjacent compartments. CO concentrations in the engine compartment never exceeded $80 \mathrm{ppm}$ when the canvas was installed and $41 \mathrm{ppm}$ when the canvas was fully removed. Cockpit concentrations ranged between 0 and $50 \mathrm{ppm}$ with the canvas fully installed. Refer to Tables 12 and 13 and the graphs in Figure 11 for more details.

\section{Boat 8: 34' Twin Mercruiser 8.1L Combined Exhaust Through the Sides.}

$\mathrm{CO}$ concentrations near the stern of this particular vessel were much higher with the canvas fully installed than without it. When all curtains were installed, peak concentrations of $500 \mathrm{ppm}$ were observed for extended periods of time at speeds of 10 $\mathrm{mph}$. When the canvas was fully removed (bimini top only), peak concentrations ranged from 70 to $80 \mathrm{ppm}$ at $25 \mathrm{mph}$.

In the engine compartment, peak concentrations up to $143 \mathrm{ppm}$ were displayed with the canvas installed, compared to $31 \mathrm{ppm}$ without the canvas. CO concentrations inside the cockpit were reduced by a magnitude of 10 when the canvas was fully removed for all experiments (350 ppm vs. $7-35 \mathrm{ppm}$ ). More details about this particular boat can be found in Tables 12 and 13 and the graphs in Figure12. 


\section{Boat 9: 38' Twin Crusader 8.1 L Exhaust Underwater.}

Peak concentration on this vessel exceeded $500 \mathrm{ppm}$ at the stern of the boat when the canvas was fully installed. CO concentrations in the cockpit were below the NIOSH ceiling of $200 \mathrm{ppm}$ at all times, and lower when the canvas was fully removed (bimini top only). Inside the cabin CO concentrations never exceeded $60 \mathrm{ppm}$. Engine compartment concentrations were well below $120 \mathrm{ppm}$ at all times. As with the other vessels, CO concentrations were consistently higher at the stern of the boat and were gradually reduced toward the front of the vessel. Tables 14 and 15 and the graphs in Figure 13 contain additional information for this vessel.

\section{Boat 10: 35’ Motor Yacht Twin Crusader 8.1 L Exhaust Underwater.}

This boat exhibited CO concentrations that not only exceeded $1000 \mathrm{ppm}$ but also approached the 1200 NIOSH IDLH limit on the center of the stern, with and without the canvas. CO concentrations in the cockpit were below the NIOSH ceiling of $200 \mathrm{ppm}$ at all times, and much lower when the canvas was fully removed (bimini top only). Engine compartment concentrations were well below $200 \mathrm{ppm}$ at all times. In general, CO concentrations were consistently higher at the stern of the boat, and were gradually reduced toward the front of the vessel. Furthermore, CO concentrations tended to decrease at higher speeds. Refer to Tables 14 and 15 and the graphs in Figure 14 for more details.

\section{Summary of Trends for All Boats}

As shown above, there was a high degree of variation in the performance of different boats in terms of onboard CO concentrations. Several of the factors influencing these results include:

- Exhaust configuration (Hub, Transom, Underwater, Sides)

- Canvas configurations

- Boat speed

- Wind conditions

- CO generation rate

- Boat design and shape

- Distance between exhaust outlets and individual's breathing zone

- Fresh air ventilation of the cockpit and occupied areas

\section{Behavior of Exhaust Gases in Underwater Exhaust Configurations}

In terms of positively influencing onboard $\mathrm{CO}$ concentrations, the results above demonstrate that boats equipped with underwater exhaust exhibited significantly lower $\mathrm{CO}$ concentrations than vessels equipped with other exhaust designs. Since this factor is also one controllable by boat manufacturers, a discussion of the mechanics underlying this method of CO control is presented here.

For underwater exhaust systems, the rise of gases through water is governed by bubble size and depth of injection. The prop wash, or turbulent churning of water by the boat's propeller, may also affect the rate of release of gas into the atmosphere by: 1) breaking large bubbles into smaller bubbles, 2) causing bubbles to coalesce, or 3) by propelling bubbles deeper into the water [NIOSH 2005]. 
Regarding the behavior of individual bubbles, small bubbles (less than 1 millimeter in diameter) have a low rise velocity, and as a result, are likely to be spherical and rise in a straight path. As bubbles grow larger, their rise velocity increases, resulting in a less stable ellipsoidal bubble shape. The prop may cause some of the larger bubbles to break up and become smaller, giving more time for the bubbles to reach the surface and further reducing $\mathrm{CO}$ concentrations close to the boat. By implementing underwater exhaust configurations that entrain exhaust through the prop wash, the potential for $\mathrm{CO}$ from the exhaust to be pulled and re-entrained into the boat is greatly reduced.

\section{Influence of Canvas Configuration on Station Wagon Effect}

As stated previously, a significant station wagon effect was documented for many of the experiments conducted. This effect is produced when negative pressures at the rear of the boat and cockpit areas, which are generated when the boat is underway, draw exhaust gases, including CO, from behind the boat into inhabited areas. This effect was maximized when the boat was traveling at low speeds into the wind with the canvas fully deployed and no forward hatches, windows, or front panels opened. This stands to reason since the protection of the canvas and windows while underway serves to create a pocket of negative pressure relative to the outside. Conversely, when the canvas was removed not only was a negative pressure pocket less likely to be created, but air being drawn directly into the cockpit tended to ventilate the area.

Another interesting trend regarding the station wagon effect was observed. With the canvas installed, CO concentrations did not always change as much as expected at higher speeds. Rather it was documented that areas of high onboard CO concentration merely shifted. Figures 12-14 show a typical scenario. At lower speeds of 5-10 mph, exhaust air was re-entrained into the cockpit up to four feet from the cockpit floor. However, at $15 \mathrm{mph}$, higher CO levels were found closer to the cockpit floor. And at $25 \mathrm{mph}$, with the canvas installed, high CO concentrations were found only very close to the cockpit floor (as low at $2 \mathrm{ft}$.) on most models of boat tested. The significance of these observations is that, depending on the various boat designs and ambient factors, operating the boat at higher speeds is no guarantee of adequately ventilating inhabited areas of the boat when the canvas is installed. 


\section{CONCLUSIONS AND RECOMMENDATIONS}

Analysis of the results made several trends apparent. Chief among these are the following:

- When the canvas is deployed, CO concentrations reached instantaneous levels above the IDLH near the swimming platform for some of the evaluated boats.

- Canvas configuration significantly affects CO concentrations in the cockpit area.

- The combination of travel at low speeds into the wind with the canvas fully deployed and no forward hatches, windows or front panels opened maximized the station wagon effect, pulling significant amounts of CO into the cockpit.

- Different exhaust configurations have a major impact on how CO concentrations are entrained into the cockpit and other occupied areas. Accordingly, boats equipped with underwater exhaust exhibited significantly lower CO concentrations than vessels equipped with other exhaust designs.

- CO concentrations are typically higher at the stern of the boat and become gradually lower toward the front of the boat.

- Recirculation patterns varied with the boat speed. At lower speeds the recirculation was observed to be as high as $4 \mathrm{ft}$ measured from cockpit floor. This height was reduced to $2 \mathrm{ft}$ when going at $25 \mathrm{mph}$.

- Stationary smoke tests in the engine compartment showed satisfactory sealing of the bulkhead between the engine and adjacent compartments on all boats.

- Warning labels were missing important information to properly warn users of potential hazards and preventive/corrective measures to prevent $\mathrm{CO}$ poisonings.

- When underway, with the cabin door closed, the cabin is typically under negative pressure when the $\mathrm{A} / \mathrm{C}$ is running. This condition can lead to $\mathrm{CO}$ intrusions if a leak should occur.

Based on the preceding results and observations, the following recommendations are made regarding lowering $\mathrm{CO}$ concentrations on express cruisers to appropriate levels, and also future research regarding the issue:

- Underwater exhaust will significantly reduce CO concentrations inside the cockpit and other occupied areas compared to surface exhaust.

- Because of the station wagon effect, some canvas configurations should not be used while the boat is moving or propulsion and/or generator engines are running.

- The possibility of adding force draft blowers into the cabin, creating a positive pressure to minimize CO intrusions, should be studied. Auxiliary blowers can be fitted and routed to ventilate the cockpit and swim platform areas in order to minimize or break negative pressure areas throughout the vessel.

- Since properly sealed cabin doors directly influenced the level of CO in cabins, door suppliers should be encouraged to develop better sealing methods and designs.

- Windshield manufacturers should be encouraged to study the possibility of maximizing ventilation of occupied areas by improving the design of the center 
and side wings of the windshield.

- Due care should be exercised when designing the powered ventilation system on the engine compartment to locate the air intake on the opposite side of the generator exhaust. Also, potentially moving the intake farther forward on the vessel would help minimize the intake of CO exhaust into the engine compartment.

- The development of cleaner burning engines with catalytic converters should be continued since they have the potential to greatly reduce $\mathrm{CO}$ concentrations to safer levels.

- It is recommended that the American Boat and Yacht Council (ABYC) examine their standards and emphasize ventilation problems that can lead to CO intrusions, taking a strong position against through-transom exhaust designs. Since the National Marine Manufacturers Association (NMMA) uses ABYC standards in their certification, the result will be a large number of boats built to this higher standard.

- Computational fluid dynamics (CFD) and other types of modeling should continue to be conducted to better assess exhaust plume configurations.

- Further research should be made to evaluate new control technologies to reduce $\mathrm{CO}$ concentrations on express cruisers as they continue to emerge. 


\section{REFERENCES}

ACGIH (1996). Documentation of Threshold Limit Values and Biological Exposure Indices. Cincinnati, $\mathrm{OH}$, American Conference of Governmental Industrial Hygienists.

CDC (1988). MMWR 37, supp (S-7) NIOSH Recommendations for Occupational Safety and Health Standards. Atlanta, GA, Department of Health and Human Services, Public Health Service, Centers for Disease Control and Prevention, National Institute for Occupational Safety and Health.

CDC (2000). MMWR 49, Houseboat-Associated Carbon Monoxide Poisonings on Lake Powell- Arizon and Utah, 2000. Atlanta, GA, Department of Health and Human Services, Public Health Service, Centers for Disease Control and Prevention, National Institute for Occupational Safety and Health.

CFR (1997). 29 CFR 1910.1000, Chapter XVII - Occupational Safety and Health Administration. Code of Federal Regulations, Table Z-1, Limits for Air Contaminants. Washington, DC: U.S. Federal Register.

CFR (1997). 29 CFR 1910.1000, Code of Federal Regulations. Washington, DC: U.S., Government Printing Office, Federal Register.

Department of the Interior (2004, October). Boat-Related Carbon Monoxide (CO) Poisonings. Retrieved January 19, 2004, from http://safetynet.smis.doi.gov/thelistbystate10-19-04.pdf

Earnest, G. S., R. L. Mickelsen, et al. (1997). “Carbon Monoxide Poisonings from Small, Gasoline-Powered, Internal Combustion Engines: Just What Is a "Well-Ventilated Area"?” Am. Ind. Hyg. Assoc.

J. 58(11): 787-791.

Ehlers, J. J., J. B. McCammon, et al. (1996). NIOSH/CDPHE/CPSC/OSHA/EPA Alert: Preventing Carbon Monoxide Poisoning from Small Gasoline-Powered Engines and Tools, U.S. Department of Health and Human Services, Public Health Service, Centers for Disease Control and Prevention, National Institute for Occupational Safety and Health.

EPA (1991). Air Quality Criteria for Carbon Monoxide. Washington, DC, U.S. Environmental Protection Agency.

EPA (1996). Environmental Fact Sheet: Emission Standards for New Gasoline Marine Engines. Ann Arbor, Michigan, Environmental Protection Agency: 4. 
Forbes, W. H., F. Sargent, et al. (1945). "The Rate of CO Uptake by Normal Man.” Am Journal of Physiology 143:594-608.

Kovein, R. J., G. S. Earnest, et al. (1998). CO Poisoning from Small Gasoline-Powered Engines: A Control Technology Solution, U.S. Department of Health and Human Services, Public Health Service, Centers for Disease Control and Prevention, National Institute for Occupational Safety and Health.

NIOSH (1972). Criteria for a Recommended Standard: Occupational Exposure to Carbon Monoxide. Cincinnati, OH, National Institute for Occupational Safety and Health.

NIOSH (1977). Occupational Diseases: A Guide to their Recognition. Cincinnati, $\mathrm{OH}$, National Institute for Occupational Safety and Health.

NIOSH (1979). A Guide to Work Relatedness of Disease. Cincinnati, OH, Department of Health Education and Welfare, Public Health Service, Centers for Disease Control, National Institute for Occupational Safety and Health.

NIOSH (2000). Pocket Guide to Chemical Hazards and Other Databases: Immediately Dangerous to Life and Health Concentrations, DHHS (NIOSH).

NIOSH (2005). Reducing Carbon Monoxide Exposure by Optimization of the Fresh Air Exhaust System, DHHS (NIOSH).

Proctor, N. H., J. P. Hughes, et al. (1988). Chemical Hazards of the Workplace. Philadelphia, PA, J.P. Lippincott Co.

WHO (1999). Environmental Health Criteria 213 - Carbon Monoxide (Second Edition). Geneva, Switzerland, World Health Organization. 
Table 1: Experiment Conditions, Boats 1 \& 2

\begin{tabular}{|c|c|c|c|c|c|c|c|c|}
\hline 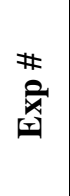 & 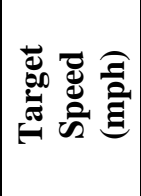 & 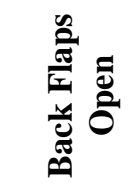 & 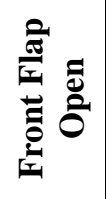 & 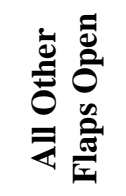 & 党 & $\begin{array}{l}\text { పే } \\
\dot{\Xi}\end{array}$ & 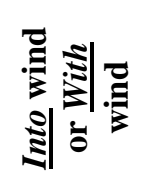 & 总 \\
\hline 1 & 5 & $\mathrm{y}$ & $\mathrm{n}$ & $\mathrm{n}$ & $\mathrm{n}$ & $\mathrm{y}$ & $\mathrm{i}$ & Boat 1 \\
\hline 2 & 5 & $\mathrm{y}$ & $\mathrm{y}$ & $\mathrm{n}$ & $\mathrm{n}$ & $\mathrm{y}$ & $\mathrm{i}$ & Boat 1 \\
\hline 3 & 5 & $\mathrm{y}$ & $\mathrm{y}$ & $\mathrm{n}$ & $\mathrm{n}$ & $\mathrm{y}$ & $\mathrm{w}$ & Boat 1 \\
\hline 4 & 5 & $\mathrm{y}$ & $\mathrm{n}$ & $\mathrm{n}$ & $\mathrm{n}$ & $\mathrm{y}$ & $\mathrm{w}$ & Boat 1 \\
\hline 5 & 10 & $\mathrm{y}$ & $\mathrm{y}$ & $\mathrm{n}$ & $\mathrm{n}$ & $\mathrm{y}$ & $\mathrm{i}$ & Boat 1 \\
\hline 6 & 10 & $\mathrm{y}$ & $\mathrm{y}$ & $\mathrm{n}$ & $\mathrm{n}$ & $\mathrm{y}$ & $\mathrm{W}$ & Boat 1 \\
\hline 7 & 15 & $\mathrm{y}$ & $\mathrm{y}$ & $\mathrm{n}$ & $\mathrm{n}$ & $\mathrm{y}$ & $\mathrm{i}$ & Boat 1 \\
\hline 8 & 15 & $\mathrm{y}$ & $\mathrm{y}$ & $\mathrm{n}$ & $\mathrm{n}$ & $\mathrm{y}$ & $\mathrm{W}$ & Boat 1 \\
\hline 9 & 25 & $\mathrm{y}$ & $\mathrm{y}$ & $\mathrm{n}$ & $\mathrm{n}$ & $\mathrm{y}$ & $\mathrm{i}$ & Boat 1 \\
\hline 10 & 25 & $\mathrm{y}$ & $\mathrm{y}$ & $\mathrm{n}$ & $\mathrm{n}$ & $\mathrm{y}$ & $\mathrm{W}$ & Boat 1 \\
\hline 11 & 10 & $\mathrm{y}$ & $\mathrm{n}$ & $\mathrm{n}$ & $\mathrm{n}$ & $\mathrm{y}$ & $\mathrm{i}$ & Boat 1 \\
\hline 12 & 25 & $\mathrm{y}$ & $\mathrm{n}$ & $\mathrm{n}$ & $\mathrm{n}$ & $\mathrm{y}$ & $\mathrm{i}$ & Boat 1 \\
\hline 13 & 25 & $\mathrm{y}$ & $\mathrm{n}$ & $\mathrm{n}$ & $\mathrm{n}$ & $\mathrm{y}$ & $\mathrm{w}$ & Boat 1 \\
\hline 14 & 5 & $\mathrm{y}$ & $\mathrm{y}$ & $\mathrm{y}$ & $\mathrm{n}$ & $\mathrm{y}$ & $\mathrm{i}$ & Boat 1 \\
\hline 15 & 5 & $\mathrm{y}$ & $\mathrm{y}$ & $\mathrm{y}$ & $\mathrm{n}$ & $\mathrm{y}$ & $\mathrm{W}$ & Boat 1 \\
\hline 16 & 10 & $\mathrm{y}$ & $\mathrm{y}$ & $\mathrm{y}$ & $\mathrm{n}$ & $\mathrm{y}$ & $\mathrm{i}$ & Boat 1 \\
\hline 17 & 10 & $\mathrm{y}$ & $\mathrm{y}$ & $\mathrm{y}$ & $\mathrm{n}$ & $\mathrm{y}$ & $\mathrm{w}$ & Boat 1 \\
\hline 18 & 15 & $\mathrm{y}$ & $\mathrm{y}$ & $\mathrm{y}$ & $\mathrm{n}$ & $\mathrm{y}$ & $\mathrm{i}$ & Boat 1 \\
\hline 19 & 15 & $\mathrm{y}$ & $\mathrm{y}$ & $\mathrm{y}$ & $\mathrm{y}$ & $\mathrm{y}$ & $\mathrm{w}$ & Boat 1 \\
\hline 20 & 25 & $\mathrm{y}$ & $\mathrm{y}$ & $\mathrm{y}$ & $\mathrm{y}$ & $\mathrm{y}$ & $\mathrm{i}$ & Boat 1 \\
\hline 21 & 25 & $\mathrm{y}$ & $\mathrm{y}$ & $\mathrm{y}$ & $\mathrm{y}$ & $\mathrm{y}$ & $\mathrm{w}$ & Boat 1 \\
\hline 22 & 15 & $\mathrm{y}$ & $\mathrm{y}$ & $\mathrm{y}$ & $\mathrm{n}$ & $\mathrm{y}$ & $\mathrm{n} / \mathrm{a}$ & Boat 1 / hatch and 2 side windows open in cabin \\
\hline 23 & 15 & $\mathrm{y}$ & $\mathrm{y}$ & $\mathrm{y}$ & $\mathrm{n}$ & $\mathrm{n}$ & $\mathrm{n} / \mathrm{a}$ & Boat 1 / hatch and 2 side windows closed in cabin \\
\hline 24 & $\mathrm{n} / \mathrm{a}$ & $\mathrm{y}$ & $\mathrm{y}$ & $\mathrm{y}$ & $\mathrm{y}$ & $\mathrm{y}$ & $\mathrm{n} / \mathrm{a}$ & Boat 1 / at dock / generator and air conditioner on \\
\hline 25 & 5 & $\mathrm{y}$ & $\mathrm{y}$ & $\mathrm{n}$ & $\mathrm{n}$ & $\mathrm{y}$ & $\mathrm{n} / \mathrm{a}$ & Boat 2 \\
\hline 26 & 10 & $\mathrm{y}$ & $\mathrm{y}$ & $\mathrm{n}$ & $\mathrm{n}$ & $\mathrm{y}$ & $\mathrm{n} / \mathrm{a}$ & Boat 2 \\
\hline 27 & 5 & $\mathrm{y}$ & $\mathrm{n}$ & $\mathrm{n}$ & $\mathrm{n}$ & $\mathrm{y}$ & $\mathrm{n} / \mathrm{a}$ & Boat 2 / stopped early CO levels too high \\
\hline 28 & 15 & $\mathrm{y}$ & $\mathrm{y}$ & $\mathrm{n}$ & $\mathrm{n}$ & $\mathrm{y}$ & $\mathrm{n} / \mathrm{a}$ & Boat 2 \\
\hline 29 & 25 & $\mathrm{y}$ & $\mathrm{y}$ & $\mathrm{n}$ & $\mathrm{n}$ & $\mathrm{y}$ & $\mathrm{n} / \mathrm{a}$ & Boat 2 \\
\hline 30 & 5 & $\mathrm{y}$ & $\mathrm{y}$ & $\mathrm{y}$ & $\mathrm{n}$ & $\mathrm{y}$ & $\mathrm{n} / \mathrm{a}$ & Boat 2 \\
\hline 31 & 10 & $\mathrm{y}$ & $\mathrm{y}$ & $\mathrm{y}$ & $\mathrm{n}$ & $\mathrm{y}$ & $\mathrm{n} / \mathrm{a}$ & Boat 2 \\
\hline 32 & 15 & $\mathrm{y}$ & $\mathrm{y}$ & $\mathrm{y}$ & $\mathrm{n}$ & $\mathrm{y}$ & $\mathrm{n} / \mathrm{a}$ & Boat 2 \\
\hline 33 & 15 & $\mathrm{y}$ & $\mathrm{y}$ & $\mathrm{y}$ & $\mathrm{y}$ & $\mathrm{y}$ & $\mathrm{n} / \mathrm{a}$ & Boat 2 \\
\hline 34 & 25 & $\mathrm{y}$ & $\mathrm{y}$ & $\mathrm{y}$ & $\mathrm{y}$ & $\mathrm{y}$ & $\mathrm{n} / \mathrm{a}$ & Boat 2 \\
\hline 35 & 15 & $\mathrm{y}$ & $\mathrm{y}$ & $\mathrm{y}$ & $\mathrm{n}$ & $\mathrm{y}$ & $\mathrm{n} / \mathrm{a}$ & Boat 2 / hatch and 2 side windows open in cabin \\
\hline 36 & 15 & $\mathrm{y}$ & $\mathrm{y}$ & $\mathrm{y}$ & $\mathrm{n}$ & $\mathrm{n}$ & $\mathrm{n} / \mathrm{a}$ & Boat 2 / hatch and 2 side windows closed in cabin \\
\hline 37 & 32 & $\mathrm{y}$ & $\mathrm{y}$ & $\mathrm{y}$ & $\mathrm{y}$ & $\mathrm{n}$ & $\mathrm{n} / \mathrm{a}$ & Boat 2 \\
\hline 38 & $\mathrm{n} / \mathrm{a}$ & $\mathrm{y}$ & $\mathrm{y}$ & $\mathrm{y}$ & $\mathrm{y}$ & $\mathrm{y}$ & $\mathrm{n} / \mathrm{a}$ & Boat 2 / at dock / generator and AC on \\
\hline
\end{tabular}


Table 2: Experiment Conditions, Boats 3 \& 4.

\begin{tabular}{|c|c|c|c|c|c|c|c|c|c|}
\hline 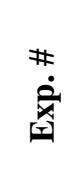 & 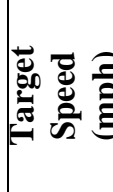 & يَّة & 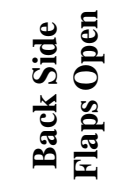 & 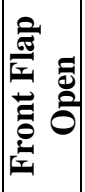 & 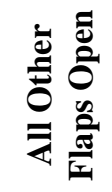 & 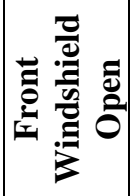 & 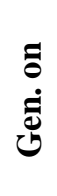 & 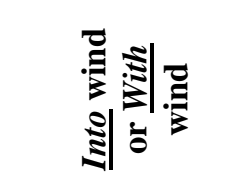 & 害哭 \\
\hline 1 & $\mathrm{n} / \mathrm{a}$ & $\mathrm{y}$ & $\mathrm{n}$ & $\mathrm{n}$ & $\mathrm{n}$ & $\mathrm{n}$ & $\mathrm{y}$ & near dead calm & $\begin{array}{l}\text { Boat } 4 \text { / AC is on /' drive engines } \\
\text { off }\end{array}$ \\
\hline 2 & 5 & $\mathrm{y}$ & $\mathrm{n}$ & $\mathrm{n}$ & $\mathrm{n}$ & $\mathrm{n}$ & $\mathrm{y}$ & near dead calm & $\begin{array}{l}\text { Boat } 4 \text { / stopped short lots of } \\
\text { alarms going off }\end{array}$ \\
\hline 3 & 25 & $\mathrm{y}$ & $\mathrm{n}$ & $\mathrm{y}$ & $\mathrm{n}$ & $\mathrm{n}$ & $\mathrm{y}$ & near dead calm & Boat 4 \\
\hline 4 & 15 & $\mathrm{y}$ & $\mathrm{n}$ & $\mathrm{y}$ & $\mathrm{n}$ & $\mathrm{n}$ & $\mathrm{y}$ & near dead calm & Boat 4 \\
\hline 5 & 10 & $\mathrm{y}$ & $\mathrm{n}$ & $\mathrm{y}$ & $\mathrm{n}$ & $\mathrm{n}$ & $\mathrm{y}$ & near dead calm & Boat 4 \\
\hline 6 & 25 & $\mathrm{y}$ & $\mathrm{n}$ & $\mathrm{n}$ & $\mathrm{n}$ & $\mathrm{n}$ & $\mathrm{y}$ & near dead calm & Boat 4 \\
\hline 7 & 15 & $\mathrm{y}$ & $\mathrm{n}$ & $\mathrm{n}$ & $\mathrm{n}$ & $\mathrm{n}$ & $\mathrm{y}$ & near dead calm & Boat 4 \\
\hline 8 & 25 & $\mathrm{y}$ & $\mathrm{y}$ & $\mathrm{y}$ & $\mathrm{n}$ & $\mathrm{n}$ & $\mathrm{y}$ & $\mathrm{n} / \mathrm{a}$ & Boat 4 \\
\hline 9 & 15 & $\mathrm{y}$ & $\mathrm{y}$ & $\mathrm{y}$ & $\mathrm{n}$ & $\mathrm{n}$ & $\mathrm{y}$ & $\mathrm{n} / \mathrm{a}$ & $\begin{array}{l}\text { Boat } 4 \text { / high levels of CO } \\
\text { detected / opened all flaps after } \\
\text { experiment }\end{array}$ \\
\hline 10 & 15 & $\mathrm{y}$ & $\mathrm{y}$ & $\mathrm{y}$ & $\mathrm{y}$ & $\mathrm{n}$ & $\mathrm{y}$ & $\mathrm{n} / \mathrm{a}$ & Boat 4 \\
\hline 11 & 15 & $\mathrm{y}$ & $\mathrm{y}$ & $\mathrm{y}$ & $\mathrm{y}$ & $\mathrm{y}$ & $\mathrm{y}$ & $\mathrm{n} / \mathrm{a}$ & Boat 4 \\
\hline 12 & 5 & $\mathrm{y}$ & $\mathrm{y}$ & $\mathrm{y}$ & $\mathrm{y}$ & $\mathrm{n}$ & $\mathrm{y}$ & $\mathrm{n} / \mathrm{a}$ & Boat 4 \\
\hline 13 & 10 & $\mathrm{y}$ & $\mathrm{y}$ & $\mathrm{y}$ & $\mathrm{y}$ & $\mathrm{n}$ & $\mathrm{y}$ & $\mathrm{n} / \mathrm{a}$ & Boat 4 \\
\hline 14 & 25 & $\mathrm{y}$ & $\mathrm{y}$ & $\mathrm{y}$ & $\mathrm{y}$ & $\mathrm{y}$ & $\mathrm{y}$ & $\mathrm{n} / \mathrm{a}$ & Boat 4 \\
\hline 15 & 15 & $\mathrm{y}$ & $\mathrm{y}$ & $\mathrm{y}$ & $\mathrm{y}$ & $\mathrm{y}$ & $\mathrm{y}$ & $\mathrm{n} / \mathrm{a}$ & $\begin{array}{l}\text { Boat } 4 \text { / } 4 \text { hatches and } 2 \text { portholes } \\
\text { open in cabin }\end{array}$ \\
\hline 16 & 10 & $\mathrm{y}$ & $\mathrm{y}$ & $\mathrm{y}$ & $\mathrm{y}$ & $\mathrm{n}$ & $\mathrm{y}$ & $\mathrm{n} / \mathrm{a}$ & $\begin{array}{l}\text { Boat } 4 \text { / hatches closed BUT } \\
\text { exhaust through hub }\end{array}$ \\
\hline 17 & 5 & $\mathrm{y}$ & $\mathrm{y}$ & $\mathrm{y}$ & $\mathrm{y}$ & $\mathrm{n}$ & $\mathrm{y}$ & $\mathrm{n} / \mathrm{a}$ & Boat 4 \\
\hline 18 & $\mathrm{n} / \mathrm{a}$ & $\mathrm{y}$ & $\mathrm{y}$ & $\mathrm{n}$ & $\mathrm{n}$ & $\mathrm{n}$ & $\mathrm{y}$ & not measured & Boat 3 / stationary at dock \\
\hline 19 & 25 & $\mathrm{y}$ & $\mathrm{y}$ & $\mathrm{n}$ & $\mathrm{n}$ & $\mathrm{n}$ & $\mathrm{y}$ & not measured & Boat 3 \\
\hline 20 & 15 & $\mathrm{y}$ & $\mathrm{y}$ & $\mathrm{n}$ & $\mathrm{n}$ & $\mathrm{n}$ & $\mathrm{y}$ & not measured & Boat 3 \\
\hline 21 & 10 & $\mathrm{y}$ & $\mathrm{y}$ & $\mathrm{n}$ & $\mathrm{n}$ & $\mathrm{n}$ & $\mathrm{y}$ & not measured & Boat 3 \\
\hline 22 & 5 & $\mathrm{y}$ & $\mathrm{y}$ & $\mathrm{n}$ & $\mathrm{n}$ & $\mathrm{n}$ & $\mathrm{y}$ & not measured & Boat 3 \\
\hline 23 & 5 & $\mathrm{y}$ & $\mathrm{y}$ & $\mathrm{y}$ & $\mathrm{n}$ & $\mathrm{n}$ & $\mathrm{y}$ & not measured & Boat 3 \\
\hline 24 & 10 & $\mathrm{y}$ & $\mathrm{y}$ & $\mathrm{y}$ & $\mathrm{n}$ & $\mathrm{n}$ & $\mathrm{y}$ & not measured & Boat 3 \\
\hline 25 & 15 & $\mathrm{y}$ & $\mathrm{y}$ & $\mathrm{y}$ & $\mathrm{n}$ & $\mathrm{n}$ & $\mathrm{y}$ & not measured & Boat 3 \\
\hline 26 & 25 & $\mathrm{y}$ & $\mathrm{y}$ & $\mathrm{y}$ & $\mathrm{n}$ & $\mathrm{n}$ & $\mathrm{y}$ & not measured & Boat 3 \\
\hline 27 & 5 & $\mathrm{y}$ & $\mathrm{y}$ & $\mathrm{y}$ & $\mathrm{y}$ & $\mathrm{n}$ & $\mathrm{y}$ & not measured & Boat 3 \\
\hline 28 & 10 & $\mathrm{y}$ & $\mathrm{y}$ & $\mathrm{y}$ & $\mathrm{y}$ & $\mathrm{n}$ & $\mathrm{y}$ & not measured & Boat 3 \\
\hline 29 & 15 & $\mathrm{y}$ & $\mathrm{y}$ & $\mathrm{y}$ & $\mathrm{y}$ & $\mathrm{n}$ & $\mathrm{y}$ & not measured & Boat 3 \\
\hline 30 & 15 & $\mathrm{y}$ & $\mathrm{y}$ & $\mathrm{y}$ & $\mathrm{y}$ & $\mathrm{y}$ & $\mathrm{y}$ & not measured & Boat 3 \\
\hline 31 & 25 & $\mathrm{y}$ & $\mathrm{y}$ & $\mathrm{y}$ & $\mathrm{y}$ & $\mathrm{y}$ & $\mathrm{y}$ & not measured & Boat 3 \\
\hline 32 & 15 & $\mathrm{y}$ & $\mathrm{y}$ & $\mathrm{y}$ & $\mathrm{y}$ & $\mathrm{y}$ & $\mathrm{y}$ & into wind & $\begin{array}{l}\text { Boat } 3 \text { / } 3 \text { hatches and } 5 \text { windows } \\
\text { in cabin open }\end{array}$ \\
\hline
\end{tabular}


Table 3: Experiment Conditions, Boats 5 \& 6.

\begin{tabular}{|c|c|c|c|c|c|c|c|c|c|}
\hline 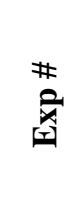 & 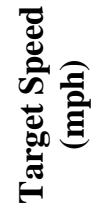 & 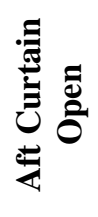 & 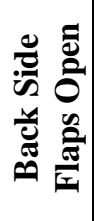 & 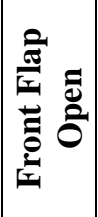 & 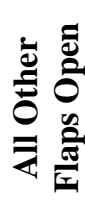 & 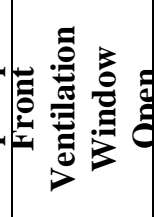 & 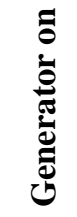 & 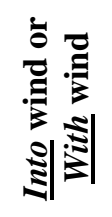 & 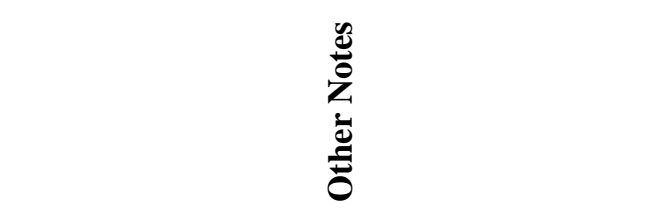 \\
\hline 1 & 5 & $\mathrm{y}$ & $\mathrm{n}$ & $\mathrm{n}$ & $\mathrm{n}$ & $\mathrm{y}$ & $\mathrm{y}$ & $\mathrm{n} / \mathrm{a}$ & $\begin{array}{l}\text { Boat } 5 \text { / Exhaust through bypass at sides above } \\
\text { the waterline }\end{array}$ \\
\hline 2 & 5 & $\mathrm{y}$ & $\mathrm{n}$ & $\mathrm{n}$ & $\mathrm{n}$ & $\mathrm{y}$ & $\mathrm{y}$ & $\mathrm{n} / \mathrm{a}$ & $\begin{array}{l}\text { Boat } 5 \text { / Exhaust through bypass at sides above } \\
\text { the waterline }\end{array}$ \\
\hline 3 & 10 & $\mathrm{y}$ & $\mathrm{n}$ & $\mathrm{n}$ & $\mathrm{n}$ & $\mathrm{n}$ & $\mathrm{y}$ & $\mathrm{n} / \mathrm{a}$ & Boat 5 / Exhaust underwater \\
\hline 4 & 15 & $\mathrm{y}$ & $\mathrm{n}$ & $\mathrm{n}$ & $\mathrm{n}$ & $\mathrm{y}$ & $\mathrm{y}$ & $\mathrm{n} / \mathrm{a}$ & Boat 5 / Exhaust underwater \\
\hline 5 & 15 & $\mathrm{y}$ & $\mathrm{n}$ & $\mathrm{n}$ & $\mathrm{n}$ & $\mathrm{n}$ & $\mathrm{y}$ & $\mathrm{n} / \mathrm{a}$ & Boat 5 / Exhaust underwater \\
\hline 6 & 25 & $\mathrm{y}$ & $\mathrm{n}$ & $\mathrm{n}$ & $\mathrm{n}$ & $\mathrm{n}$ & $\mathrm{y}$ & $\mathrm{n} / \mathrm{a}$ & Boat 5 / Exhaust underwater \\
\hline 7 & 25 & $\mathrm{y}$ & $\mathrm{y}$ & $\mathrm{n}$ & $\mathrm{n}$ & $\mathrm{n}$ & $\mathrm{y}$ & $\mathrm{n} / \mathrm{a}$ & Boat 5 / Exhaust underwater \\
\hline 8 & 15 & $\mathrm{y}$ & $\mathrm{y}$ & $\mathrm{n}$ & $\mathrm{n}$ & $\mathrm{n}$ & $\mathrm{y}$ & $\mathrm{n} / \mathrm{a}$ & Boat 5 / Exhaust underwater \\
\hline 9 & 15 & $\mathrm{y}$ & $\mathrm{y}$ & $\mathrm{n}$ & $\mathrm{n}$ & $\mathrm{y}$ & $\mathrm{y}$ & $\mathrm{n} / \mathrm{a}$ & Boat 5 / Exhaust underwater \\
\hline 10 & 10 & $\mathrm{y}$ & $\mathrm{y}$ & $\mathrm{n}$ & $\mathrm{n}$ & $\mathrm{n}$ & $\mathrm{y}$ & $\mathrm{n} / \mathrm{a}$ & Boat 5 / Exhaust underwater \\
\hline 11 & 5 & $\mathrm{y}$ & $\mathrm{y}$ & $\mathrm{n}$ & $\mathrm{n}$ & $\mathrm{n}$ & $\mathrm{y}$ & $\mathrm{n} / \mathrm{a}$ & Boat 5 / Exhaust underwater \\
\hline 12 & 15 & $\mathrm{y}$ & $\mathrm{y}$ & $\mathrm{y}$ & $\mathrm{n}$ & $\mathrm{n}$ & $\mathrm{y}$ & $\mathrm{n} / \mathrm{a}$ & Boat 5 / Exhaust underwater \\
\hline 13 & 25 & $\mathrm{y}$ & $\mathrm{y}$ & $\mathrm{y}$ & $\mathrm{y}$ & $\mathrm{n}$ & $\mathrm{y}$ & $\mathrm{n} / \mathrm{a}$ & Boat 5 / Exhaust underwater \\
\hline 14 & 15 & $\mathrm{y}$ & $\mathrm{y}$ & $\mathrm{y}$ & $\mathrm{y}$ & $\mathrm{n}$ & $\mathrm{y}$ & $\mathrm{n} / \mathrm{a}$ & Boat 5 / Exhaust underwater \\
\hline 15 & 5 & $\mathrm{y}$ & $\mathrm{y}$ & $\mathrm{y}$ & $\mathrm{y}$ & $\mathrm{n}$ & $\mathrm{y}$ & $\mathrm{n} / \mathrm{a}$ & Boat 5 / Exhaust underwater \\
\hline 16 & 10 & $\mathrm{y}$ & $\mathrm{y}$ & $\mathrm{y}$ & $\mathrm{y}$ & $\mathrm{n}$ & $\mathrm{y}$ & $\mathrm{n} / \mathrm{a}$ & Boat 5 / Exhaust underwater \\
\hline 17 & 15 & $\mathrm{y}$ & $\mathrm{y}$ & $\mathrm{y}$ & $\mathrm{y}$ & $\mathrm{y}$ & $\mathrm{y}$ & $\mathrm{n} / \mathrm{a}$ & Boat 5 / Exhaust underwater \\
\hline 18 & 15 & $\mathrm{y}$ & $\mathrm{y}$ & $\mathrm{y}$ & $\mathrm{y}$ & $\mathrm{y}$ & $\mathrm{y}$ & $\mathrm{n} / \mathrm{a}$ & Boat 5 / Exhaust underwater \\
\hline 19 & 25 & $\mathrm{y}$ & $\mathrm{n}$ & $\mathrm{n}$ & $\mathrm{n}$ & $\mathrm{n}$ & $\mathrm{y}$ & $\mathrm{n} / \mathrm{a}$ & Boat 6 / NE 3-5 mph \\
\hline 20 & 5 & $\mathrm{y}$ & $\mathrm{n}$ & $\mathrm{n}$ & $\mathrm{n}$ & $\mathrm{n}$ & $\mathrm{y}$ & $\mathrm{n} / \mathrm{a}$ & Boat 6 / NE 3-5 mph \\
\hline 21 & 10 & $\mathrm{y}$ & $\mathrm{n}$ & $\mathrm{n}$ & $\mathrm{n}$ & $\mathrm{n}$ & $\mathrm{y}$ & $\mathrm{n} / \mathrm{a}$ & Boat 6 / NE 3-5 mph \\
\hline 22 & 15 & $\mathrm{y}$ & $\mathrm{n}$ & $\mathrm{n}$ & $\mathrm{n}$ & $\mathrm{n}$ & $\mathrm{y}$ & $\mathrm{n} / \mathrm{a}$ & Boat 6 / NE 3-5 mph \\
\hline 23 & 15 & $\mathrm{y}$ & $\mathrm{n}$ & $\mathrm{n}$ & $\mathrm{n}$ & $\mathrm{y}$ & $\mathrm{y}$ & $\mathrm{n} / \mathrm{a}$ & Boat 6 / NE 3-5 mph \\
\hline 24 & 5 & $\mathrm{y}$ & $\mathrm{y}$ & $\mathrm{n}$ & $\mathrm{n}$ & $\mathrm{n}$ & $\mathrm{y}$ & $\mathrm{n} / \mathrm{a}$ & Boat 6 / NE 3-3 mph \\
\hline 25 & 10 & $\mathrm{y}$ & $\mathrm{y}$ & $\mathrm{n}$ & $\mathrm{n}$ & $\mathrm{n}$ & $\mathrm{y}$ & $\mathrm{n} / \mathrm{a}$ & Boat 6 / NE 3-3 mph \\
\hline 26 & 15 & $\mathrm{y}$ & $\mathrm{y}$ & $\mathrm{n}$ & $\mathrm{n}$ & $\mathrm{n}$ & $\mathrm{y}$ & $\mathrm{n} / \mathrm{a}$ & Boat 6 / NE 3-3 mph \\
\hline 27 & 15 & $\mathrm{y}$ & $\mathrm{y}$ & $\mathrm{n}$ & $\mathrm{n}$ & $\mathrm{y}$ & $\mathrm{y}$ & $\mathrm{n} / \mathrm{a}$ & Boat 6 / NE 3-3 mph \\
\hline 28 & 25 & $\mathrm{y}$ & $\mathrm{y}$ & $\mathrm{n}$ & $\mathrm{n}$ & $\mathrm{n}$ & $\mathrm{y}$ & $\mathrm{n} / \mathrm{a}$ & Boat 6 / NE 3-3 mph \\
\hline 29 & 15 & $\mathrm{y}$ & $\mathrm{y}$ & $\mathrm{y}$ & $\mathrm{n}$ & $\mathrm{n}$ & $\mathrm{y}$ & $\mathrm{n} / \mathrm{a}$ & Boat 6 / E 5-10 mph \\
\hline 30 & 25 & $\mathrm{y}$ & $\mathrm{y}$ & $\mathrm{y}$ & $\mathrm{y}$ & $\mathrm{n}$ & $\mathrm{y}$ & n/a & Boat 6 / E 5-10 mph \\
\hline 31 & 15 & $\mathrm{y}$ & $\mathrm{y}$ & $\mathrm{y}$ & $\mathrm{y}$ & $\mathrm{n}$ & $\mathrm{y}$ & $\mathrm{n} / \mathrm{a}$ & Boat 6 / E 5-10 mph \\
\hline 32 & 15 & $\mathrm{y}$ & $\mathrm{y}$ & $\mathrm{y}$ & $\mathrm{y}$ & $\mathrm{y}$ & $\mathrm{y}$ & $\mathrm{n} / \mathrm{a}$ & Boat 6 / E 5-10 mph \\
\hline 33 & 5 & $\mathrm{y}$ & $\mathrm{y}$ & $\mathrm{y}$ & $\mathrm{y}$ & $\mathrm{n}$ & $\mathrm{y}$ & $\mathrm{n} / \mathrm{a}$ & Boat 6 / E 5-10 mph \\
\hline 34 & 10 & $\mathrm{y}$ & $\mathrm{y}$ & $\mathrm{y}$ & $\mathrm{y}$ & $\mathrm{n}$ & $\mathrm{y}$ & $\mathrm{n} / \mathrm{a}$ & Boat 6 / E 5-10 mph \\
\hline 35 & 15 & $\mathrm{y}$ & $\mathrm{y}$ & $\mathrm{y}$ & $\mathrm{y}$ & $\mathrm{n}$ & $\mathrm{y}$ & $\mathrm{n} / \mathrm{a}$ & Boat 6 / Hatch open and cabin door open \\
\hline 36 & 0 & $\mathrm{y}$ & $\mathrm{y}$ & $\mathrm{y}$ & $\mathrm{y}$ & $\mathrm{n}$ & $\mathrm{y}$ & $\mathrm{n} / \mathrm{a}$ & Boat 6 / Idle at the dock \\
\hline
\end{tabular}


Table 4: Experiment Conditions, Boats 7 \& 8.

\begin{tabular}{|c|c|c|c|c|c|c|c|c|c|}
\hline $\begin{array}{l}\# \\
\text { \# } \\
\text { 爻 }\end{array}$ & 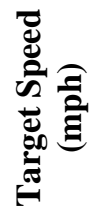 & ơ & 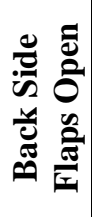 & 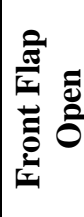 & 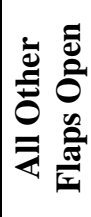 & 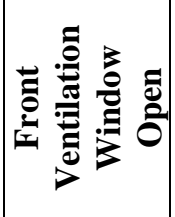 & 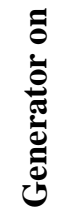 & 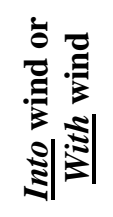 & 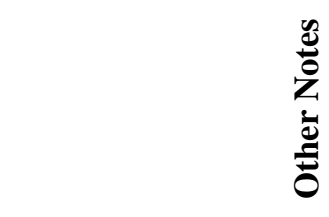 \\
\hline 1 & 5 & $\mathrm{y}$ & $\mathrm{n}$ & $\mathrm{n}$ & $\mathrm{n}$ & $\mathrm{n}$ & $\mathrm{y}$ & $\mathrm{n} / \mathrm{a}$ & Boat 7 \\
\hline 2 & 10 & $\mathrm{y}$ & $\mathrm{n}$ & $\mathrm{n}$ & $\mathrm{n}$ & $\mathrm{n}$ & $\mathrm{y}$ & $\mathrm{n} / \mathrm{a}$ & Boat 7 \\
\hline 3 & 15 & $\mathrm{y}$ & $\mathrm{y}$ & $\mathrm{n}$ & $\mathrm{n}$ & $\mathrm{n}$ & $\mathrm{y}$ & $\mathrm{n} / \mathrm{a}$ & Boat 7 \\
\hline 4 & 25 & $\mathrm{y}$ & $\mathrm{y}$ & $\mathrm{n}$ & $\mathrm{n}$ & $\mathrm{n}$ & $\mathrm{y}$ & $\mathrm{n} / \mathrm{a}$ & Boat 7 \\
\hline 5 & 5 & $\mathrm{y}$ & $\mathrm{y}$ & $\mathrm{n}$ & $\mathrm{n}$ & $\mathrm{n}$ & $\mathrm{y}$ & $\mathrm{n} / \mathrm{a}$ & Boat 7 \\
\hline 6 & 10 & $\mathrm{y}$ & $\mathrm{y}$ & $n$ & $\mathrm{n}$ & $\mathrm{n}$ & $\mathrm{y}$ & $\mathrm{n} / \mathrm{a}$ & Boat 7 \\
\hline 7 & 15 & $\mathrm{y}$ & $\mathrm{y}$ & $\mathrm{y}$ & $\mathrm{y}$ & $\mathrm{n}$ & $\mathrm{y}$ & $\mathrm{w}$ & Boat 7 \\
\hline 8 & 25 & $\mathrm{y}$ & $\mathrm{y}$ & $\mathrm{y}$ & $\mathrm{y}$ & $\mathrm{n}$ & $\mathrm{y}$ & $\mathrm{W}$ & Boat 7 \\
\hline 9 & 5 & $\mathrm{y}$ & $\mathrm{y}$ & $\mathrm{y}$ & $\mathrm{y}$ & $\mathrm{n}$ & $\mathrm{y}$ & $\mathrm{W}$ & Boat 7 \\
\hline 10 & 10 & $\mathrm{y}$ & $\mathrm{y}$ & $\mathrm{y}$ & $\mathrm{y}$ & $\mathrm{n}$ & $\mathrm{y}$ & $\mathrm{i}$ & Boat 7 \\
\hline 11 & 15 & $\mathrm{y}$ & $\mathrm{y}$ & $\mathrm{y}$ & $\mathrm{y}$ & $\mathrm{n}$ & $\mathrm{y}$ & $\mathrm{i}$ & Boat 7 \\
\hline 12 & 5 & $\mathrm{y}$ & $\mathrm{y}$ & $\mathrm{y}$ & $\mathrm{y}$ & $\mathrm{n}$ & $\mathrm{y}$ & $\mathrm{i}$ & Boat 7 \\
\hline 13 & 10 & $\mathrm{y}$ & $\mathrm{y}$ & $\mathrm{y}$ & $\mathrm{y}$ & $\mathrm{n}$ & $\mathrm{y}$ & $\mathrm{i}$ & Boat 7 \\
\hline 14 & 15 & $\mathrm{y}$ & $\mathrm{n}$ & $\mathrm{n}$ & $\mathrm{n}$ & $\mathrm{n}$ & $\mathrm{y}$ & $\mathrm{i}$ & Boat 7 \\
\hline 15 & 5 & $\mathrm{y}$ & $\mathrm{n}$ & $\mathrm{n}$ & $\mathrm{n}$ & $\mathrm{n}$ & $\mathrm{y}$ & $\mathrm{i}$ & Boat 8 \\
\hline 16 & 10 & $\mathrm{y}$ & $\mathrm{n}$ & $\mathrm{n}$ & $\mathrm{n}$ & $\mathrm{n}$ & $\mathrm{y}$ & $\mathrm{i}$ & Boat 8 \\
\hline 17 & 15 & $\mathrm{y}$ & $\mathrm{n}$ & $\mathrm{n}$ & $\mathrm{n}$ & $\mathrm{n}$ & $\mathrm{y}$ & $\mathrm{i}$ & Boat 8 \\
\hline 18 & 25 & $\mathrm{y}$ & $\mathrm{y}$ & $\mathrm{n}$ & $\mathrm{n}$ & $\mathrm{n}$ & $\mathrm{y}$ & $\mathrm{i}$ & Boat 8 \\
\hline 19 & 5 & $\mathrm{y}$ & $\mathrm{y}$ & $\mathrm{n}$ & $\mathrm{n}$ & $\mathrm{n}$ & $\mathrm{y}$ & $\mathrm{i}$ & Boat 8 \\
\hline 20 & 10 & $\mathrm{y}$ & $\mathrm{y}$ & $\mathrm{n}$ & $\mathrm{n}$ & $\mathrm{n}$ & $\mathrm{y}$ & $\mathrm{i}$ & Boat 8 \\
\hline 21 & 15 & $\mathrm{y}$ & $\mathrm{y}$ & $\mathrm{n}$ & $\mathrm{n}$ & $\mathrm{n}$ & $\mathrm{y}$ & $\mathrm{w}$ & Boat 8 \\
\hline 22 & 25 & $\mathrm{y}$ & $\mathrm{y}$ & $\mathrm{y}$ & $\mathrm{y}$ & $\mathrm{n}$ & $\mathrm{y}$ & $\mathrm{W}$ & Boat 8 \\
\hline 23 & 5 & $\mathrm{y}$ & $\mathrm{y}$ & $\mathrm{y}$ & $\mathrm{y}$ & $\mathrm{n}$ & $\mathrm{y}$ & $\mathrm{W}$ & Boat 8 \\
\hline 24 & 10 & $\mathrm{y}$ & $\mathrm{y}$ & $\mathrm{y}$ & $\mathrm{y}$ & $\mathrm{n}$ & $\mathrm{y}$ & $\mathrm{w}$ & Boat 8 \\
\hline 25 & 15 & $\mathrm{y}$ & $\mathrm{y}$ & $\mathrm{y}$ & $\mathrm{y}$ & $\mathrm{n}$ & $\mathrm{y}$ & $\mathrm{W}$ & Boat 8 \\
\hline 26 & 25 & $\mathrm{y}$ & $\mathrm{y}$ & $\mathrm{y}$ & $\mathrm{y}$ & $\mathrm{y}$ & $\mathrm{y}$ & $\mathrm{i}$ & Boat 8 \\
\hline 27 & 5 & $\mathrm{y}$ & $\mathrm{y}$ & $\mathrm{y}$ & $\mathrm{y}$ & $\mathrm{y}$ & $\mathrm{y}$ & $\mathrm{w}$ & Boat 8 \\
\hline 28 & 5 & $\mathrm{y}$ & $\mathrm{n}$ & $\mathrm{n}$ & $\mathrm{n}$ & $\mathrm{n}$ & $\mathrm{y}$ & $\mathrm{n} / \mathrm{a}$ & Boat 8 \\
\hline 29 & 5 & $\mathrm{y}$ & $\mathrm{n}$ & $\mathrm{n}$ & $\mathrm{n}$ & $\mathrm{n}$ & $\mathrm{y}$ & $\mathrm{n} / \mathrm{a}$ & Boat 8 \\
\hline
\end{tabular}


Table 5: Experiment Conditions, Boats 9 \& 10.

\begin{tabular}{|c|c|c|c|c|c|c|c|c|c|}
\hline $\begin{array}{l}\# \\
\text { \# } \\
\text { 爻 }\end{array}$ & 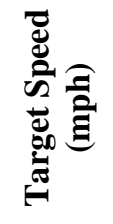 & قَّ & 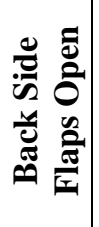 & 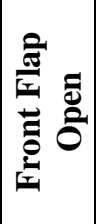 & 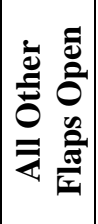 & 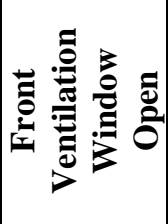 & 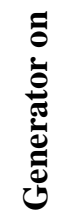 & 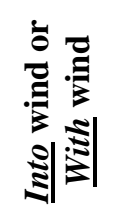 & 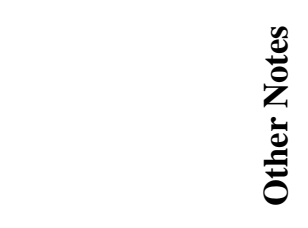 \\
\hline 1 & 5 & yes & no & no & no & no & yes & $\mathrm{n} / \mathrm{a}$ & Boat 9 \\
\hline 2 & 10 & yes & no & no & no & no & yes & $\mathrm{n} / \mathrm{a}$ & Boat 9 \\
\hline 3 & 15 & yes & no & no & no & no & yes & $\mathrm{n} / \mathrm{a}$ & Boat 9 \\
\hline 4 & 20 & yes & no & no & no & no & yes & $\mathrm{n} / \mathrm{a}$ & Boat 9 \\
\hline 5 & 25 & yes & no & no & no & no & yes & $\mathrm{n} / \mathrm{a}$ & Boat 9 \\
\hline 6 & 5 & yes & yes & no & no & no & yes & $\mathrm{n} / \mathrm{a}$ & Boat 9 \\
\hline 7 & 10 & yes & yes & no & no & no & yes & $\mathrm{n} / \mathrm{a}$ & Boat 9 \\
\hline 8 & 15 & yes & yes & no & no & no & yes & $\mathrm{n} / \mathrm{a}$ & Boat 9 \\
\hline 9 & 25 & yes & yes & no & no & no & yes & $\mathrm{n} / \mathrm{a}$ & Boat 9 \\
\hline 10 & 10 & yes & yes & yes & yes & no & yes & $\mathrm{n} / \mathrm{a}$ & Boat 9 \\
\hline 11 & 5 & yes & yes & yes & yes & no & yes & $\mathrm{n} / \mathrm{a}$ & Boat 9 \\
\hline 12 & $\begin{array}{l}\text { At } \\
\text { Dock }\end{array}$ & yes & no & no & no & no & yes & $\mathrm{n} / \mathrm{a}$ & Boat 9 \\
\hline 13 & 5 & yes & no & no & no & no & yes & $\mathrm{n} / \mathrm{a}$ & Boat 10 \\
\hline 14 & 10 & yes & no & no & no & no & yes & $\mathrm{n} / \mathrm{a}$ & Boat 10 \\
\hline 15 & 15 & yes & no & no & no & no & yes & $\mathrm{n} / \mathrm{a}$ & Boat 10 \\
\hline 16 & 25 & yes & no & no & no & no & yes & $\mathrm{n} / \mathrm{a}$ & Boat 10 \\
\hline 17 & 5 & yes & yes & no & no & no & yes & $\mathrm{n} / \mathrm{a}$ & Boat 10 \\
\hline 18 & 10 & yes & yes & no & no & no & yes & $\mathrm{n} / \mathrm{a}$ & Boat 10 \\
\hline 19 & 15 & yes & yes & no & no & no & yes & $\mathrm{n} / \mathrm{a}$ & Boat 10 \\
\hline 20 & 25 & yes & yes & no & no & no & yes & $\mathrm{n} / \mathrm{a}$ & Boat 10 \\
\hline 21 & 10 & yes & yes & yes & yes & no & yes & $\mathrm{n} / \mathrm{a}$ & Boat 10 \\
\hline 22 & 5 & yes & yes & yes & yes & no & yes & $\mathrm{n} / \mathrm{a}$ & Boat 10 \\
\hline 23 & $\begin{array}{l}\text { At } \\
\text { Dock }\end{array}$ & yes & no & no & no & no & yes & $\mathrm{n} / \mathrm{a}$ & Boat 10 \\
\hline
\end{tabular}


Table 6: Average ToxiUltra CO Values, Boats 1 \& 2.

All measurements are expressed in parts per million (ppm)

\begin{tabular}{|c|c|c|c|c|c|c|c|c|c|c|}
\hline $\begin{array}{c}\text { Experiment } \\
\#\end{array}$ & TU1 & TU2 & TU3 & TU4 & TU5 & TU6 & TU8 & TU10 & TU11 & TU12 \\
\hline 1 & 209 & 303 & 75 & 204 & 61 & 220 & 183 & 85 & & \\
\hline 2 & 46 & 274 & 118 & 39 & 49 & 27 & 32 & 51 & & \\
\hline 3 & 14 & 24 & 41 & 18 & 48 & 19 & 18 & 24 & & \\
\hline 4 & 37 & 61 & 98 & 28 & 48 & 30 & 22 & 15 & & \\
\hline 5 & 537 & 912 & 215 & 316 & 52 & 71 & 94 & 52 & & \\
\hline 6 & 437 & 919 & 69 & 100 & 64 & 171 & 111 & 80 & & \\
\hline 7 & 285 & 798 & 193 & 159 & 49 & 43 & 76 & 36 & & \\
\hline 8 & 40 & 177 & 46 & 22 & 47 & 18 & 14 & 15 & & \\
\hline 9 & 45 & 191 & 49 & 29 & 46 & 12 & 14 & 7 & & \\
\hline 10 & 1 & 45 & 25 & 7 & 46 & 7 & 2 & 1 & & \\
\hline 11 & 334 & 423 & 130 & 333 & 69 & 306 & 252 & 87 & & \\
\hline 12 & 48 & 62 & 33 & 65 & 51 & 62 & 64 & 54 & 54 & \\
\hline 13 & 15 & 38 & 20 & 38 & 49 & 28 & 27 & 22 & 32 & \\
\hline 14 & 37 & 34 & 17 & 9 & 47 & 23 & 30 & 18 & 41 & 13 \\
\hline 15 & 117 & 351 & 17 & 12 & 50 & 25 & 19 & 10 & 296 & 140 \\
\hline 16 & 11 & 22 & 28 & 8 & 47 & 13 & 10 & 6 & 24 & 20 \\
\hline 17 & 31 & 58 & 6 & 10 & 47 & 18 & 17 & 6 & 59 & 32 \\
\hline 18 & 228 & 294 & 176 & 111 & 55 & 157 & 141 & 80 & 321 & 188 \\
\hline 19 & 170 & 537 & 45 & 15 & 53 & 22 & 3 & 37 & 511 & 224 \\
\hline 20 & 52 & 177 & 6 & 6 & 47 & 7 & 0 & 4 & 179 & 65 \\
\hline 21 & 26 & 220 & 17 & 10 & 47 & 6 & -1 & 3 & 193 & 94 \\
\hline 22 & 334 & 521 & 176 & 167 & 62 & 87 & 110 & 0 & 460 & 281 \\
\hline 23 & 197 & 257 & 50 & 105 & 60 & 156 & 136 & 50 & 221 & 206 \\
\hline 24 & 3 & 5 & 3 & 5 & 47 & 15 & 7 & 0 & 6 & 9 \\
\hline 25 & 48 & 595 & 247 & 14 & 48 & 17 & 39 & 34 & 591 & 193 \\
\hline 26 & 20 & 497 & 213 & 18 & 48 & 13 & 21 & 12 & 470 & 118 \\
\hline 27 & 388 & 682 & 372 & 438 & 82 & 139 & 156 & 28 & 689 & 240 \\
\hline 28 & 69 & 1084 & 57 & 45 & 47 & 16 & 24 & 12 & 1143 & 154 \\
\hline 29 & 8 & 821 & 22 & 12 & 47 & 7 & 7 & 1 & 850 & 68 \\
\hline 30 & 161 & 474 & 281 & 91 & 55 & 53 & 67 & 20 & 438 & 190 \\
\hline 31 & 106 & 120 & 33 & 126 & 47 & 21 & 36 & 25 & 118 & 77 \\
\hline 32 & 241 & 371 & 440 & 178 & 64 & 195 & 220 & 135 & 334 & 144 \\
\hline 33 & 324 & 675 & 797 & 89 & 83 & 143 & 7 & 107 & 621 & 217 \\
\hline 34 & 83 & 152 & 125 & 35 & 50 & 16 & 0 & 26 & 153 & 58 \\
\hline 35 & 154 & 199 & 307 & 124 & 62 & 18 & 16 & 0 & 197 & 87 \\
\hline 36 & 214 & 401 & 434 & 345 & 68 & 245 & 221 & 205 & 346 & 131 \\
\hline 37 & 121 & 277 & 250 & 95 & 56 & 16 & 2 & 13 & 259 & 92 \\
\hline 38 & 35 & 24 & 21 & 19 & 47 & 19 & 10 & 10 & 24 & 51 \\
\hline
\end{tabular}


Table 7: Maximum ToxiUltra CO Values, Boats 1 \& 2.

\begin{tabular}{|l|l|}
\hline & Above $50 \mathrm{ppm}$ \\
\hline & Above $200 \mathrm{ppm}$ \\
\hline & Above $1000 \mathrm{ppm}$ \\
\hline
\end{tabular}

\begin{tabular}{|c|c|c|c|c|c|c|c|c|c|c|}
\hline $\begin{array}{c}\text { Experiment } \\
\#\end{array}$ & TU1 & TU2 & TU3 & TU4 & TU5 & TU6 & TU8 & TU10 & TU11 & TU12 \\
\hline 1 & 257 & 469 & 120 & 265 & 65 & 273 & 221 & 89 & 0 & 0 \\
\hline 2 & 133 & 347 & 227 & 69 & 50 & 39 & 61 & 76 & 0 & 0 \\
\hline 3 & 38 & 74 & 197 & 39 & 49 & 32 & 26 & 25 & 0 & 0 \\
\hline 4 & 91 & 246 & 166 & 52 & 49 & 39 & 31 & 17 & 0 & 0 \\
\hline 5 & 997 & 1091 & 496 & 550 & 58 & 143 & 154 & 78 & 0 & 0 \\
\hline 6 & 708 & 1091 & 139 & 152 & 72 & 271 & 167 & 83 & 0 & 0 \\
\hline 7 & 590 & 1080 & 348 & 426 & 51 & 77 & 174 & 53 & 0 & 0 \\
\hline 8 & 106 & 382 & 103 & 49 & 50 & 38 & 22 & 19 & 0 & 0 \\
\hline 9 & 69 & 340 & 167 & 48 & 47 & 17 & 27 & 15 & 0 & 0 \\
\hline 10 & 5 & 300 & 163 & 23 & 47 & 14 & 3 & 2 & 0 & 0 \\
\hline 11 & 406 & 488 & 203 & 351 & 71 & 328 & 281 & 135 & 0 & 0 \\
\hline 12 & 78 & 173 & 111 & 88 & 52 & 83 & 89 & 76 & 126 & 0 \\
\hline 13 & 26 & 181 & 81 & 152 & 55 & 39 & 39 & 35 & 100 & 0 \\
\hline 14 & 124 & 114 & 28 & 19 & 48 & 41 & 72 & 34 & 150 & 20 \\
\hline 15 & 438 & 709 & 45 & 25 & 56 & 78 & 44 & 23 & 631 & 327 \\
\hline 16 & 17 & 34 & 39 & 11 & 47 & 14 & 13 & 8 & 36 & 26 \\
\hline 17 & 55 & 110 & 27 & 17 & 51 & 26 & 28 & 7 & 103 & 92 \\
\hline 18 & 487 & 584 & 255 & 235 & 59 & 270 & 251 & 173 & 554 & 323 \\
\hline 19 & 512 & 860 & 131 & 33 & 75 & 54 & 5 & 67 & 789 & 379 \\
\hline 20 & 105 & 237 & 13 & 14 & 47 & 11 & 1 & 8 & 287 & 88 \\
\hline 21 & 65 & 329 & 40 & 47 & 48 & 18 & 1 & 22 & 317 & 146 \\
\hline 22 & 744 & 730 & 321 & 221 & 79 & 303 & 175 & 0 & 736 & 431 \\
\hline 23 & 684 & 649 & 147 & 329 & 81 & 519 & 401 & 101 & 556 & 604 \\
\hline 24 & 5 & 13 & 5 & 62 & 54 & 103 & 72 & 0 & 9 & 32 \\
\hline 25 & 57 & 1081 & 741 & 21 & 52 & 23 & 75 & 46 & 1011 & 250 \\
\hline 26 & 33 & 722 & 665 & 114 & 56 & 21 & 22 & 18 & 668 & 194 \\
\hline 27 & 529 & 879 & 515 & 603 & 104 & 241 & 248 & 33 & 839 & 274 \\
\hline 28 & 132 & 1084 & 136 & 92 & 49 & 22 & 36 & 21 & 1143 & 288 \\
\hline 29 & 12 & 1086 & 106 & 35 & 49 & 16 & 8 & 2 & 1145 & 111 \\
\hline 30 & 318 & 973 & 594 & 312 & 64 & 166 & 142 & 21 & 831 & 267 \\
\hline 31 & 142 & 142 & 45 & 187 & 47 & 30 & 54 & 26 & 146 & 81 \\
\hline 32 & 522 & 865 & 1095 & 272 & 83 & 369 & 368 & 176 & 652 & 231 \\
\hline 33 & 595 & 1086 & 1071 & 153 & 101 & 179 & 15 & 181 & 1049 & 433 \\
\hline 34 & 159 & 310 & 305 & 56 & 53 & 25 & -1 & 55 & 296 & 106 \\
\hline 35 & 309 & 606 & 767 & 301 & 86 & 34 & 50 & -1 & 508 & 161 \\
\hline 36 & 883 & 1084 & 1056 & 1020 & 109 & 623 & 587 & 502 & 1096 & 259 \\
\hline 37 & 453 & 1089 & 929 & 348 & 98 & 57 & 9 & 27 & 1147 & 250 \\
\hline 38 & 199 & 274 & 98 & 107 & 50 & 100 & 42 & 16 & 290 & 140 \\
\hline
\end{tabular}


Table 8: Average ToxiUltra CO Values, Boats 3 \& 4.

All measurements are expressed in parts per million (ppm)

\begin{tabular}{|c|c|c|c|c|c|c|c|c|c|c|}
\hline $\begin{array}{c}\text { Experiment } \\
\#\end{array}$ & TU 1 & TU 2 & TU 3 & TU 4 & TU 5 & TU 6 & TU 7 & TU 8 & TU 10 & TU 12 \\
\hline $\mathbf{1}$ & & & & & & & & & & \\
\hline $\mathbf{2}$ & 502 & 48 & 46 & 31 & 39 & 33 & 33 & 32 & 13 & 45 \\
\hline $\mathbf{3}$ & 28 & 48 & 74 & 28 & 501 & 337 & 356 & 315 & 108 & 168 \\
\hline $\mathbf{4}$ & 96 & 256 & 428 & 46 & 151 & 69 & 44 & 71 & 34 & 63 \\
\hline $\mathbf{5}$ & 287 & 361 & 356 & 121 & 196 & 129 & 114 & 122 & 68 & 114 \\
\hline $\mathbf{6}$ & 121 & 131 & 166 & 88 & 97 & 68 & 86 & 60 & 66 & 91 \\
\hline $\mathbf{7}$ & 223 & 350 & 449 & 237 & 437 & 241 & 241 & 219 & 66 & 157 \\
\hline $\mathbf{8}$ & 167 & 150 & 140 & 118 & 114 & 96 & 81 & 91 & 67 & 92 \\
\hline $\mathbf{9}$ & 314 & 397 & 476 & 237 & 386 & 286 & 218 & 255 & 135 & 187 \\
\hline $\mathbf{1 0}$ & 15 & 21 & 76 & 18 & 33 & 49 & 36 & 51 & 76 & 52 \\
\hline $\mathbf{1 1}$ & 13 & 18 & 49 & 7 & 28 & 19 & 16 & 18 & 15 & 21 \\
\hline $\mathbf{1 2}$ & 73 & 81 & 178 & 16 & 58 & 28 & 25 & 24 & 11 & 25 \\
\hline $\mathbf{1 3}$ & 18 & 50 & 12 & 9 & 9 & 21 & 12 & 15 & 5 & 17 \\
\hline $\mathbf{1 4}$ & 18 & 50 & 12 & 9 & 9 & 21 & 12 & 15 & 5 & 17 \\
\hline $\mathbf{1 5}$ & 25 & 43 & 27 & 8 & 15 & 20 & 16 & 16 & 3 & 15 \\
\hline $\mathbf{1 6}$ & 23 & 241 & 235 & 14 & 103 & 48 & 31 & 36 & 5 & 24 \\
\hline $\mathbf{1 7}$ & 225 & 128 & 173 & 68 & 72 & 59 & 57 & 44 & 9 & 54 \\
\hline $\mathbf{1 8}$ & 79 & 97 & 37 & 36 & 39 & 54 & 41 & 33 & 10 & 16 \\
\hline $\mathbf{1 9}$ & 150 & 167 & 50 & 62 & 50 & 81 & 85 & 64 & 45 & 53 \\
\hline $\mathbf{2 0}$ & 68 & 137 & 33 & 41 & 62 & 78 & 81 & 46 & 21 & 28 \\
\hline $\mathbf{2 1}$ & 186 & 277 & 35 & 76 & 74 & 116 & 99 & 70 & 25 & 35 \\
\hline $\mathbf{2 2}$ & 253 & 430 & 103 & 127 & 98 & 152 & 144 & 93 & 36 & 59 \\
\hline $\mathbf{2 3}$ & 381 & 338 & 63 & 207 & 66 & 151 & 206 & 139 & 54 & 74 \\
\hline $\mathbf{2 4}$ & 329 & 321 & 49 & 158 & 67 & 162 & 176 & 147 & 52 & 61 \\
\hline $\mathbf{2 5}$ & 74 & 57 & 16 & 55 & 18 & 67 & 71 & 48 & 39 & 39 \\
\hline $\mathbf{2 6}$ & 59 & 60 & 14 & 31 & 29 & 59 & 45 & 39 & 16 & 26 \\
\hline $\mathbf{2 7}$ & 52 & 62 & 52 & 29 & 122 & 103 & 58 & 84 & 27 & 39 \\
\hline $\mathbf{2 8}$ & 150 & 43 & 37 & 32 & 92 & 111 & 83 & 95 & 58 & 49 \\
\hline $\mathbf{2 9}$ & 13 & 11 & 8 & 11 & 16 & 36 & 30 & 27 & 27 & 28 \\
\hline $\mathbf{3 0}$ & 7 & 10 & 9 & 7 & 17 & 23 & 18 & 14 & 8 & 19 \\
\hline $\mathbf{3 1}$ & 5 & 5 & 8 & 5 & 16 & 16 & 9 & 11 & 5 & 16 \\
\hline $\mathbf{3 2}$ & 65 & 72 & 31 & 6 & 31 & 17 & 9 & 10 & 5 & 35 \\
\hline & & & & & & & & & & \\
\hline
\end{tabular}


Table 9: Maximum ToxiUltra CO Values, Boats 3 \& 4.

\begin{tabular}{|l|l|}
\hline & Above $50 \mathrm{ppm}$ \\
\hline & Above $200 \mathrm{ppm}$ \\
\hline & Above $1000 \mathrm{ppm}$ \\
\hline
\end{tabular}

\begin{tabular}{|c|c|c|c|c|c|c|c|c|c|c|}
\hline $\begin{array}{c}\text { Experiment } \\
\#\end{array}$ & TU 1 & TU 2 & TU 3 & TU 4 & TU 5 & TU 6 & TU 7 & TU 8 & TU 10 & TU 12 \\
\hline $\mathbf{1}$ & & & & & & & & & & \\
\hline $\mathbf{2}$ & 624 & 102 & 96 & 63 & 59 & 54 & 55 & 57 & 20 & 64 \\
\hline $\mathbf{3}$ & 76 & 99 & 194 & 51 & 88 & 51 & 41 & 68 & 132 & 73 \\
\hline $\mathbf{4}$ & 215 & 449 & 669 & 107 & 279 & 148 & 79 & 143 & 45 & 111 \\
\hline $\mathbf{5}$ & 751 & 535 & 552 & 187 & 367 & 175 & 168 & 164 & 85 & 139 \\
\hline $\mathbf{6}$ & 381 & 305 & 437 & 167 & 163 & 96 & 123 & 89 & 79 & 138 \\
\hline $\mathbf{7}$ & 368 & 556 & 531 & 318 & 449 & 316 & 315 & 282 & 93 & 198 \\
\hline $\mathbf{8}$ & 339 & 293 & 431 & 269 & 333 & 226 & 140 & 220 & 110 & 161 \\
\hline $\mathbf{9}$ & 622 & 658 & 638 & 409 & 543 & 433 & 343 & 365 & 166 & 297 \\
\hline $\mathbf{1 0}$ & 17 & 30 & 136 & 34 & 59 & 68 & 56 & 67 & 157 & 101 \\
\hline $\mathbf{1 1}$ & 14 & 24 & 63 & 8 & 36 & 25 & 20 & 19 & 19 & 25 \\
\hline $\mathbf{1 2}$ & 242 & 173 & 374 & 62 & 209 & 36 & 39 & 29 & 12 & 32 \\
\hline $\mathbf{1 3}$ & 40 & 102 & 23 & 28 & 10 & 28 & 16 & 19 & 8 & 34 \\
\hline $\mathbf{1 4}$ & 40 & 102 & 23 & 28 & 10 & 28 & 16 & 19 & 8 & 34 \\
\hline $\mathbf{1 5}$ & 56 & 78 & 56 & 10 & 26 & 25 & 26 & 22 & 3 & 17 \\
\hline $\mathbf{1 6}$ & 35 & 645 & 404 & 24 & 176 & 70 & 38 & 53 & 7 & 34 \\
\hline $\mathbf{1 7}$ & 358 & 318 & 440 & 164 & 138 & 71 & 71 & 55 & 11 & 74 \\
\hline $\mathbf{1 8}$ & 143 & 180 & 81 & 54 & 53 & 76 & 58 & 47 & 16 & 25 \\
\hline $\mathbf{1 9}$ & 658 & 581 & 190 & 158 & 207 & 197 & 235 & 180 & 59 & 117 \\
\hline $\mathbf{2 0}$ & 199 & 285 & 84 & 103 & 139 & 154 & 147 & 101 & 27 & 44 \\
\hline $\mathbf{2 1}$ & 233 & 324 & 46 & 99 & 81 & 130 & 113 & 81 & 30 & 41 \\
\hline $\mathbf{2 2}$ & 405 & 614 & 199 & 167 & 126 & 172 & 172 & 110 & 42 & 67 \\
\hline $\mathbf{2 3}$ & 527 & 453 & 114 & 234 & 73 & 180 & 239 & 174 & 56 & 79 \\
\hline $\mathbf{2 4}$ & 385 & 413 & 94 & 181 & 79 & 191 & 198 & 176 & 56 & 68 \\
\hline $\mathbf{2 5}$ & 206 & 158 & 58 & 149 & 39 & 121 & 156 & 107 & 51 & 64 \\
\hline $\mathbf{2 6}$ & 100 & 97 & 27 & 43 & 42 & 78 & 55 & 55 & 20 & 30 \\
\hline $\mathbf{2 7}$ & 166 & 107 & 81 & 39 & 200 & 150 & 101 & 125 & 34 & 44 \\
\hline $\mathbf{2 8}$ & 283 & 53 & 46 & 41 & 115 & 138 & 93 & 114 & 63 & 52 \\
\hline $\mathbf{2 9}$ & 19 & 16 & 13 & 21 & 20 & 48 & 45 & 40 & 52 & 42 \\
\hline $\mathbf{3 0}$ & 9 & 13 & 12 & 8 & 21 & 26 & 22 & 17 & 11 & 21 \\
\hline $\mathbf{3 1}$ & 6 & 7 & 13 & 6 & 17 & 19 & 11 & 13 & 6 & 18 \\
\hline $\mathbf{3 2}$ & 87 & 128 & 58 & 11 & 75 & 32 & 13 & 15 & 6 & 45 \\
\hline & & & & & & & & & \\
\hline
\end{tabular}


Table 10: Average ToxiUltra CO Values, Boats 5 \& 6.

All measurements are expressed in parts per million (ppm)

\begin{tabular}{|c|c|c|c|c|c|c|c|c|c|c|c|}
\hline $\begin{array}{c}\text { Experiment } \\
\#\end{array}$ & TU 1 & TU 2 & TU 3 & TU 4 & TU 5 & TU 7 & TU 8 & TU 9 & TU 10 & TU 11 & TU 12 \\
\hline 1 & 59 & 56 & 70 & 48 & 40 & 41 & 37 & 17 & 20 & 1 & 34 \\
\hline 2 & 56 & 50 & 56 & 39 & 17 & 23 & 9 & 17 & 18 & 1 & 10 \\
\hline 3 & 122 & 56 & 73 & 39 & 35 & 32 & 32 & 16 & 16 & 1 & 32 \\
\hline 4 & 27 & 26 & 38 & 14 & 15 & 10 & 7 & 16 & 16 & 1 & 13 \\
\hline 5 & 58 & 43 & 50 & 38 & 34 & 38 & 37 & 15 & 15 & 1 & 32 \\
\hline 6 & 0 & 5 & 4 & 8 & 3 & 7 & 7 & 15 & 14 & 1 & 0 \\
\hline 7 & 2 & 5 & 6 & 5 & 2 & 5 & 5 & 13 & 13 & 1 & 0 \\
\hline 8 & 13 & 11 & 25 & 14 & 11 & 14 & 15 & 12 & 12 & 0 & 10 \\
\hline 9 & 77 & 47 & 30 & 25 & 25 & 18 & 11 & 12 & 11 & 1 & 21 \\
\hline 10 & 110 & 58 & 38 & 28 & 18 & 24 & 26 & 12 & 11 & 1 & 14 \\
\hline 11 & 28 & 12 & 9 & 12 & 2 & 9 & 9 & 11 & 11 & 1 & 1 \\
\hline 12 & 125 & 89 & 82 & 59 & 10 & 33 & 37 & 11 & 10 & 1 & 9 \\
\hline 13 & 20 & 2 & 4 & 9 & 0 & 4 & 7 & 10 & 9 & 1 & 0 \\
\hline 14 & 27 & 1 & 2 & 9 & 0 & 4 & 6 & 9 & 8 & 1 & 0 \\
\hline 15 & 44 & 8 & 5 & 10 & 0 & 4 & 7 & 8 & 7 & 1 & 0 \\
\hline 16 & 23 & 5 & 5 & 11 & 0 & 5 & 8 & 8 & 7 & 1 & 0 \\
\hline 17 & 36 & 3 & 3 & 9 & 1 & 5 & 7 & 8 & 8 & 1 & 0 \\
\hline 18 & 11 & 3 & 2 & 7 & 0 & 4 & 4 & 3 & 2 & 1 & 0 \\
\hline 19 & 10 & 2 & 3 & 8 & 0 & 3 & 6 & 22 & 23 & 0 & 0 \\
\hline 20 & 105 & 190 & 168 & 39 & 49 & 38 & 43 & 21 & 20 & 0 & 41 \\
\hline 21 & 256 & 225 & 325 & 44 & 51 & 46 & 51 & 20 & 20 & 0 & 21 \\
\hline 22 & 98 & 83 & 103 & 51 & 33 & 46 & 50 & 19 & 19 & 0 & 47 \\
\hline 23 & 171 & 118 & 142 & 60 & 68 & 29 & 20 & 19 & 19 & 0 & 60 \\
\hline 24 & 24 & 5 & 13 & 13 & 3 & 5 & 7 & 18 & 18 & 0 & 6 \\
\hline 25 & 223 & 83 & 228 & 27 & 45 & 23 & 28 & 18 & 18 & 0 & 17 \\
\hline 26 & 19 & 16 & 41 & 14 & 8 & 16 & 18 & 18 & 18 & 0 & 10 \\
\hline 27 & 20 & 26 & 55 & 17 & 13 & 9 & 14 & 17 & 18 & 0 & 12 \\
\hline 28 & 9 & 55 & 37 & 7 & 3 & 6 & 8 & 17 & 17 & 0 & 1 \\
\hline 29 & 9 & 1 & 3 & 6 & 0 & 4 & 5 & 16 & 16 & 0 & 0 \\
\hline 30 & 6 & 7 & 1 & 3 & 0 & 2 & 4 & 14 & 14 & 0 & 0 \\
\hline 31 & 4 & 0 & 1 & 2 & 0 & 2 & 4 & 14 & 14 & 0 & 0 \\
\hline 32 & 5 & 0 & 1 & 3 & 0 & 2 & 4 & 13 & 13 & 0 & 0 \\
\hline 33 & 47 & 12 & 7 & 8 & 1 & 3 & 6 & 10 & 10 & 0 & 1 \\
\hline 34 & 116 & 9 & 2 & 5 & 0 & 2 & 4 & 10 & 10 & 0 & 1 \\
\hline 35 & 17 & 3 & 2 & 6 & 0 & 3 & 6 & 3 & 3 & 0 & 0 \\
\hline 36 & 79 & 57 & 59 & 24 & 14 & 8 & 11 & 2 & 2 & 0 & 26 \\
\hline
\end{tabular}


Table 11: Maximum ToxiUltra CO Values, Boats 5 \& 6 .

\begin{tabular}{|l|l|}
\hline & Above $50 \mathrm{ppm}$ \\
\hline & Above $200 \mathrm{ppm}$ \\
\hline & Above $1000 \mathrm{ppm}$ \\
\hline
\end{tabular}

\begin{tabular}{|c|c|c|c|c|c|c|c|c|c|c|c|}
\hline $\begin{array}{c}\text { Experiment } \\
\#\end{array}$ & TU 1 & TU 2 & TU 3 & TU 4 & TU 5 & TU 7 & TU 8 & TU 9 & TU 10 & TU 11 & TU 12 \\
\hline 1 & 88 & 71 & 89 & 54 & 43 & 46 & 42 & 18 & 21 & 1 & 38 \\
\hline 2 & 105 & 91 & 106 & 58 & 52 & 36 & 13 & 18 & 19 & 1 & 36 \\
\hline 3 & 293 & 144 & 131 & 54 & 59 & 54 & 51 & 17 & 17 & 1 & 53 \\
\hline 4 & 40 & 31 & 49 & 17 & 19 & 17 & 10 & 16 & 17 & 1 & 17 \\
\hline 5 & 122 & 71 & 62 & 53 & 44 & 49 & 48 & 15 & 15 & 1 & 41 \\
\hline 6 & 0 & 23 & 12 & 11 & 9 & 19 & 16 & 15 & 15 & 1 & 4 \\
\hline 7 & 4 & 14 & 15 & 7 & 3 & 9 & 8 & 14 & 14 & 1 & 1 \\
\hline 8 & 29 & 16 & 41 & 20 & 19 & 22 & 22 & 13 & 13 & 1 & 17 \\
\hline 9 & 108 & 129 & 44 & 36 & 39 & 26 & 12 & 13 & 12 & 1 & 26 \\
\hline 10 & 138 & 252 & 132 & 43 & 49 & 70 & 88 & 12 & 12 & 1 & 21 \\
\hline 11 & 76 & 35 & 33 & 25 & 13 & 20 & 17 & 12 & 12 & 1 & 8 \\
\hline 12 & 153 & 111 & 106 & 73 & 14 & 43 & 46 & 12 & 11 & 1 & 12 \\
\hline 13 & 28 & 5 & 6 & 12 & 0 & 5 & 7 & 10 & 10 & 1 & 0 \\
\hline 14 & 43 & 1 & 3 & 12 & 0 & 4 & 6 & 9 & 9 & 1 & 0 \\
\hline 15 & 54 & 12 & 8 & 12 & 0 & 5 & 8 & 9 & 8 & 1 & 0 \\
\hline 16 & 32 & 6 & 10 & 12 & 0 & 6 & 9 & 8 & 8 & 1 & 0 \\
\hline 17 & 73 & 4 & 3 & 10 & 1 & 5 & 9 & 8 & 8 & 1 & 0 \\
\hline 18 & 12 & 5 & 3 & 7 & 0 & 4 & 4 & 7 & 6 & 1 & 0 \\
\hline 19 & 12 & 4 & 5 & 10 & 1 & 4 & 7 & 23 & 24 & 1 & 1 \\
\hline 20 & 184 & 385 & 282 & 66 & 72 & 58 & 63 & 21 & 21 & 1 & 76 \\
\hline 21 & 433 & 412 & 513 & 63 & 77 & 69 & 74 & 20 & 20 & 1 & 39 \\
\hline 22 & 237 & 148 & 168 & 80 & 57 & 76 & 80 & 20 & 20 & 1 & 84 \\
\hline 23 & 410 & 211 & 219 & 96 & 142 & 51 & 32 & 20 & 19 & 1 & 108 \\
\hline 24 & 30 & 13 & 28 & 15 & 6 & 9 & 9 & 19 & 19 & 1 & 8 \\
\hline 25 & 386 & 270 & 320 & 39 & 83 & 38 & 45 & 19 & 18 & 0 & 29 \\
\hline 26 & 30 & 58 & 128 & 26 & 16 & 24 & 26 & 18 & 19 & 1 & 21 \\
\hline 27 & 41 & 68 & 133 & 29 & 31 & 16 & 23 & 18 & 18 & 0 & 24 \\
\hline 28 & 37 & 466 & 306 & 21 & 28 & 31 & 28 & 17 & 17 & 1 & 7 \\
\hline 29 & 26 & 10 & 6 & 8 & 0 & 8 & 10 & 17 & 17 & 1 & 2 \\
\hline 30 & 24 & 67 & 4 & 4 & 0 & 4 & 5 & 15 & 15 & 1 & 0 \\
\hline 31 & 4 & 0 & 1 & 2 & 0 & 3 & 5 & 14 & 14 & 0 & 0 \\
\hline 32 & 9 & 0 & 1 & 4 & 0 & 3 & 5 & 14 & 14 & 1 & 0 \\
\hline 33 & 87 & 51 & 18 & 14 & 3 & 4 & 7 & 10 & 10 & 0 & 4 \\
\hline 34 & 166 & 19 & 3 & 6 & 0 & 3 & 5 & 11 & 10 & 1 & 2 \\
\hline 35 & 52 & 22 & 3 & 8 & 0 & 5 & 7 & 7 & 6 & 1 & 3 \\
\hline 36 & 200 & 197 & 139 & 51 & 31 & 17 & 21 & 3 & 3 & 0 & 52 \\
\hline
\end{tabular}


Table 12: Average ToxiUltra CO Values, Boats 7 \& 8.

All measurements are expressed in parts per million (ppm)

\begin{tabular}{|c|c|c|c|c|c|c|c|c|c|c|c|}
\hline $\begin{array}{c}\text { Experiment } \\
\#\end{array}$ & TU 1 & TU 2 & TU 3 & TU 4 & TU 5 & TU 6 & TU 7 & TU 8 & TU 9 & TU 10 & TU 11 \\
\hline 1 & 3 & 259 & 90 & 33 & 34 & 22 & 27 & 29 & 11 & 9 & 6 \\
\hline 2 & 31 & 264 & 78 & 26 & 29 & 24 & 25 & 24 & 17 & 15 & 6 \\
\hline 3 & 133 & 245 & 127 & 30 & 28 & 25 & 28 & 31 & 20 & 19 & 4 \\
\hline 4 & 134 & 166 & 175 & 17 & 17 & 13 & 16 & 10 & 16 & 21 & 4 \\
\hline 5 & 59 & 20 & 329 & 3 & 5 & 2 & 2 & 1 & 10 & 15 & 3 \\
\hline 6 & 40 & 11 & 160 & 2 & 0 & 0 & 1 & 1 & 5 & 9 & 1 \\
\hline 7 & 12 & 9 & 28 & 2 & 0 & 0 & 1 & 1 & 4 & 6 & 38 \\
\hline 8 & 127 & 6 & 36 & 1 & 0 & 0 & 1 & 0 & 2 & 4 & 30 \\
\hline 9 & 395 & 3 & 2 & 1 & 0 & 0 & 0 & 1 & 3 & 3 & 8 \\
\hline 10 & 35 & 7 & 9 & 2 & 1 & 0 & 1 & 2 & 3 & 3 & 6 \\
\hline 11 & 72 & 37 & 56 & 2 & 1 & 1 & 1 & 1 & 2 & 3 & 2 \\
\hline 12 & 74 & 181 & 160 & 1 & 0 & 0 & 1 & 0 & 2 & 3 & 2 \\
\hline 13 & 48 & 185 & 108 & 1 & 0 & 0 & 3 & 0 & 1 & 2 & 1 \\
\hline 14 & 102 & 250 & 140 & 1 & 0 & 0 & 1 & 0 & 1 & 2 & 15 \\
\hline 15 & 52 & 130 & 167 & 1 & 0 & 0 & 0 & 1 & 1 & 1 & 2 \\
\hline 16 & 269 & 317 & 402 & 113 & 133 & 72 & 93 & 123 & 7 & 8 & 69 \\
\hline 17 & 364 & 346 & 355 & 244 & 270 & 251 & 222 & 182 & 58 & 55 & 42 \\
\hline 18 & 93 & 39 & 43 & 50 & 52 & 52 & 54 & 65 & 52 & 57 & 71 \\
\hline 19 & 139 & 110 & 157 & 80 & 73 & 78 & 84 & 75 & 50 & 52 & 72 \\
\hline 20 & 189 & 149 & 178 & 92 & 94 & 102 & 111 & 106 & 48 & 50 & 14 \\
\hline 21 & 273 & 176 & 210 & 140 & 150 & 155 & 161 & 129 & 58 & 58 & 9 \\
\hline 22 & 12 & 20 & 31 & 8 & 8 & 12 & 15 & 5 & 45 & 52 & 14 \\
\hline 23 & 3 & 3 & 5 & 3 & 2 & 4 & 7 & 1 & 26 & 30 & 12 \\
\hline 24 & 1 & 2 & 3 & 2 & 0 & 2 & 3 & 4 & 18 & 21 & 4 \\
\hline 25 & 20 & 20 & 34 & 6 & 8 & 6 & 6 & 1 & 15 & 17 & 6 \\
\hline 26 & 7 & 7 & 16 & 3 & 0 & 1 & 3 & 2 & 11 & 13 & 14 \\
\hline 27 & 19 & 7 & 12 & 5 & 3 & 6 & 7 & 8 & 8 & 9 & 67 \\
\hline 28 & 45 & 25 & 76 & 14 & 7 & 15 & 15 & 14 & 7 & 8 & 5 \\
\hline 29 & 8 & 8 & 15 & 3 & 2 & 2 & 1 & 1 & 5 & 7 & 18 \\
\hline
\end{tabular}


Table 13: Maximum ToxiUltra CO Values, Boats 7 \& 8 .

\begin{tabular}{|l|l|}
\hline & Above $50 \mathrm{ppm}$ \\
\hline & Above $200 \mathrm{ppm}$ \\
\hline & Above $1000 \mathrm{ppm}$ \\
\hline
\end{tabular}

\begin{tabular}{|c|c|c|c|c|c|c|c|c|c|c|c|}
\hline Experiment \# & TU 1 & TU 2 & TU 3 & TU 4 & TU 5 & TU 6 & TU 7 & TU 8 & TU 9 & TU 10 & TU 11 \\
\hline 1 & 12 & 376 & 132 & 39 & 53 & 29 & 39 & 38 & 14 & 11 & 7 \\
\hline 2 & 53 & 463 & 113 & 38 & 52 & 35 & 37 & 34 & 17 & 18 & 7 \\
\hline 3 & 345 & 560 & 358 & 50 & 47 & 43 & 47 & 56 & 27 & 21 & 5 \\
\hline 4 & 341 & 395 & 304 & 56 & 59 & 50 & 47 & 41 & 26 & 24 & 5 \\
\hline 5 & 101 & 51 & 432 & 15 & 45 & 19 & 5 & 2 & 15 & 17 & 6 \\
\hline 6 & 69 & 11 & 379 & 2 & 1 & 0 & 1 & 1 & 6 & 11 & 2 \\
\hline 7 & 38 & 11 & 145 & 7 & 1 & 1 & 3 & 2 & 5 & 8 & 82 \\
\hline 8 & 544 & 8 & 410 & 3 & 1 & 1 & 2 & 1 & 4 & 5 & 71 \\
\hline 9 & 723 & 6 & 3 & 2 & 1 & 0 & 1 & 2 & 3 & 4 & 18 \\
\hline 10 & 67 & 21 & 31 & 8 & 3 & 3 & 4 & 6 & 3 & 4 & 41 \\
\hline 11 & 448 & 372 & 404 & 6 & 8 & 4 & 2 & 5 & 3 & 4 & 3 \\
\hline 12 & 115 & 370 & 248 & 2 & 1 & 0 & 3 & 1 & 2 & 4 & 5 \\
\hline 13 & 73 & 243 & 172 & 2 & 0 & 0 & 3 & 1 & 2 & 3 & 2 \\
\hline 14 & 132 & 343 & 230 & 2 & 1 & 0 & 2 & 1 & 1 & 2 & 80 \\
\hline 15 & 110 & 338 & 265 & 3 & 0 & 2 & 3 & 4 & 1 & 2 & 7 \\
\hline 16 & 423 & 520 & 697 & 251 & 288 & 131 & 204 & 286 & 21 & 20 & 143 \\
\hline 17 & 501 & 552 & 569 & 377 & 376 & 350 & 350 & 346 & 69 & 69 & 72 \\
\hline 18 & 122 & 55 & 70 & 70 & 76 & 71 & 71 & 105 & 56 & 65 & 84 \\
\hline 19 & 264 & 219 & 380 & 125 & 135 & 137 & 134 & 134 & 55 & 57 & 82 \\
\hline 20 & 307 & 183 & 214 & 101 & 107 & 108 & 119 & 143 & 48 & 51 & 29 \\
\hline 21 & 448 & 270 & 339 & 244 & 283 & 276 & 270 & 271 & 66 & 66 & 14 \\
\hline 22 & 29 & 47 & 93 & 15 & 18 & 26 & 24 & 12 & 57 & 64 & 32 \\
\hline 23 & 11 & 12 & 15 & 8 & 8 & 8 & 11 & 6 & 34 & 39 & 28 \\
\hline 24 & 4 & 2 & 12 & 5 & 1 & 3 & 7 & 23 & 21 & 24 & 8 \\
\hline 25 & 64 & 42 & 59 & 21 & 25 & 22 & 16 & 3 & 16 & 18 & 11 \\
\hline 26 & 24 & 15 & 80 & 14 & 2 & 9 & 10 & 11 & 13 & 15 & 19 \\
\hline 27 & 71 & 35 & 34 & 12 & 9 & 19 & 20 & 22 & 9 & 11 & 169 \\
\hline 28 & 68 & 62 & 159 & 25 & 11 & 20 & 21 & 23 & 8 & 9 & 31 \\
\hline 29 & 45 & 56 & 104 & 10 & 9 & 12 & 5 & 5 & 7 & 9 & 31 \\
\hline
\end{tabular}


Table 14: Average ToxiUltra CO Values, Boats 9 \& 10.

All measurements are expressed in parts per million (ppm)

\begin{tabular}{|c|c|c|c|c|c|c|c|c|c|c|c|c|c|c|}
\hline Experiment \# & TU 1 & TU 2 & TU 3 & TU 4 & TU 5 & TU 6 & TU 7 & TU 8 & TU 9 & TU 10 & TU 11 & TU 12 & TU 13 & TU 14 \\
\hline 1 & 249 & 224 & 206 & 24 & 19 & 34 & 19 & 21 & 4 & 5 & 35 & 49 & 62 & 36 \\
\hline 2 & 344 & 398 & 192 & 50 & 28 & 37 & 32 & 34 & 10 & 7 & 33 & 65 & 81 & 58 \\
\hline 3 & 103 & 127 & 65 & 31 & 20 & 25 & 20 & 25 & 10 & 10 & 16 & 25 & 32 & 26 \\
\hline 4 & 59 & 75 & 40 & 24 & 14 & 15 & 14 & 13 & 8 & 9 & 8 & 21 & 24 & 21 \\
\hline 5 & 30 & 20 & 16 & 11 & 12 & 13 & 8 & 12 & 7 & 7 & 7 & 8 & 5 & 12 \\
\hline 6 & 149 & 164 & 141 & 54 & 23 & 29 & 31 & 28 & 7 & 7 & 3 & 41 & 51 & 32 \\
\hline 7 & 212 & 229 & 178 & 85 & 35 & 43 & 43 & 43 & 7 & 7 & 3 & 54 & 66 & 44 \\
\hline 8 & 97 & 116 & 102 & 45 & 26 & 32 & 26 & 33 & 7 & 7 & 14 & 42 & 36 & 31 \\
\hline 9 & 26 & 11 & 50 & 10 & 8 & 7 & 2 & 5 & 6 & 7 & 7 & 8 & 3 & 2 \\
\hline 10 & 207 & 254 & 136 & 24 & 9 & 7 & 7 & 9 & 6 & 7 & 6 & 53 & 62 & 45 \\
\hline 11 & 183 & 203 & 156 & 32 & 12 & 9 & 15 & 13 & 8 & 7 & 2 & 38 & 69 & 52 \\
\hline 12 & 16 & 10 & 17 & 10 & 15 & 15 & 9 & 13 & 6 & 7 & 24 & 6 & 2 & 1 \\
\hline 13 & 252 & 331 & 218 & 68 & 64 & 72 & 81 & 69 & 33 & 35 & 254 & 115 & 111 & 97 \\
\hline 14 & 375 & 540 & 315 & 126 & 117 & 97 & 119 & 87 & 44 & 43 & 116 & 229 & 227 & 227 \\
\hline 15 & 208 & 237 & 164 & 120 & 126 & 67 & 77 & 44 & 46 & 38 & 60 & 167 & 161 & 170 \\
\hline 16 & 136 & 162 & 73 & 21 & 22 & 12 & 8 & 8 & 23 & 21 & 85 & 35 & 30 & 36 \\
\hline 17 & 113 & 145 & 58 & 9 & 10 & 7 & 7 & 5 & 18 & 21 & 165 & 23 & 23 & 8 \\
\hline 18 & 353 & 540 & 292 & 82 & 113 & 61 & 68 & 63 & 21 & 22 & 117 & 126 & 122 & 134 \\
\hline 19 & 165 & 174 & 166 & 66 & 80 & 61 & 58 & 46 & 18 & 18 & 88 & 96 & 86 & 97 \\
\hline 20 & 25 & 14 & 33 & 10 & 11 & 7 & 5 & 6 & 11 & 10 & 53 & 11 & 6 & 16 \\
\hline 21 & 525 & 944 & 561 & 11 & 24 & 11 & 6 & 10 & 8 & 9 & 88 & 19 & 21 & 14 \\
\hline 22 & 422 & 740 & 525 & 15 & 20 & 8 & 8 & 11 & 8 & 8 & 113 & 37 & 26 & 18 \\
\hline 23 & 27 & 13 & 27 & 10 & 9 & 9 & 4 & 8 & 5 & 8 & 173 & 6 & 3 & 1 \\
\hline
\end{tabular}


Table 15: Maximum ToxiUltra CO Values, Boats 9 \& 10.

\begin{tabular}{|l|l|}
\hline & Above $50 \mathrm{ppm}$ \\
\hline & Above $200 \mathrm{ppm}$ \\
\hline & Above $1000 \mathrm{ppm}$ \\
\hline
\end{tabular}

\begin{tabular}{|c|c|c|c|c|c|c|c|c|c|c|c|c|c|c|}
\hline Experiment \# & TU 1 & TU 2 & TU 3 & TU 4 & TU 5 & TU 6 & TU 7 & TU 8 & TU 9 & TU 10 & TU 11 & TU 12 & TU 13 & TU 14 \\
\hline 1 & 446 & 421 & 321 & 40 & 40 & 68 & 41 & 38 & 5 & 6 & 76 & 106 & 106 & 86 \\
\hline 2 & 488 & 489 & 227 & 85 & 34 & 46 & 42 & 40 & 12 & 9 & 61 & 83 & 138 & 99 \\
\hline 3 & 389 & 529 & 230 & 83 & 37 & 52 & 41 & 44 & 11 & 10 & 31 & 80 & 115 & 96 \\
\hline 4 & 253 & 389 & 133 & 56 & 25 & 23 & 31 & 20 & 9 & 10 & 10 & 60 & 97 & 111 \\
\hline 5 & 187 & 165 & 69 & 31 & 25 & 26 & 21 & 23 & 8 & 8 & 10 & 20 & 25 & 89 \\
\hline 6 & 216 & 315 & 224 & 72 & 34 & 44 & 38 & 43 & 9 & 8 & 5 & 51 & 66 & 40 \\
\hline 7 & 284 & 336 & 216 & 98 & 42 & 53 & 51 & 53 & 8 & 8 & 4 & 103 & 123 & 61 \\
\hline 8 & 292 & 376 & 316 & 65 & 44 & 50 & 43 & 49 & 7 & 8 & 19 & 91 & 72 & 74 \\
\hline 9 & 144 & 60 & 258 & 22 & 21 & 18 & 12 & 15 & 7 & 7 & 19 & 25 & 13 & 13 \\
\hline 10 & 257 & 327 & 169 & 48 & 12 & 9 & 10 & 12 & 7 & 7 & 14 & 63 & 84 & 54 \\
\hline 11 & 226 & 286 & 177 & 56 & 18 & 17 & 28 & 19 & 9 & 8 & 5 & 49 & 85 & 67 \\
\hline 12 & 118 & 49 & 106 & 51 & 72 & 62 & 58 & 60 & 7 & 8 & 100 & 26 & 22 & 33 \\
\hline 13 & 553 & 1112 & 736 & 100 & 99 & 123 & 157 & 135 & 41 & 42 & 462 & 227 & 207 & 171 \\
\hline 14 & 533 & 720 & 393 & 158 & 156 & 146 & 163 & 127 & 51 & 44 & 169 & 246 & 245 & 251 \\
\hline 15 & 334 & 519 & 334 & 157 & 166 & 113 & 135 & 76 & 54 & 43 & 108 & 235 & 232 & 238 \\
\hline 16 & 450 & 547 & 267 & 70 & 81 & 70 & 62 & 57 & 41 & 35 & 131 & 122 & 120 & 121 \\
\hline 17 & 361 & 601 & 283 & 23 & 42 & 23 & 30 & 18 & 20 & 22 & 224 & 136 & 174 & 69 \\
\hline 18 & 391 & 610 & 367 & 146 & 205 & 94 & 112 & 108 & 22 & 24 & 189 & 155 & 165 & 206 \\
\hline 19 & 320 & 408 & 244 & 104 & 128 & 124 & 94 & 83 & 21 & 21 & 141 & 195 & 192 & 203 \\
\hline 20 & 89 & 43 & 94 & 21 & 31 & 22 & 18 & 20 & 13 & 12 & 89 & 27 & 17 & 51 \\
\hline 21 & 683 & 1111 & 761 & 33 & 60 & 38 & 29 & 44 & 9 & 11 & 153 & 54 & 66 & 43 \\
\hline 22 & 615 & 882 & 594 & 47 & 68 & 27 & 31 & 43 & 10 & 9 & 139 & 65 & 56 & 44 \\
\hline 23 & 235 & 76 & 45 & 30 & 18 & 37 & 22 & 37 & 9 & 10 & 217 & 22 & 10 & 13 \\
\hline
\end{tabular}


Table 16: Evacuated Container Concentrations, Boats 1 \& 2 .

\begin{tabular}{|l|l|l|c|}
\hline Boat & $\begin{array}{c}\text { Container } \\
\text { ID \# }\end{array}$ & Condition & $\begin{array}{c}\text { Concentration } \\
\text { (ppm) }\end{array}$ \\
\hline Boat 1 & D9426 & $5 \mathrm{mph}$, all canvas closed, aft panel open, front screen opened & 1027 \\
\hline Boat 1 & D9413 & $\begin{array}{l}10 \mathrm{mph} \text {, canvas closed, aft panel open, front screen opened } \\
25 \mathrm{mph} \text { into wind, canvas closed, aft panel open, front screen } \\
\text { opened }\end{array}$ & 657 \\
\hline Boat 1 & D9427 & $\begin{array}{l}25 \mathrm{mph} \text { with wind, canvas closed, aft panel open, front screen } \\
\text { opened }\end{array}$ & 120 \\
\hline Boat 1 & D9425 & $10 \mathrm{mph}$, all panel opened & 4 \\
\hline Boat 1 & D9441 & $5 \mathrm{mph}$ no wind, all canvas closed, aft panel open & 341 \\
\hline Boat 2 & D9453 & $10 \mathrm{mph}$, no wind, all canvas closed, aft panel open & 102 \\
\hline Boat 2 & D9432 & $15 \mathrm{mph}$, no wind, all canvas closed, aft panel open & 1516 \\
\hline Boat 2 & D9434 & & \\
\hline
\end{tabular}


Table 17: Evacuated Container Concentrations, Boats 3 \& 4 .

\begin{tabular}{|l|l|l|c|}
\hline Boat & $\begin{array}{c}\text { Container } \\
\text { ID \# }\end{array}$ & Condition & $\begin{array}{c}\text { Concentration } \\
\text { (ppm) }\end{array}$ \\
\hline Boat 4 & D9428 & $5 \mathrm{mph}$, all canvas installed, aft panel opened & 340 \\
\hline Boat 4 & D9429 & $\begin{array}{l}25 \mathrm{mph} \text {, all canvas installed, aft panel opened, opening } \\
\text { front screen }\end{array}$ & 10 \\
\hline Boat 4 & $\mathrm{D} 9431$ & $25 \mathrm{mph}$, partial canvas installed & 232 \\
\hline Boat 4 & $\mathrm{D} 9882$ & $15 \mathrm{mph}$, all canvas opened, center windshield opened & 5 \\
\hline Boat 4 & D9881 & $15 \mathrm{mph}$, all canvas opened, center windshield opened & 26 \\
\hline Boat 4 & D9877 & $5 \mathrm{mph}$, all canvas opened, center windshield opened & 7 \\
\hline Boat 3 & D9875 & $25 \mathrm{mph}$. all canvas installed, aft panel opened & 242 \\
\hline Boat 3 & $\mathrm{D} 9609$ & $10 \mathrm{mph}$. all canvas installed, aft panel opened & 129 \\
\hline Boat 3 & $\mathrm{D} 9608$ & $\begin{array}{l}10 \mathrm{mph} \text {, back fully opened, and center of windshield } \\
\text { opened }\end{array}$ & 21 \\
\hline Boat 3 & $\mathrm{D} 9879$ & $5 \mathrm{mph}$, all canvas removed & 1 \\
\hline Boat 3 & D9870 & $15 \mathrm{mph}$, all canvas removed & 2 \\
\hline Boat 3 & D9430 & $15 \mathrm{mph}$, all canvas removed, center of windshield opened & 1 \\
\hline Boat 3 & D9880 & $25 \mathrm{mph}$, all canvas removed, center of windshield opened & \\
\hline
\end{tabular}


Table 18: Evacuated Container Concentrations, Boats 5 \& 6 .

\begin{tabular}{|l|l|l|c|}
\hline Boat & $\begin{array}{c}\text { Container } \\
\text { ID \# }\end{array}$ & Condition & $\begin{array}{c}\text { Concentration } \\
\text { (ppm) }\end{array}$ \\
\hline Boat 5 & D9442 & $5 \mathrm{mph}$, canvas fully closed, aft panel open & 24 \\
\hline Boat 5 & D9433 & $\begin{array}{l}25 \mathrm{mph} \text {, canvas fully closed, aft panel open, center window } \\
\text { opened }\end{array}$ & 1 \\
\hline Boat 5 & D9443 & $\begin{array}{l}15 \mathrm{mph} \text {, canvas fully closed, aft panel open, center window } \\
\text { opened }\end{array}$ & 45 \\
\hline Boat 5 & D9444 & $5 \mathrm{mph}$, all canvas removed, bimini top only & 2 \\
\hline Boat 6 & D9448 & $5 \mathrm{mph}$, canvas fully closed, aft panel open & 112 \\
\hline Boat 6 & D9447 & $15 \mathrm{mph}$, canvas fully closed, aft panel open & 65 \\
\hline Boat 6 & D9446 & $25 \mathrm{mph}$, canvas fully closed, center vent open & 1 \\
\hline
\end{tabular}


Table 19: Evacuated Container Concentrations, Boats 7 \& 8.

\begin{tabular}{|l|l|l|c|}
\hline Boat & $\begin{array}{c}\text { Container } \\
\text { ID \# }\end{array}$ & Condition & $\begin{array}{c}\text { Concentration } \\
\text { (ppm) }\end{array}$ \\
\hline Boat 7 & D9449 & $10 \mathrm{mph}$, all canvas installed, aft panel open, with the wind & 142 \\
\hline Boat 7 & D9450 & $\begin{array}{l}5 \mathrm{mph} \text {, all canvas installed, fully removed rear panels, with } \\
\text { the wind }\end{array}$ & 12 \\
\hline Boat 7 & D9452 & $10 \mathrm{mph}$, all canvas removed, bimini top only, into the wind & 7 \\
\hline Boat 7 & D9451 & $25 \mathrm{mph}$, all canvas removed, bimini top only, into the wind & 10 \\
\hline Boat 8 & D9416 & $5 \mathrm{mph}$, all canvas installed, aft panel open, into the wind & 217 \\
\hline Boat 8 & D9414 & $\begin{array}{l}5 \mathrm{mph}, \text { partial canvas, rear and side panels removed, into } \\
\text { wind }\end{array}$ & 89 \\
\hline Boat 8 & D9415 & $\begin{array}{l}25 \mathrm{mph}, \text { partial canvas, rear and side panels removed, with } \\
\text { wind }\end{array}$ & 2 \\
\hline Boat 8 & D9417 & $5 \mathrm{mph}$, all canvas removed, bimini top only, with the wind & 2 \\
\hline
\end{tabular}


Table 20: Evacuated Container Concentrations, Boats 9 \& 10 .

\begin{tabular}{|l|l|l|c|}
\hline Boat & $\begin{array}{c}\text { Container } \\
\text { ID \# }\end{array}$ & Condition & $\begin{array}{c}\text { Concentration } \\
\text { (ppm) }\end{array}$ \\
\hline Boat 9 & D9418 & $\begin{array}{l}10 \mathrm{mph} \text {, all canvas installed, aft panel open, wind difficult to } \\
\text { describe }\end{array}$ & 346 \\
\hline Boat 9 & D9419 & $25 \mathrm{mph}$, all canvas installed, aft panel open & Non Detected \\
\hline Boat 9 & M6789 & $25 \mathrm{mph}$, partial canvas & 1 \\
\hline
\end{tabular}


Table 21: Detector Tube Readings, Boats 1 \& 2 .

\begin{tabular}{|l|l|c|}
\hline Boat & Condition & $\begin{array}{c}\text { Concentration } \\
\text { (ppm) }\end{array}$ \\
\hline Boat 1 & $5 \mathrm{mph}$, all canvas closed, aft panel open, front screen opened & 20 \\
\hline Boat 1 & $10 \mathrm{mph}$, canvas closed, aft panel open, front screen opened & 700 \\
\hline Boat 1 & $10 \mathrm{mph}$, all panel opened & 40 \\
\hline Boat 1 & $15 \mathrm{mph}$, into the wind, all canvas opened & 350 \\
\hline Boat 1 & $25 \mathrm{mph}$, with the wind, all canvas opened & 290 \\
\hline Boat 2 & $5 \mathrm{mph}$, no wind, all canvas closed, aft panel open & 500 \\
\hline Boat 2 & $10 \mathrm{mph}$, no wind, all canvas closed, aft panel open & 400 \\
\hline Boat 2 & $5 \mathrm{mph}$ all canvas removed, no wind & 700 \\
\hline Boat 2 & $15 \mathrm{mph}$, all canvas removed, no wind & 300 \\
\hline
\end{tabular}


Table 22: Detector Tube Readings, Boats $3 \& 4$.

\begin{tabular}{|l|l|c|}
\hline Boat & Condition & $\begin{array}{c}\text { Concentration } \\
\text { (ppm) }\end{array}$ \\
\hline Boat 4 & $15 \mathrm{mph}$, all canvas installed, aft panel opened & $>100$ \\
\hline Boat 4 & $10 \mathrm{mph}$, all canvas installed, aft panel opened & 160 \\
\hline Boat 4 & $5 \mathrm{mph}$, all canvas opened, center windshield opened & 100 \\
\hline Boat 3 & $15 \mathrm{mph}$, all canvas closed, aft panel open & 120 \\
\hline Boat 3 & $5 \mathrm{mph}$, all canvas closed, aft panel open & 200 \\
\hline Boat 3 & $10 \mathrm{mph}$, all canvas removed, bimini top only & 75 \\
\hline
\end{tabular}


Table 23: Detector Tube Readings, Boats 5 \& 6 .

\begin{tabular}{|l|l|c|}
\hline Boat & Condition & $\begin{array}{c}\text { Concentration } \\
\text { (ppm) }\end{array}$ \\
\hline Boat 5 & $5 \mathrm{mph}$, all canvas installed, aft panel open & 50 \\
\hline Boat 5 & $25 \mathrm{mph}$, all canvas installed, aft panel open & 0 \\
\hline Boat 5 & $5 \mathrm{mph}$, partial canvas, no apparent wind & 20 \\
\hline Boat 5 & $10 \mathrm{mph}$, all canvas removed, bimini top only & 0 \\
\hline
\end{tabular}


Table 24: Detector Tube Readings, Boats 7 \& 8.

\begin{tabular}{|l|l|c|}
\hline Boat & Condition & Concentration (ppm) \\
\hline Boat 7 & $5 \mathrm{mph}$, all canvas closed, aft panel open, with the wind & 120 \\
\hline Boat 7 & $15 \mathrm{mph}$, all canvas closed, aft panel open, with the wind & 200 \\
\hline Boat 7 & $\begin{array}{l}10 \mathrm{mph} \text {, all canvas installed, fully removed rear panels, } \\
\text { with the wind }\end{array}$ & 30 \\
\hline Boat 7 & $\begin{array}{l}25 \mathrm{mph}, \text { all canvas installed, fully removed rear panels, } \\
\text { into the wind }\end{array}$ & 10 \\
\hline Boat 7 & $\begin{array}{l}10 \mathrm{mph}, \text { all canvas removed, bimini top only, with the } \\
\text { wind }\end{array}$ & 20 \\
\hline Boat 7 & $5 \mathrm{mph}$, all canvas removed, bimini top only, into the wind & 60 \\
\hline Boat 8 & $15 \mathrm{mph}$, all canvas installed, aft panel open, into the wind & 50 \\
\hline Boat 8 & $5 \mathrm{mph}$ partial canvas, into the wind & 140 \\
\hline Boat 8 & $\begin{array}{l}10 \mathrm{mph}, \text { all canvas removed, bimini top only, with the } \\
\text { wind }\end{array}$ & 30 \\
\hline
\end{tabular}


Table 25: Detector Tube Readings, Boats 9 \& 10 .

\begin{tabular}{|l|l|c|}
\hline Boat & \multicolumn{1}{|c|}{ Condition } & $\begin{array}{c}\text { Concentration } \\
\text { (ppm) }\end{array}$ \\
\hline Boat 9 & $5 \mathrm{mph}$, all canvas installed, aft panel open & 150 \\
\hline Boat 9 & $15 \mathrm{mph}$, all canvas installed, aft panel open & 10 \\
\hline Boat 9 & $15 \mathrm{mph}$, partial canvas, no apparent wind & 60 \\
\hline Boat 9 & $10 \mathrm{mph}$, all canvas removed, bimini top only & 150 \\
\hline
\end{tabular}


Table 26: Relative Wind Velocities, Boats 1 \& 2.

\begin{tabular}{|c|c|c|}
\hline Boat & Condition & Velocity (mph) \\
\hline Boat 1 & $5 \mathrm{mph}$, all canvas closed, aft panel opened & 9.37 \\
\hline Boat 1 & $\begin{array}{l}5 \mathrm{mph} \text {, all canvas closed, aft panel opened, front screen } \\
\text { opened }\end{array}$ & 11.06 \\
\hline Boat 1 & $\begin{array}{l}10 \mathrm{mph} \text {, canvas closed, aft panel open, front screen opened, } \\
\text { into wind }\end{array}$ & 11.5 \\
\hline Boat 1 & $\begin{array}{l}10 \mathrm{mph} \text {, canvas closed, aft panel open, front screen opened, } \\
\text { with wind }\end{array}$ & 0.37 \\
\hline Boat 1 & $15 \mathrm{mph}$, canvas closed, aft panel open, into the wind & 17.5 \\
\hline Boat 1 & $15 \mathrm{mph}$, canvas closed, aft panel open, with the wind & 12.12 \\
\hline Boat 1 & $25 \mathrm{mph}$, canvas closed, aft panel open, into the wind & 27.5 \\
\hline Boat 1 & $25 \mathrm{mph}$, canvas closed, aft panel open, with the wind & 20 \\
\hline Boat 1 & $10 \mathrm{mph}$, canvas closed, aft panel open, into the wind & 12.5 \\
\hline Boat 1 & $25 \mathrm{mph}$, canvas closed, aft panel open, with the wind & 20 \\
\hline Boat 1 & $5 \mathrm{mph}$, canvas opened, into the wind & 6.56 \\
\hline Boat 1 & $5 \mathrm{mph}$, canvas opened, no wind & 0 \\
\hline Boat 1 & $10 \mathrm{mph}$, canvas opened, no wind & 9 \\
\hline Boat 1 & $15 \mathrm{mph}$, canvas opened, with the wind & 16.87 \\
\hline Boat 1 & $15 \mathrm{mph}$, canvas opened, into the wind & 11.87 \\
\hline Boat 1 & $25 \mathrm{mph}$, all canvas opened, into the wind & 15.62 \\
\hline Boat 1 & $25 \mathrm{mph}$, all canvas opened, with the wind & 22.5 \\
\hline Boat 1 & $15 \mathrm{mph}$, all canvas opened, side windows opened & 18.75 \\
\hline Boat 2 & $5 \mathrm{mph}$, all canvas closed, aft panel opened, no wind & 1.62 \\
\hline Boat 2 & $10 \mathrm{mph}$, all canvas closed, aft panel opened, no wind & 3.68 \\
\hline Boat 2 & $15 \mathrm{mph}$, all canvas closed, aft panel opened, no wind & 15 \\
\hline Boat 2 & $25 \mathrm{mph}$, all canvas closed, aft panel opened, no wind & 26.25 \\
\hline Boat 2 & $5 \mathrm{mph}$, all canvas removed, bimini top only, no wind & 4.5 \\
\hline Boat 2 & $10 \mathrm{mph}$, all canvas removed, bimini top only, no wind & 2 \\
\hline Boat 2 & $15 \mathrm{mph}$, all canvas removed, bimini top only, no wind & 11.5 \\
\hline Boat 2 & $25 \mathrm{mph}$, all canvas removed, bimini top only, no wind & 22.5 \\
\hline Boat 2 & $\begin{array}{l}15 \mathrm{mph} \text {, all canvas removed, bimini top only, no wind, side } \\
\text { windows }\end{array}$ & 12.31 \\
\hline
\end{tabular}


Table 27: Relative Wind Velocities, Boats 3 \& 4.

\begin{tabular}{|c|c|c|}
\hline Boat & Condition & Velocity (mph) \\
\hline Boat 4 & $5 \mathrm{mph}$, all canvas installed, aft panel opened & 2.73 \\
\hline Boat 4 & $15 \mathrm{mph}$, all canvas installed, aft panel opened & 11.02 \\
\hline Boat 4 & $10 \mathrm{mph}$, all canvas installed, aft panel opened & 3.12 \\
\hline Boat 4 & $25 \mathrm{mph}$, all canvas installed, aft panel opened & 39.99 \\
\hline Boat 4 & $25 \mathrm{mph}$, all canvas installed, aft panel opened & 33.97 \\
\hline Boat 4 & $15 \mathrm{mph}$, all canvas opened, bimini top only & 25.56 \\
\hline Boat 4 & $\begin{array}{l}15 \mathrm{mph} \text {, all canvas opened, bimini top only, center windshield } \\
\text { opened }\end{array}$ & 21.58 \\
\hline Boat 4 & $\begin{array}{l}10 \mathrm{mph} \text {, all canvas opened, bimini top only, center windshield } \\
\text { opened }\end{array}$ & 7.27 \\
\hline Boat 4 & $\begin{array}{l}25 \mathrm{mph} \text {, all canvas opened, bimini top only, center windshield } \\
\text { opened }\end{array}$ & 35.61 \\
\hline Boat 4 & $\begin{array}{l}15 \mathrm{mph} \text {, all canvas opened, bimini top only, center windshield } \\
\text { opened }\end{array}$ & 14.77 \\
\hline Boat 4 & $\begin{array}{l}5 \mathrm{mph} \text {, all canvas opened, bimini top only, center windshield } \\
\text { opened }\end{array}$ & 2.50 \\
\hline Boat 3 & $25 \mathrm{mph}$, all canvas installed, aft panel opened & 34.42 \\
\hline Boat 3 & $15 \mathrm{mph}$, all canvas installed, aft panel opened & 28.97 \\
\hline Boat 3 & $10 \mathrm{mph}$, all canvas installed, aft panel opened & 14.88 \\
\hline Boat 3 & $5 \mathrm{mph}$, all canvas installed, aft panel opened & 10.68 \\
\hline Boat 3 & $5 \mathrm{mph}$, back fully open, center of windshield opened & 10.45 \\
\hline Boat 3 & $10 \mathrm{mph}$, back fully open, center of windshield opened & 14.20 \\
\hline Boat 3 & $15 \mathrm{mph}$, back fully open, center of windshield opened & 20.33 \\
\hline Boat 3 & $15 \mathrm{mph}$, back fully open, center of windshield opened & 18.18 \\
\hline Boat 3 & $5 \mathrm{mph}$, all canvas removed, bimini top only & 6.82 \\
\hline Boat 3 & $10 \mathrm{mph}$, all canvas removed, bimini top only & 16.98 \\
\hline Boat 3 & $15 \mathrm{mph}$, all canvas removed, bimini top only & 20.16 \\
\hline Boat 3 & $\begin{array}{l}15 \mathrm{mph} \text {, all canvas removed, bimini top only, center } \\
\text { windshield opened }\end{array}$ & 21.75 \\
\hline Boat 3 & $\begin{array}{l}25 \mathrm{mph} \text {, all canvas removed, bimini top only, center } \\
\text { windshield opened }\end{array}$ & 25.16 \\
\hline Boat 3 & $\begin{array}{l}15 \mathrm{mph} \text {, all canvas removed, bimini top only, } 2 \text { side windows } \\
\text { open }\end{array}$ & 27.26 \\
\hline
\end{tabular}


Table 28: Relative Wind Velocities, Boats 5 \& 6.

\begin{tabular}{|c|c|c|}
\hline Boat & Condition & Velocity (mph) \\
\hline Boat 5 & $5 \mathrm{mph}$, all canvas installed, aft panel open, with the wind & 7.90 \\
\hline Boat 5 & $10 \mathrm{mph}$, all canvas installed, aft panel open, with the wind & 9.66 \\
\hline Boat 5 & $15 \mathrm{mph}$, all canvas installed, aft panel open, with the wind & 16.47 \\
\hline Boat 5 & $25 \mathrm{mph}$, all canvas installed, aft panel open, into the wind & 26.13 \\
\hline Boat 5 & $5 \mathrm{mph}$, partial canvas, rear and side panels removed, into wind & 9.37 \\
\hline Boat 5 & $10 \mathrm{mph}$, partial canvas, rear and side panels removed, into wind & 14.77 \\
\hline Boat 5 & $\begin{array}{l}25 \mathrm{mph} \text {, all canvas installed, fully removed rear panels, with the } \\
\text { wind }\end{array}$ & 29.54 \\
\hline Boat 5 & $5 \mathrm{mph}$, all canvas removed, bimini top only, with the wind & 7.60 \\
\hline Boat 5 & $10 \mathrm{mph}$, all canvas removed, bimini top only, with the wind & 10.52 \\
\hline Boat 5 & $15 \mathrm{mph}$, all canvas removed, bimini top only, with the wind & 16.20 \\
\hline Boat 5 & $5 \mathrm{mph}$, all canvas removed, bimini top only, into the wind & 10.30 \\
\hline Boat 5 & $10 \mathrm{mph}$, all canvas removed, bimini top only, into the wind & 17.00 \\
\hline Boat 5 & $15 \mathrm{mph}$, all canvas removed, bimini top only, into the wind & 22.30 \\
\hline Boat 6 & $5 \mathrm{mph}$, all canvas installed, aft panel open, into the wind & 5.68 \\
\hline Boat 6 & $10 \mathrm{mph}$, all canvas installed, aft panel open, into the wind & 10.22 \\
\hline Boat 6 & $15 \mathrm{mph}$, all canvas installed, aft panel open, into the wind & 18.18 \\
\hline Boat 6 & $25 \mathrm{mph}$, all canvas installed, aft panel open, into the wind & 27.26 \\
\hline Boat 6 & $5 \mathrm{mph}$, partial canvas, into the wind & 10.22 \\
\hline Boat 6 & $10 \mathrm{mph}$, partial canvas, into the wind & 10.79 \\
\hline Boat 6 & $15 \mathrm{mph}$, partial canvas, with the wind & 16.76 \\
\hline Boat 6 & $25 \mathrm{mph}$, partial canvas, with the wind & 17.61 \\
\hline Boat 6 & $5 \mathrm{mph}$, all canvas removed, bimini top only, with the wind & 4.54 \\
\hline Boat 6 & $10 \mathrm{mph}$, all canvas removed, bimini top only, with the wind & 10.25 \\
\hline Boat 6 & $15 \mathrm{mph}$, all canvas removed, bimini top only, with the wind & 14.13 \\
\hline Boat 6 & $25 \mathrm{mph}$, all canvas removed, bimini top only, into the wind & 25.30 \\
\hline Boat 6 & $\begin{array}{l}5 \mathrm{mph} \text {, all canvas removed, bimini top only, into the wind, side } \\
\text { vents open }\end{array}$ & 6.52 \\
\hline Boat 6 & $\begin{array}{l}5 \mathrm{mph} \text {, all canvas removed, bimini top only, with the wind, side } \\
\text { vents open }\end{array}$ & 7.85 \\
\hline
\end{tabular}


Table 29: Relative Wind Velocities, Boats 7 \& 8.

\begin{tabular}{|c|c|c|}
\hline Boat & Condition & Velocity (mph) \\
\hline Boat 7 & $5 \mathrm{mph}$, all canvas installed, aft panel open, with the wind & 11.90 \\
\hline Boat 7 & $10 \mathrm{mph}$, all canvas installed, aft panel open, with the wind & 13.90 \\
\hline Boat 7 & $15 \mathrm{mph}$, all canvas installed, aft panel open, with the wind & 19.20 \\
\hline Boat 7 & $25 \mathrm{mph}$, all canvas installed, aft panel open, into the wind & 45.00 \\
\hline Boat 7 & $5 \mathrm{mph}$, partial canvas, rear and side panels removed, into wind & 23.00 \\
\hline Boat 7 & $\begin{array}{l}10 \mathrm{mph} \text {, partial canvas, rear and side panels removed, into } \\
\text { wind }\end{array}$ & 24.00 \\
\hline Boat 7 & $\begin{array}{l}25 \mathrm{mph} \text {, all canvas installed, fully removed rear panels, with the } \\
\text { wind }\end{array}$ & 7.80 \\
\hline Boat 7 & $5 \mathrm{mph}$, all canvas removed, bimini top only, with the wind & 4.70 \\
\hline Boat 7 & $10 \mathrm{mph}$, all canvas removed, bimini top only, with the wind & 8.20 \\
\hline Boat 7 & $15 \mathrm{mph}$, all canvas removed, bimini top only, with the wind & 2.10 \\
\hline Boat 7 & $5 \mathrm{mph}$, all canvas removed, bimini top only, into the wind & 16.80 \\
\hline Boat 7 & $10 \mathrm{mph}$, all canvas removed, bimini top only, into the wind & 23.00 \\
\hline Boat 7 & $15 \mathrm{mph}$, all canvas removed, bimini top only, into the wind & 25.00 \\
\hline Boat 8 & $5 \mathrm{mph}$, all canvas installed, aft panel open, into the wind & 8.00 \\
\hline Boat 8 & $10 \mathrm{mph}$, all canvas installed, aft panel open, into the wind & 14.70 \\
\hline Boat 8 & $15 \mathrm{mph}$, all canvas installed, aft panel open, into the wind & 23.00 \\
\hline Boat 8 & $25 \mathrm{mph}$, all canvas installed, aft panel open, into the wind & 36.00 \\
\hline Boat 8 & $5 \mathrm{mph}$, partial canvas, into the wind & 16.40 \\
\hline Boat 8 & $10 \mathrm{mph}$, partial canvas, into the wind & 21.00 \\
\hline Boat 8 & $15 \mathrm{mph}$, partial canvas, with the wind & 6.50 \\
\hline Boat 8 & $25 \mathrm{mph}$, partial canvas, with the wind & 8.00 \\
\hline Boat 8 & $5 \mathrm{mph}$, all canvas removed, bimini top only, with the wind & 10.60 \\
\hline Boat 8 & $10 \mathrm{mph}$, all canvas removed, bimini top only, with the wind & 4.00 \\
\hline Boat 8 & $15 \mathrm{mph}$, all canvas removed, bimini top only, with the wind & 4.10 \\
\hline Boat 8 & $25 \mathrm{mph}$, all canvas removed, bimini top only, into the wind & 27.00 \\
\hline Boat 8 & $\begin{array}{l}5 \mathrm{mph} \text {, all canvas removed, bimini top only, into the wind, side } \\
\text { vents open }\end{array}$ & 16.00 \\
\hline Boat 8 & $\begin{array}{l}5 \mathrm{mph} \text {, all canvas removed, bimini top only, with the wind, side } \\
\text { vents open }\end{array}$ & 5.70 \\
\hline
\end{tabular}


Figure 1: Typical Sample Locations

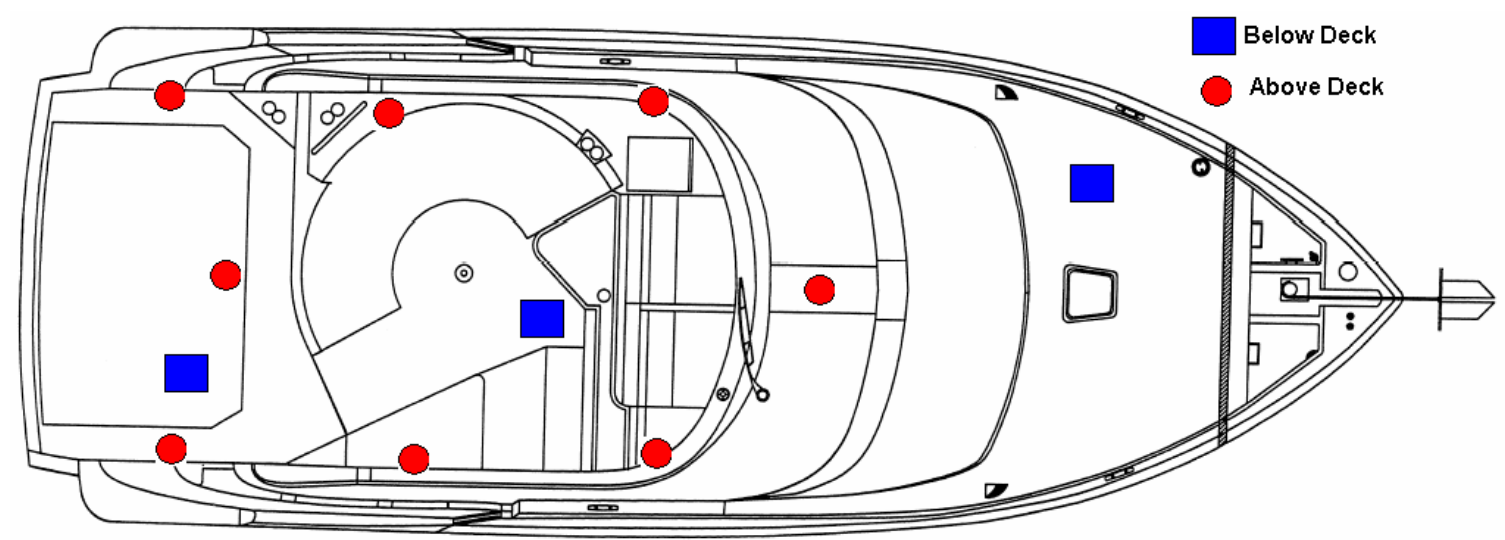

Not to Scale 
Figure 2: Typical Recirculation Patterns / 5 and $10 \mathrm{mph}$

\section{Canvas fully installed, AFT panel fully opened}

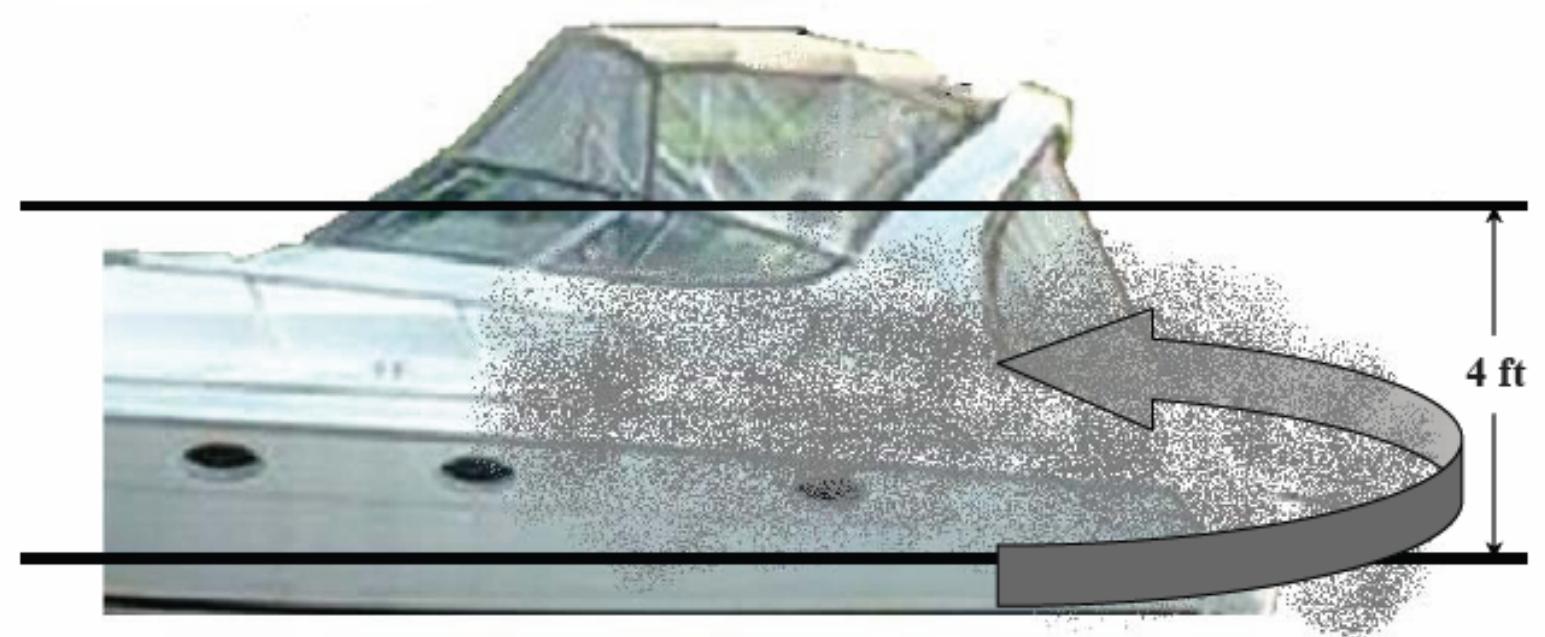

Contaminated Air

Figure 3: Typical Recirculation Patterns / 15 mph

Canvas fully installed, AFT panel fully opened

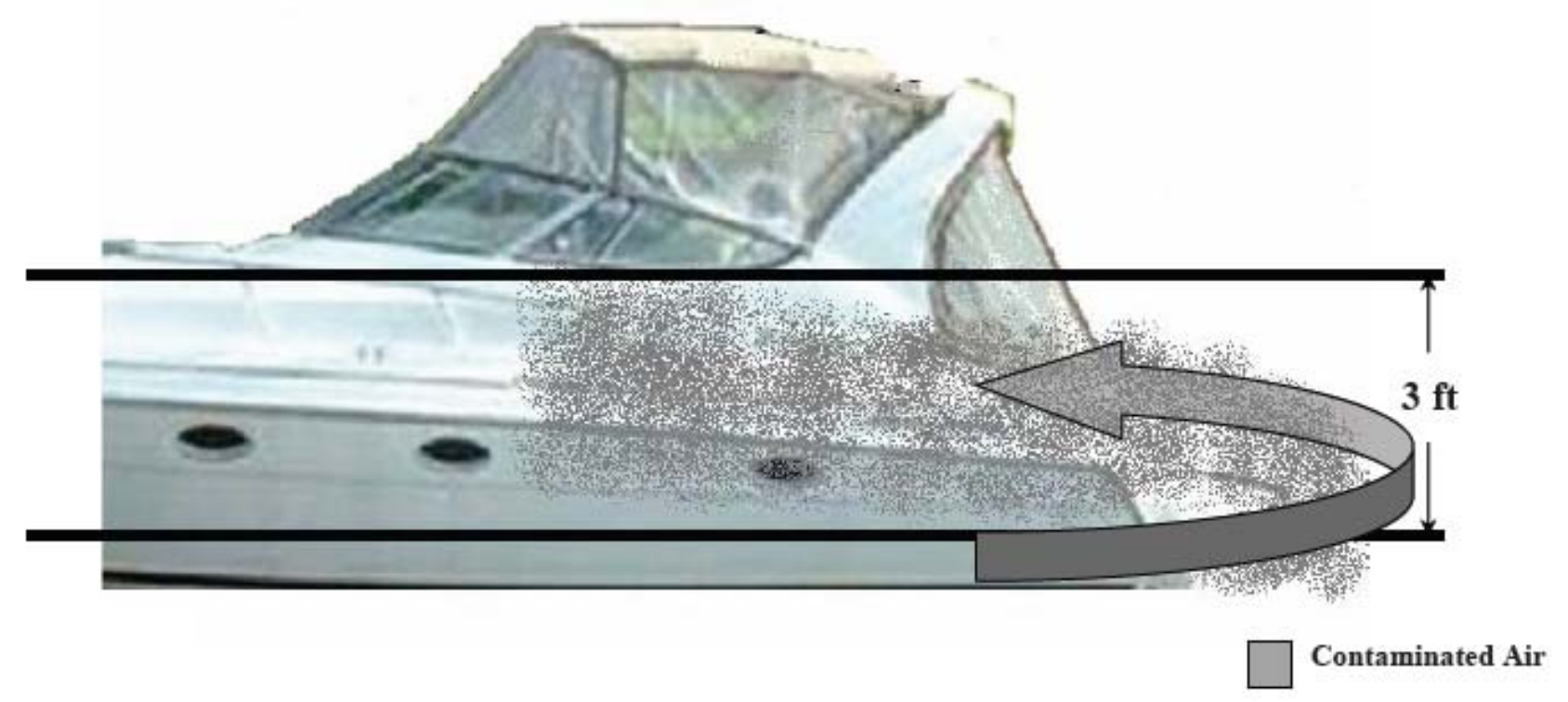


Figure 4: Typical Recirculation Patterns / 25 mph

Canvas fully installed, AFT panel fully opened

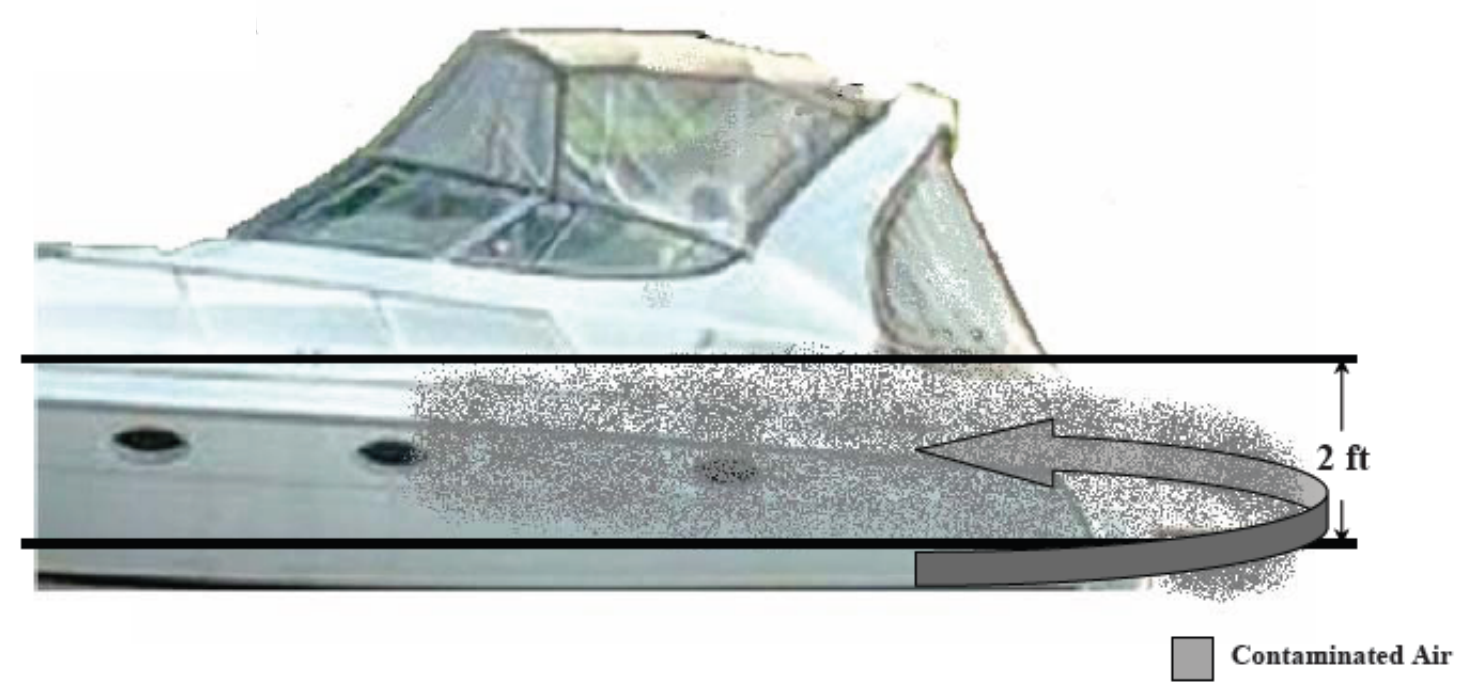


Figure 5: Boat 1 (33') Twin Volvo Penta 5.7L Exhausting Through the Hub.
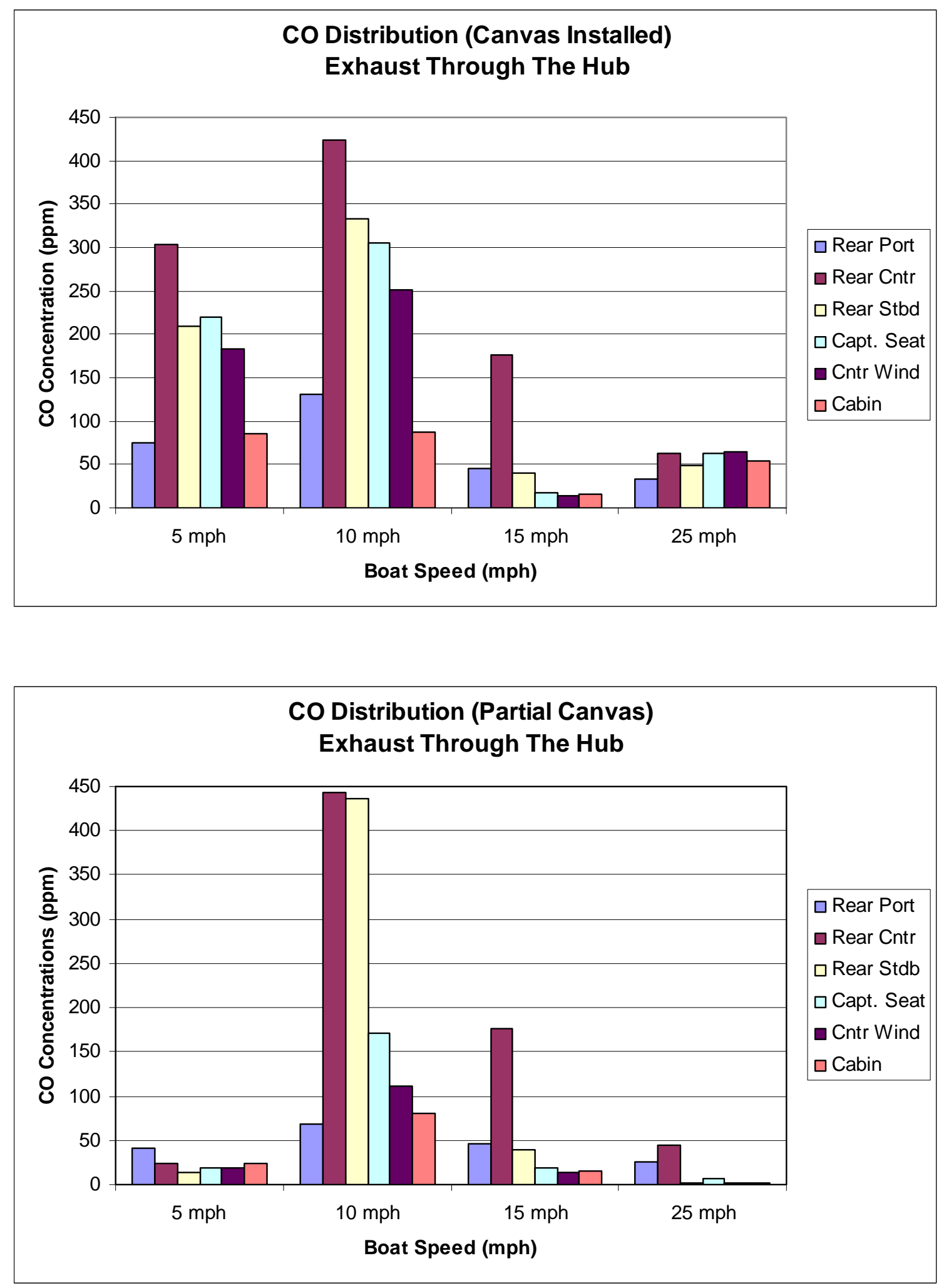


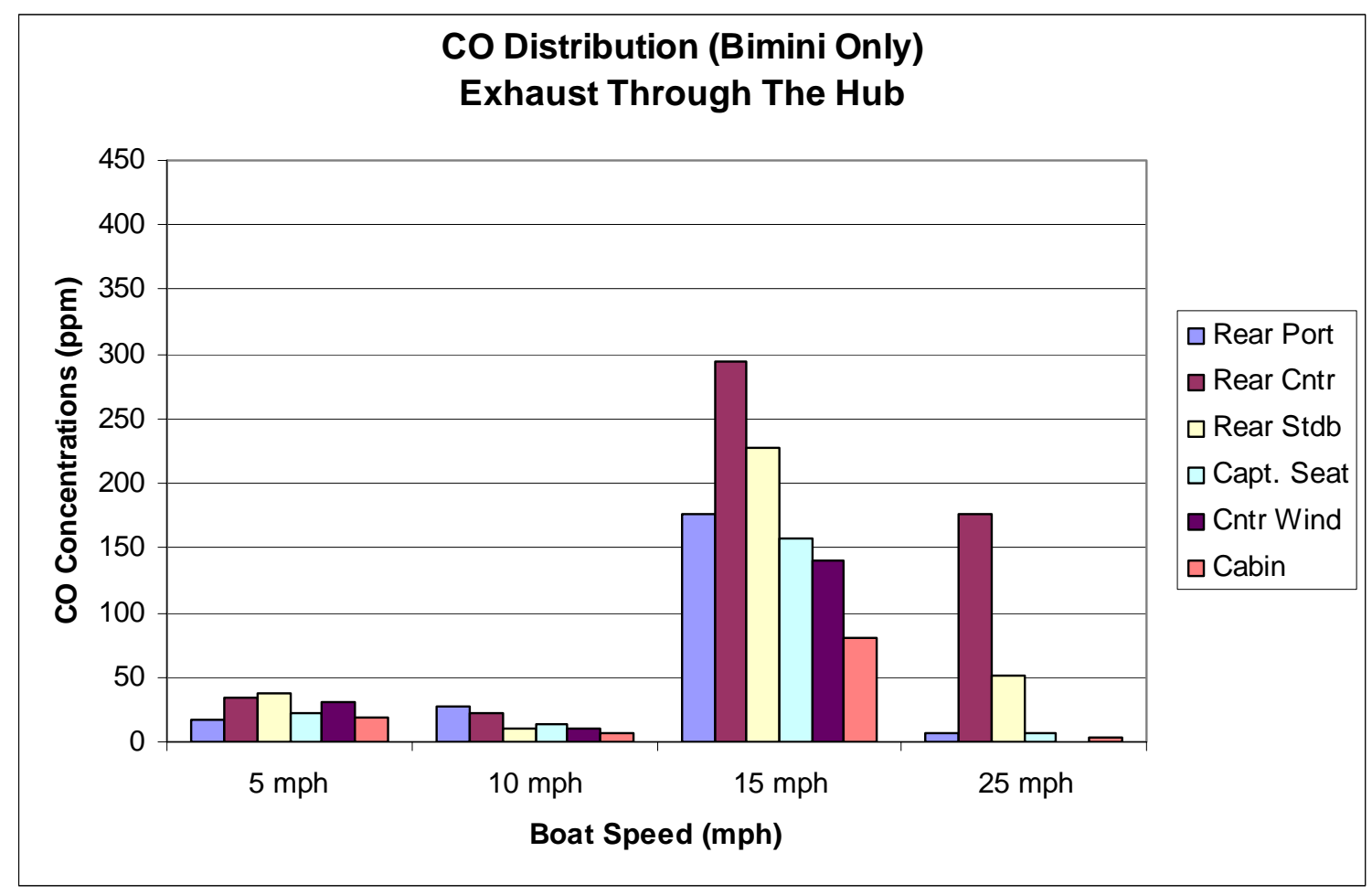


Figure 6: Boat 2 (30') Twin Mercruiser 5.0L Exhausting Through the Hub.
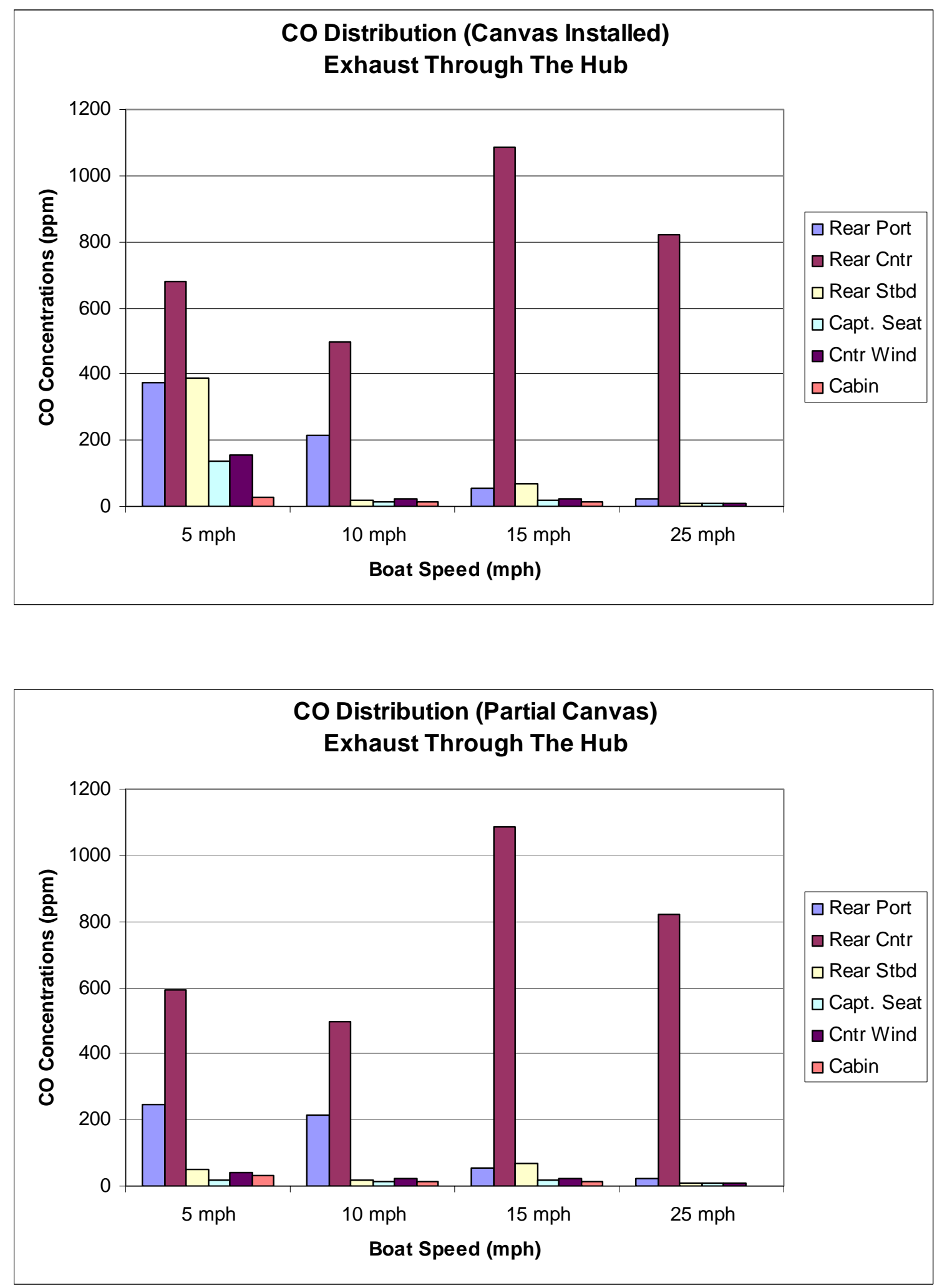


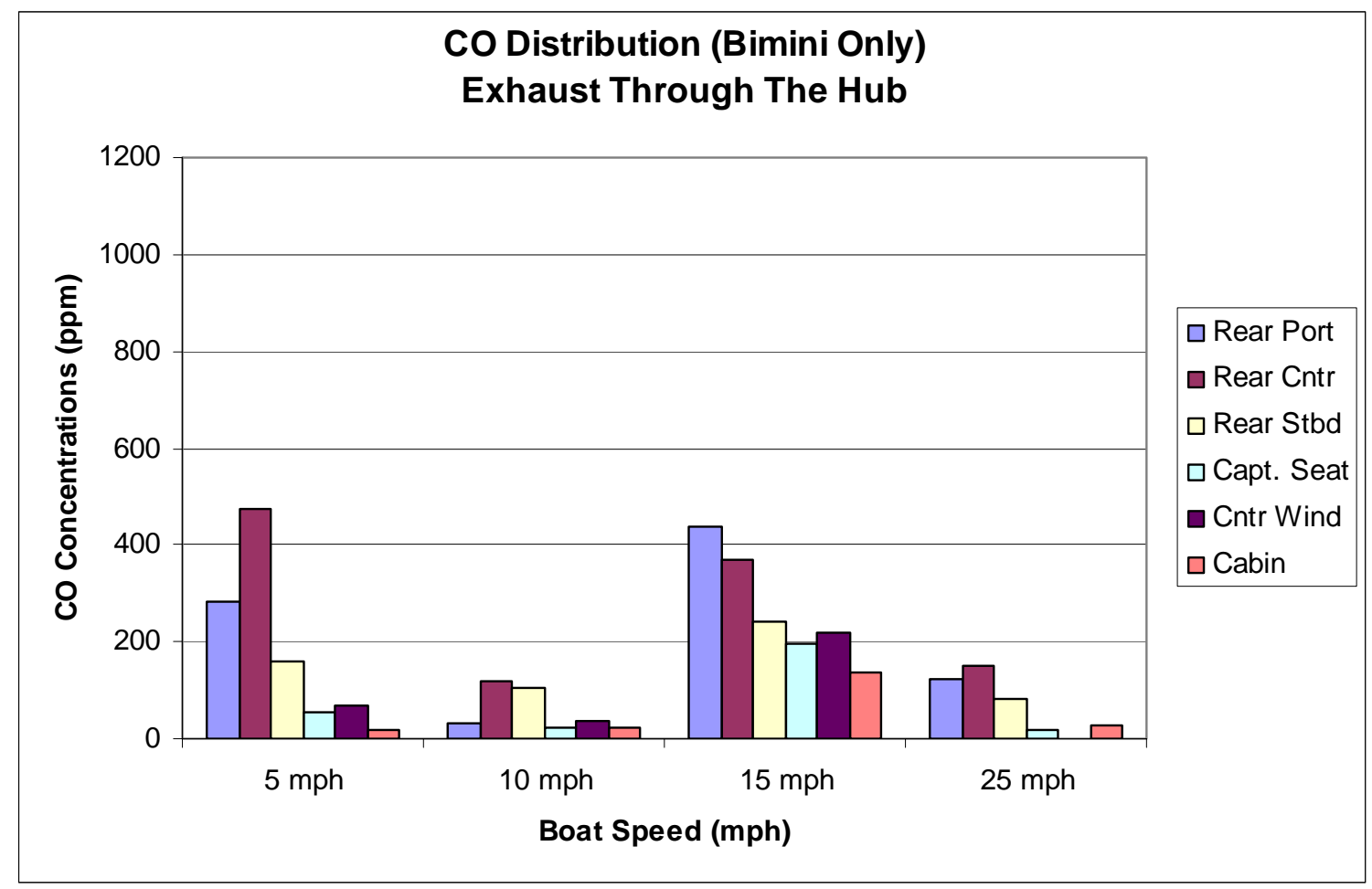


Figure 7: Boat 3 (31') Twin Volvo Penta 8.1L Exhausting Through the Hub.
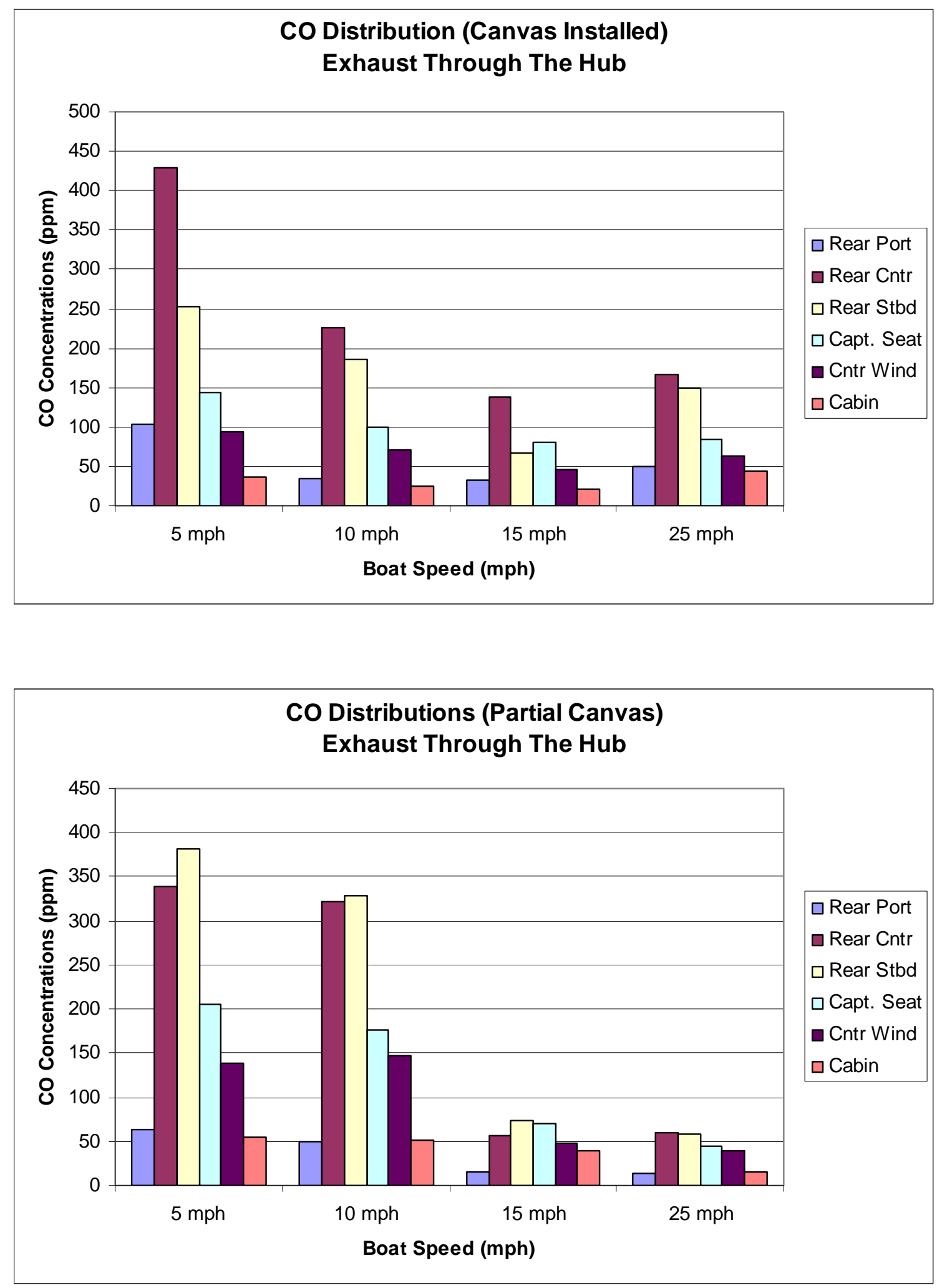


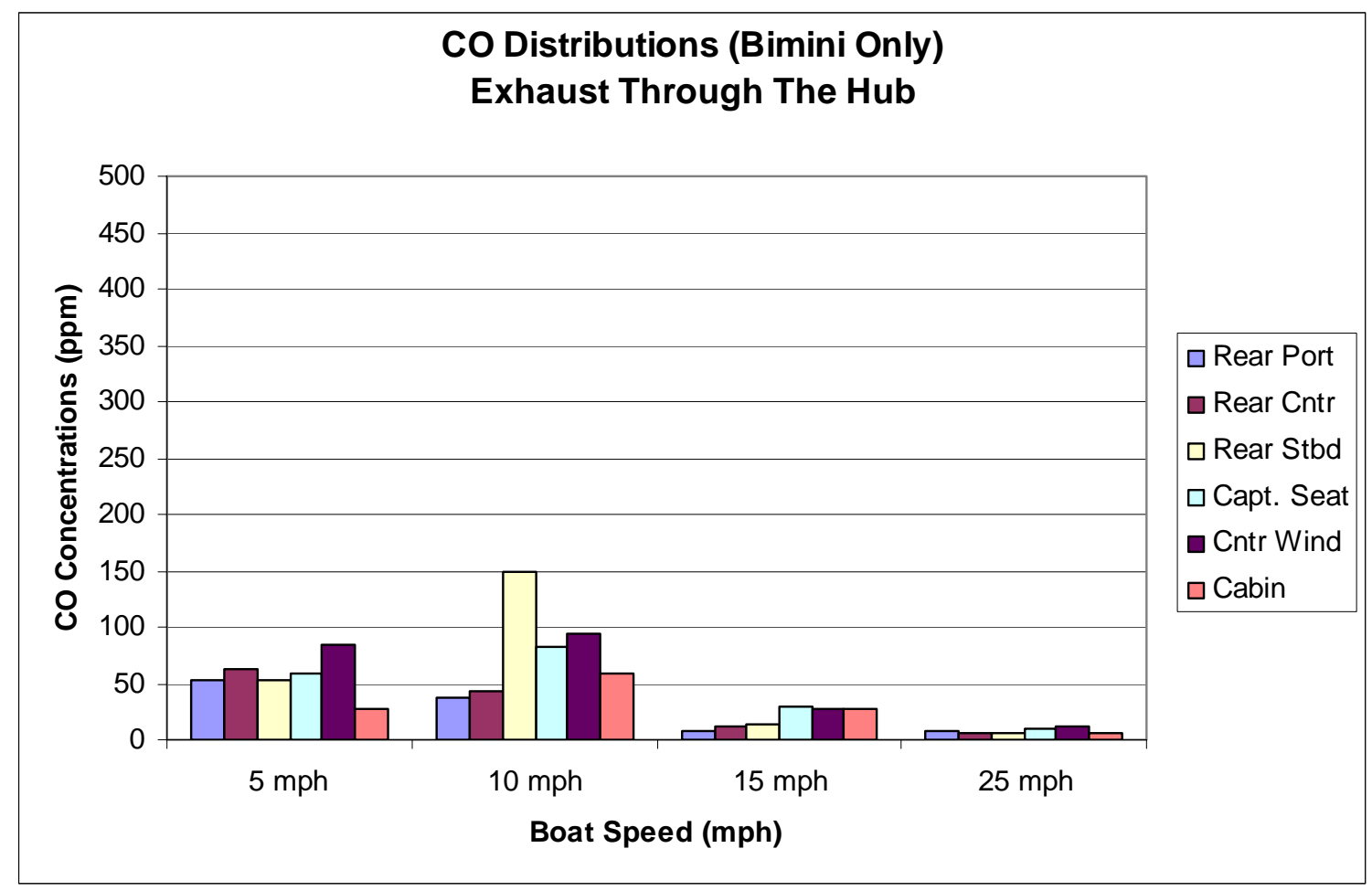


Figure 8: Boat 4 (37') Twin Mercruiser 8.1L Exhausting Through the Transom.
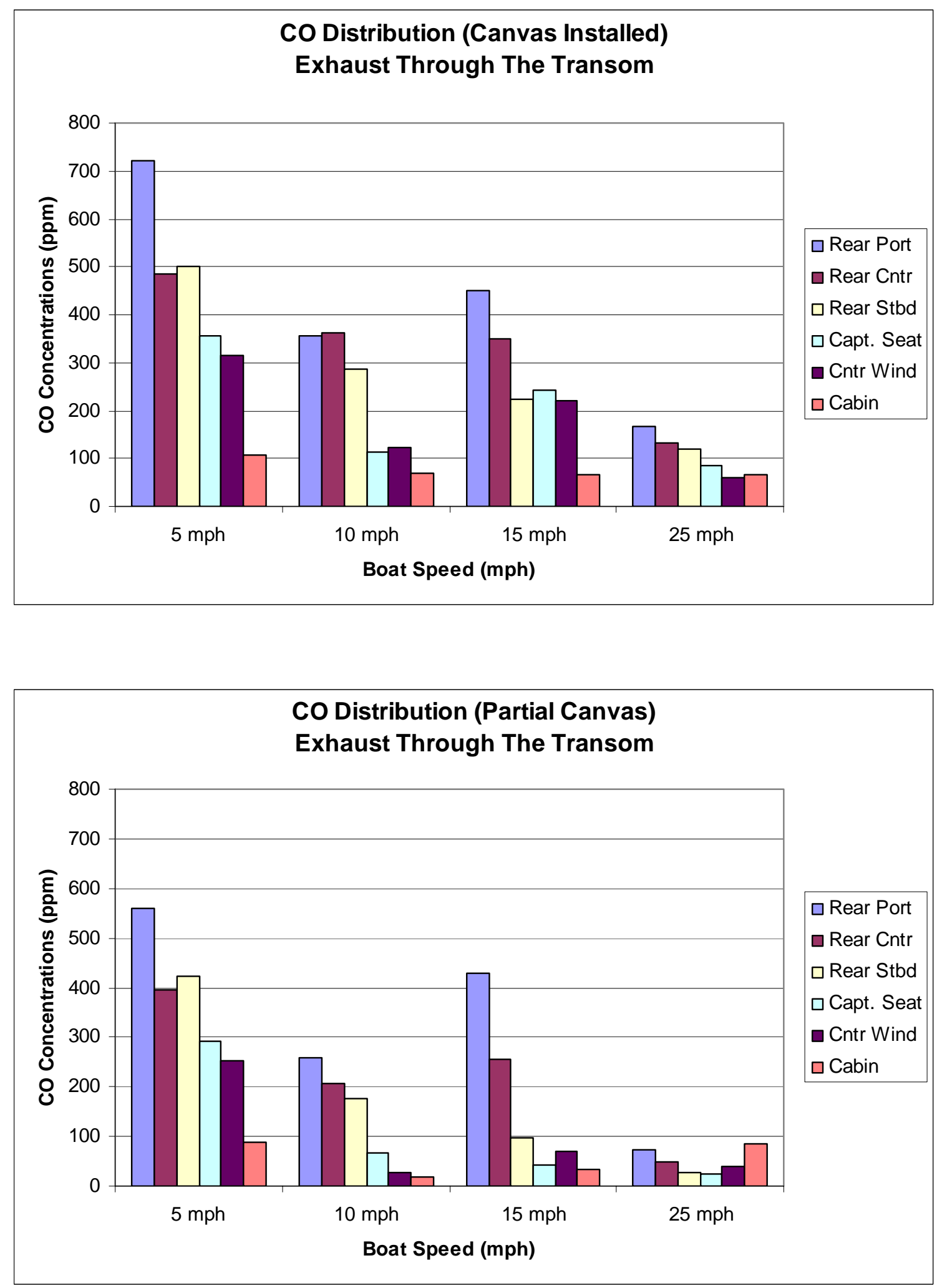


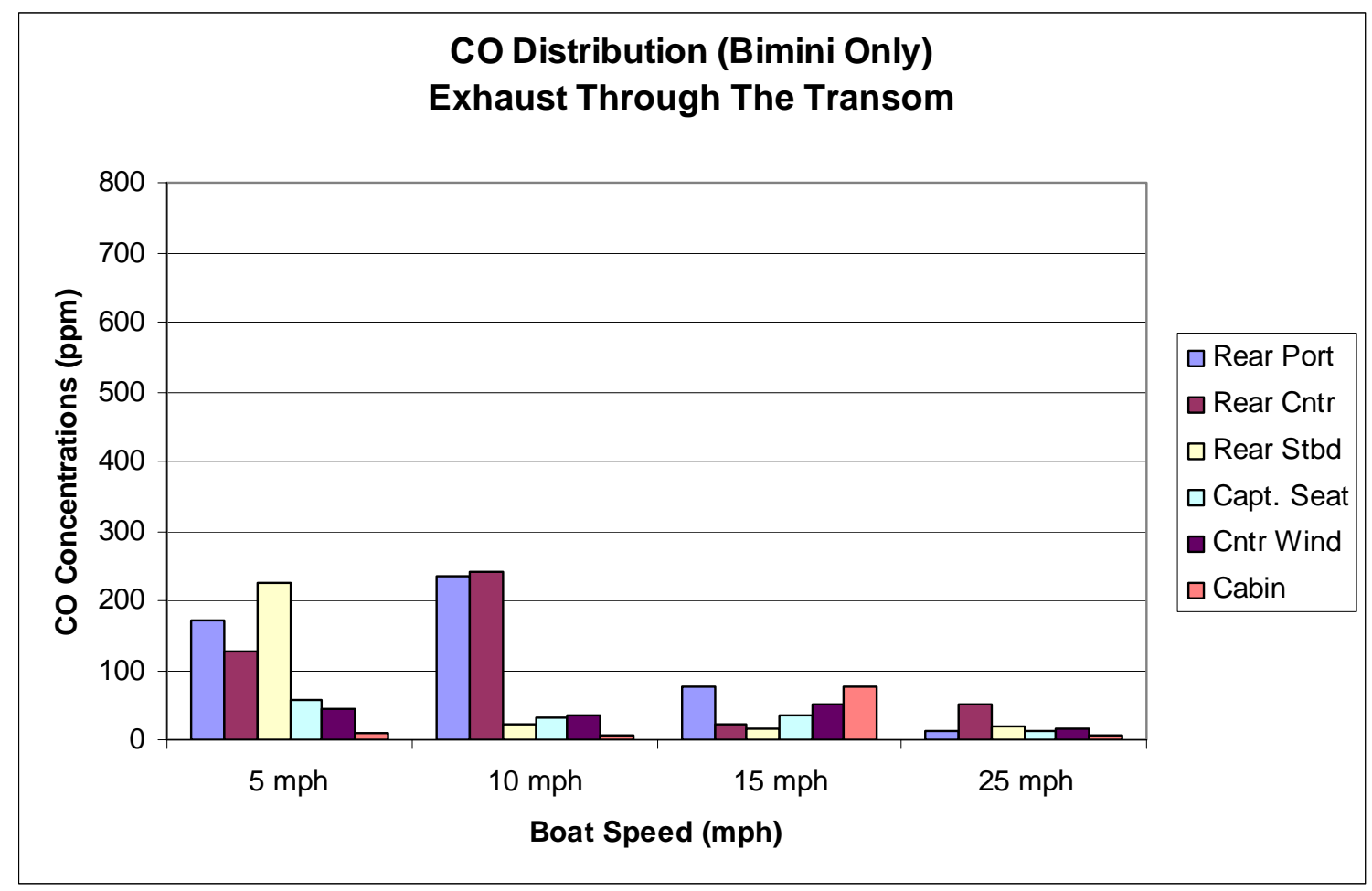


Figure 9: Boat 5 (36') Twin Mercruiser 8.1L Combined Exhaust Through the Sides and Underwater.
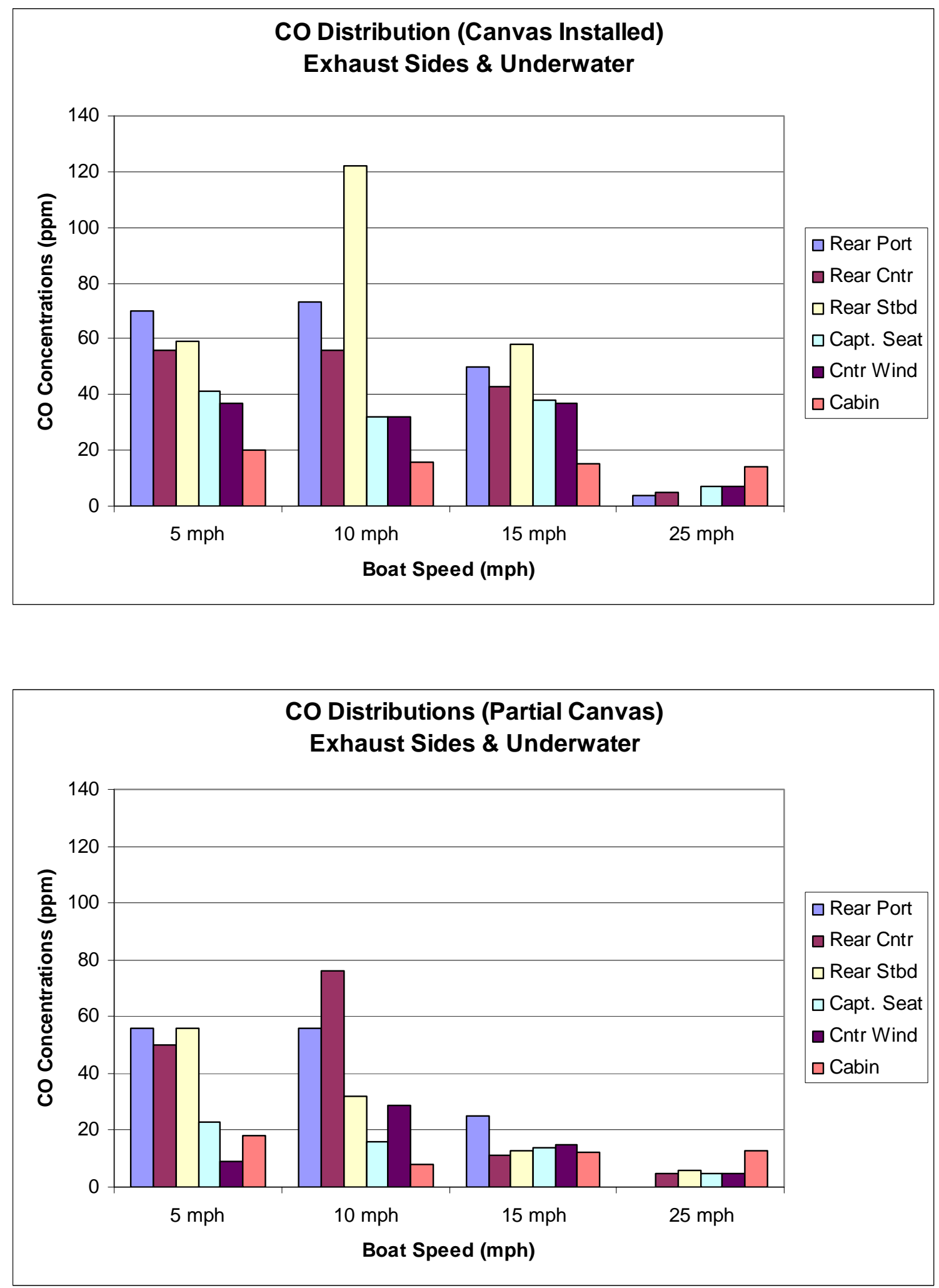


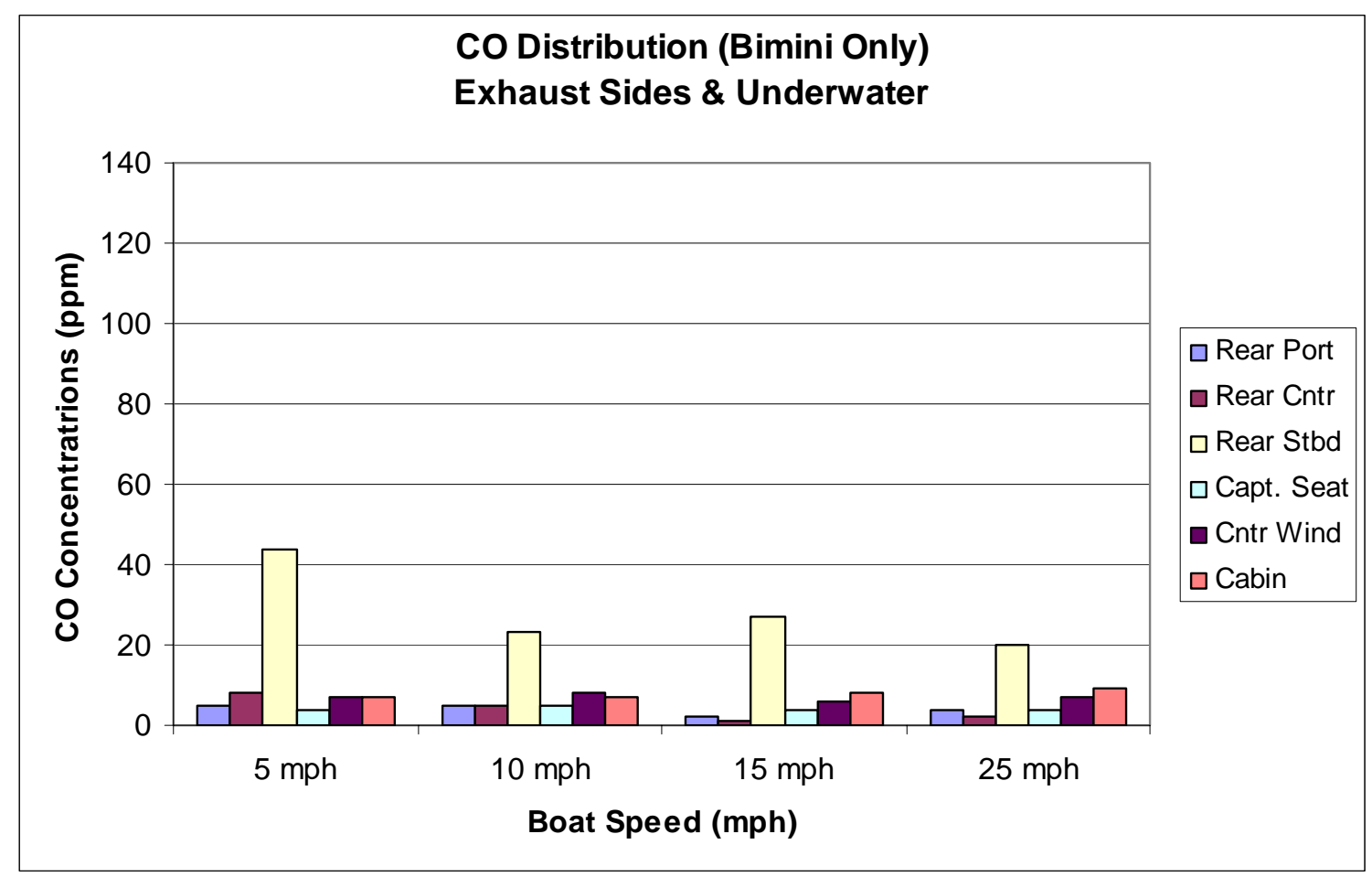


Figure 10: Boat 6 (40') Twin Mercruiser 8.1L Combined Exhaust Through the Sides and Underwater.
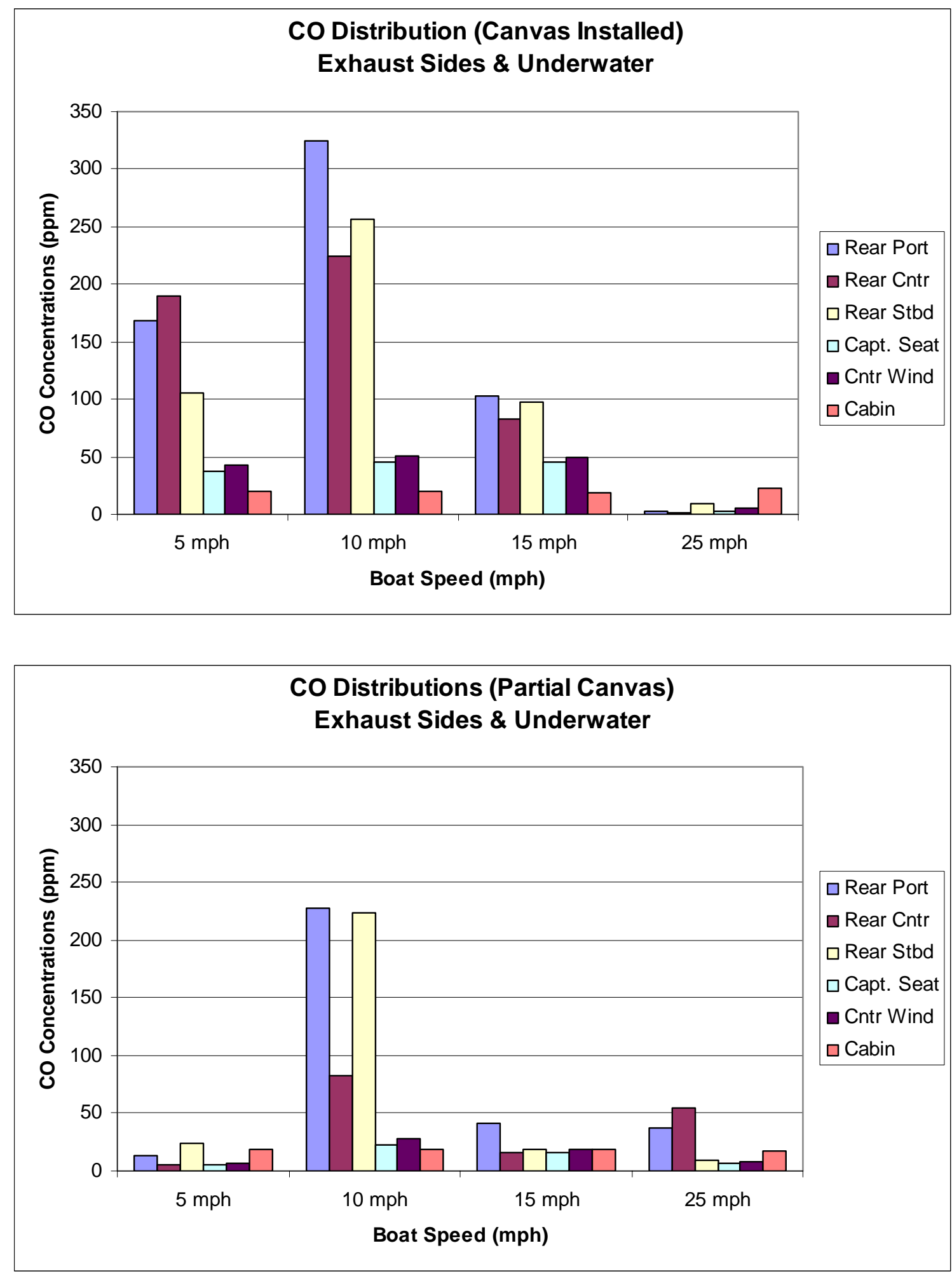


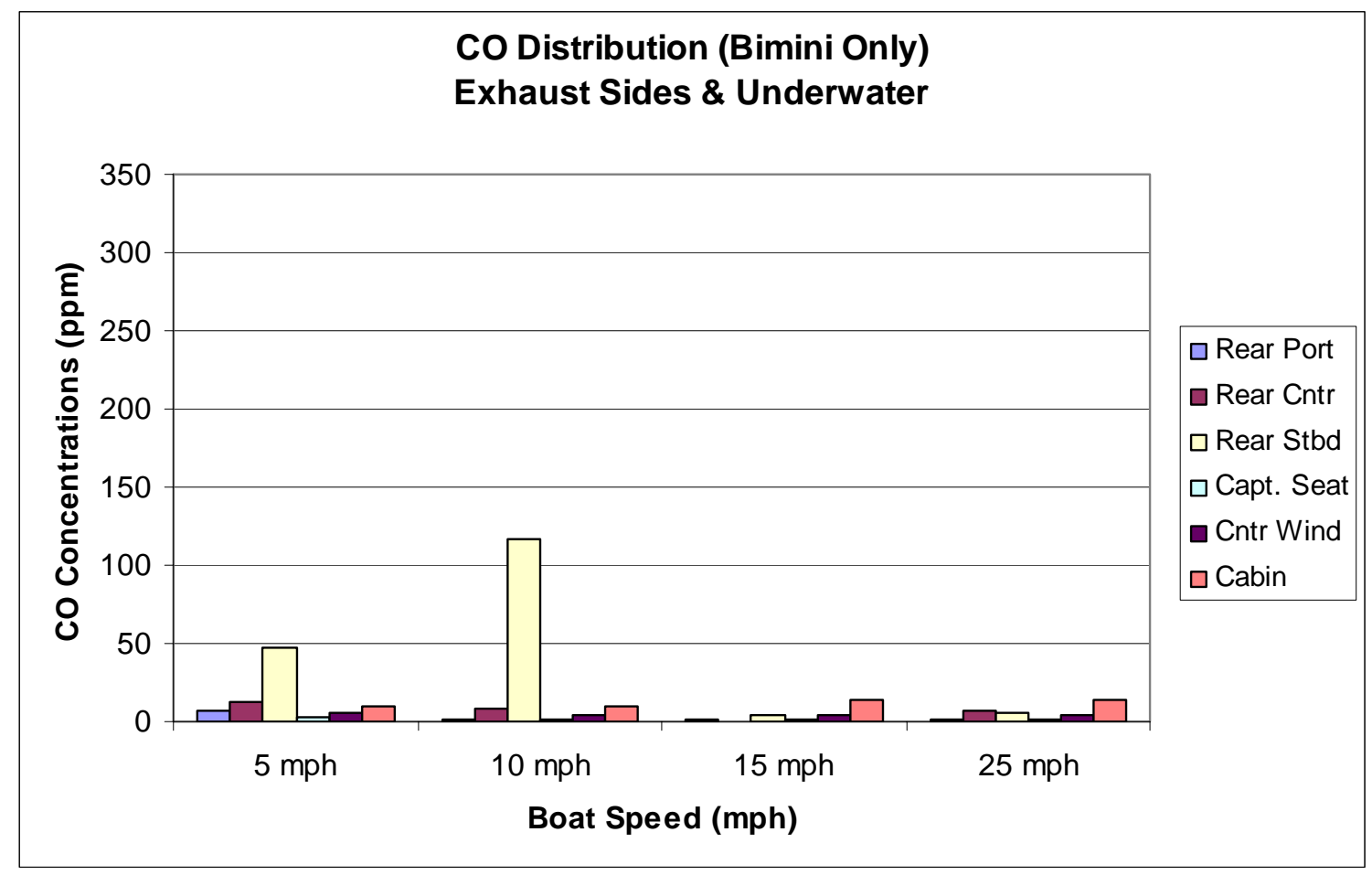


Figure 11: Boat 7 (41') Motor Yatch Twin Mercruiser 8.1L Combined Exhaust Through the Sides and Underwater.
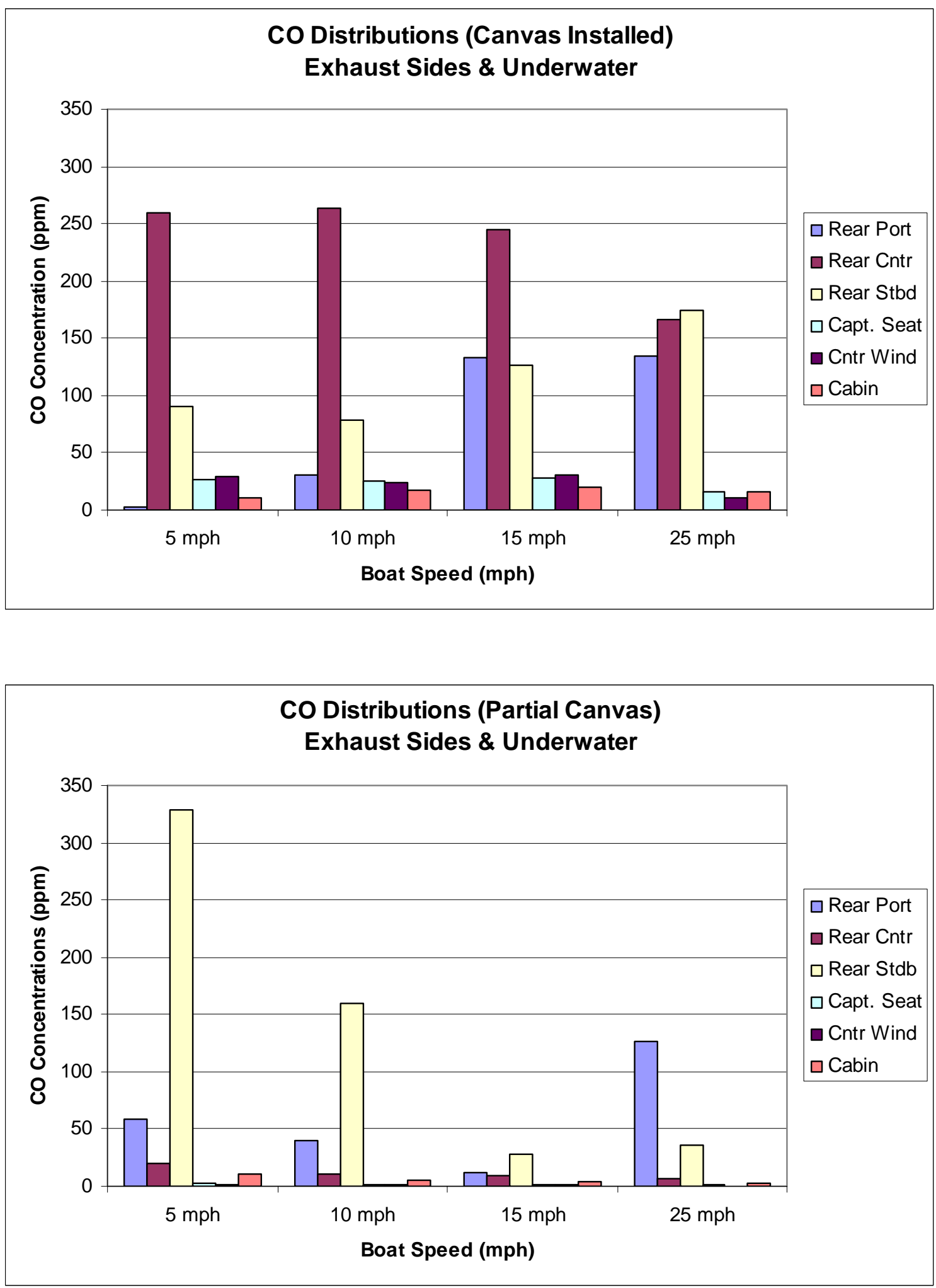


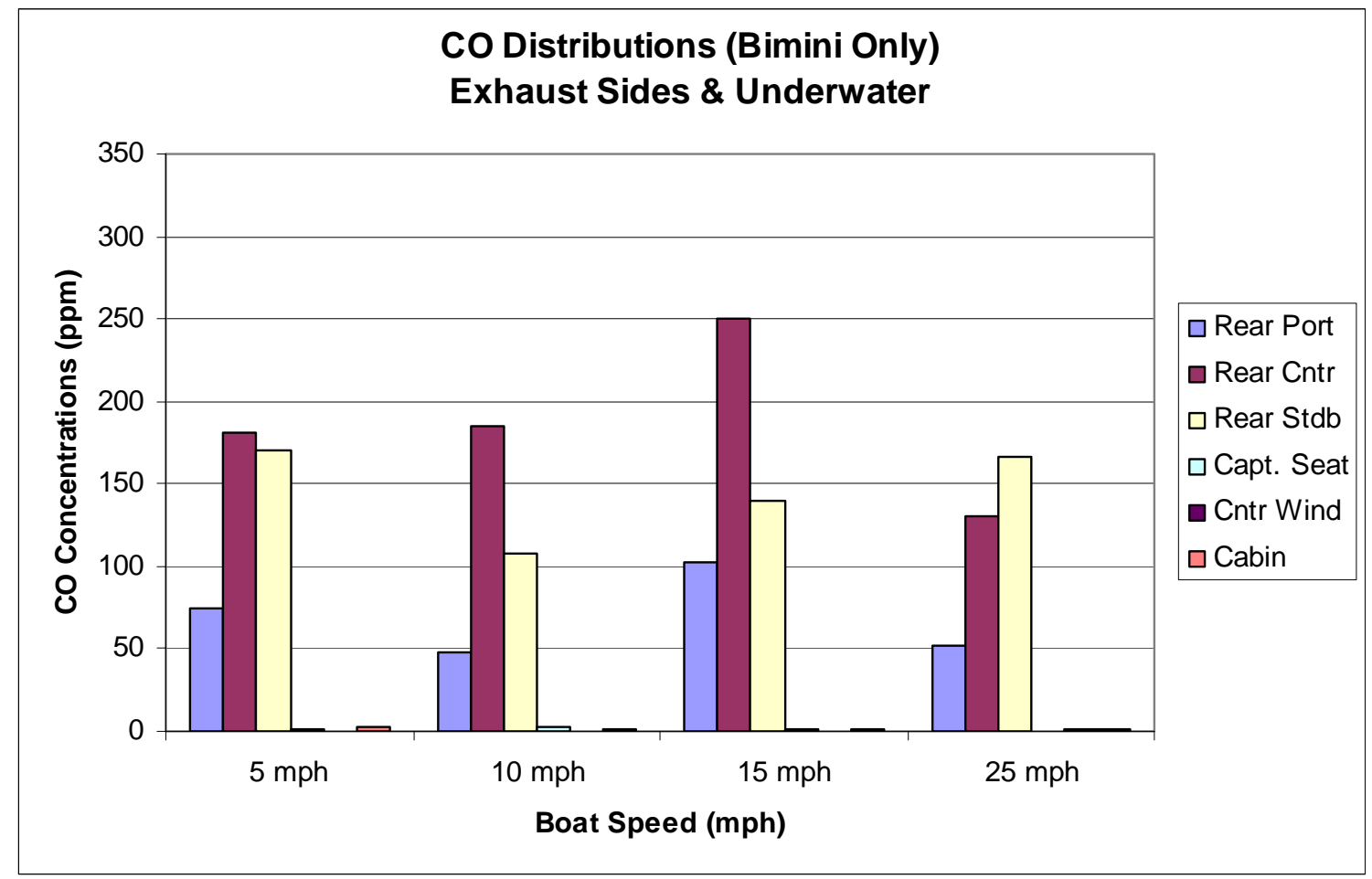


Figure 12: Boat 8 (34') Twin Mercruiser 8.1L Exhaust Through the Sides.
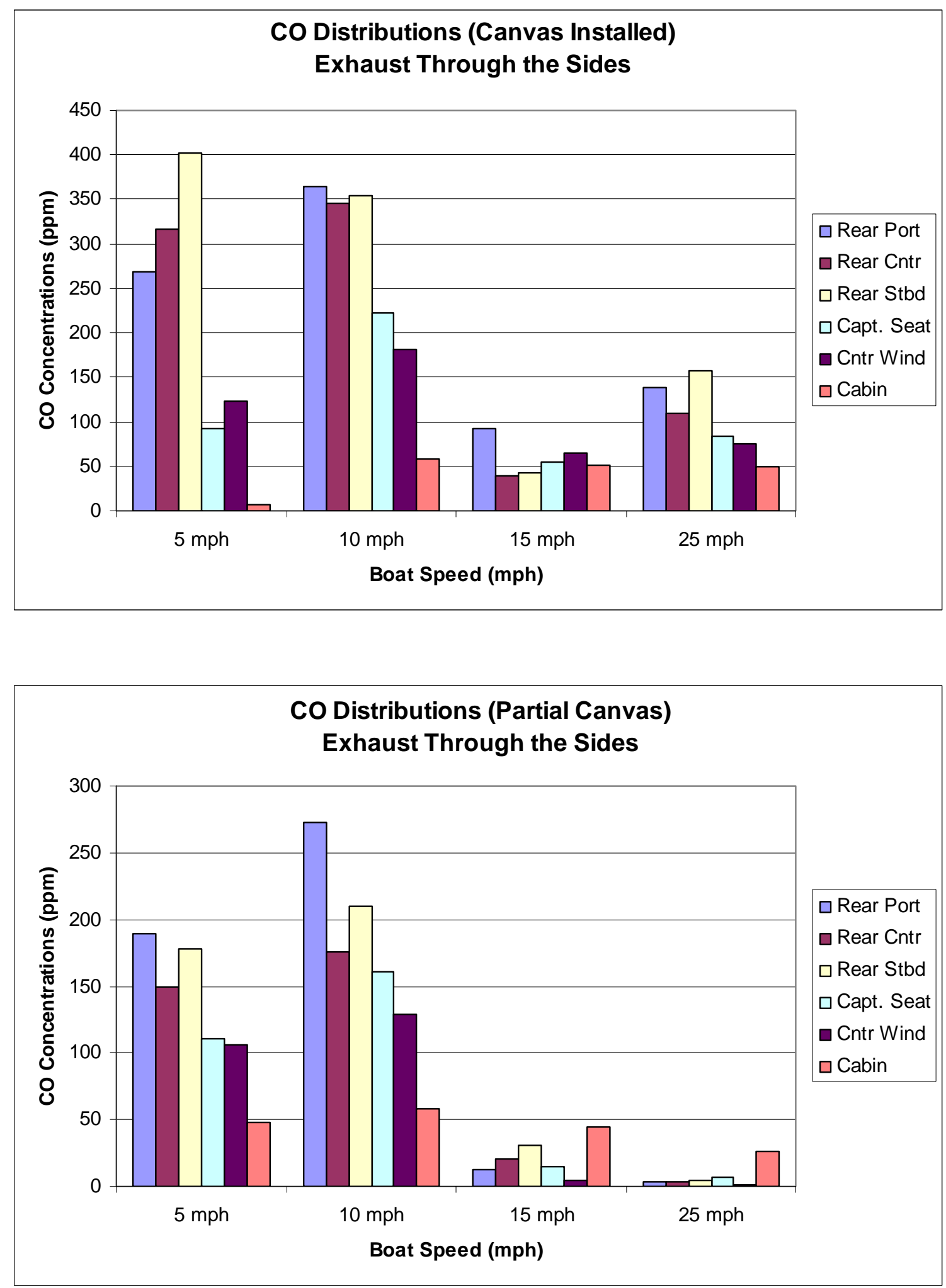


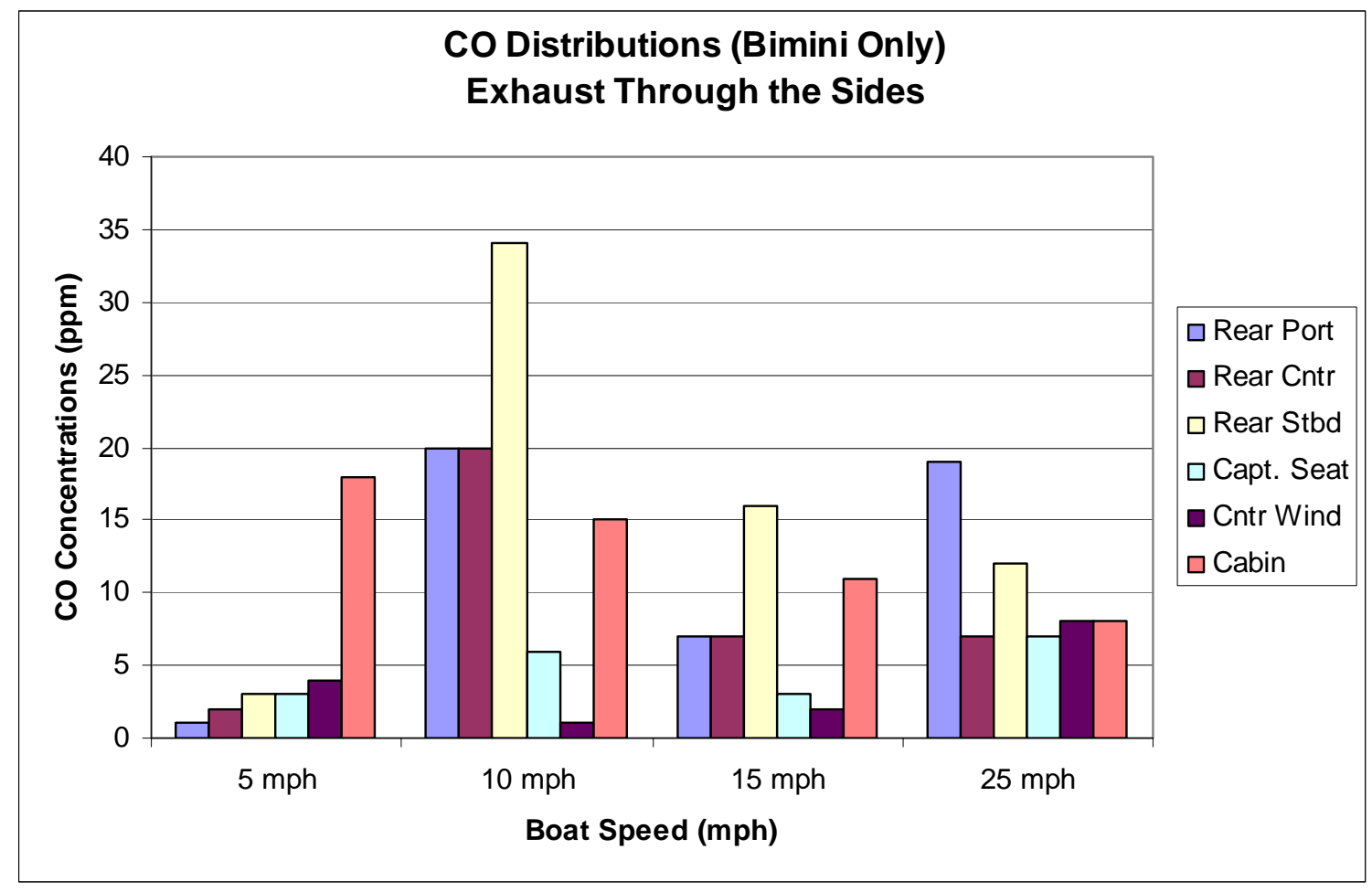


Figure 13: Boat 9 (38') Twin Crusaders 8.1L Exhaust Underwater.
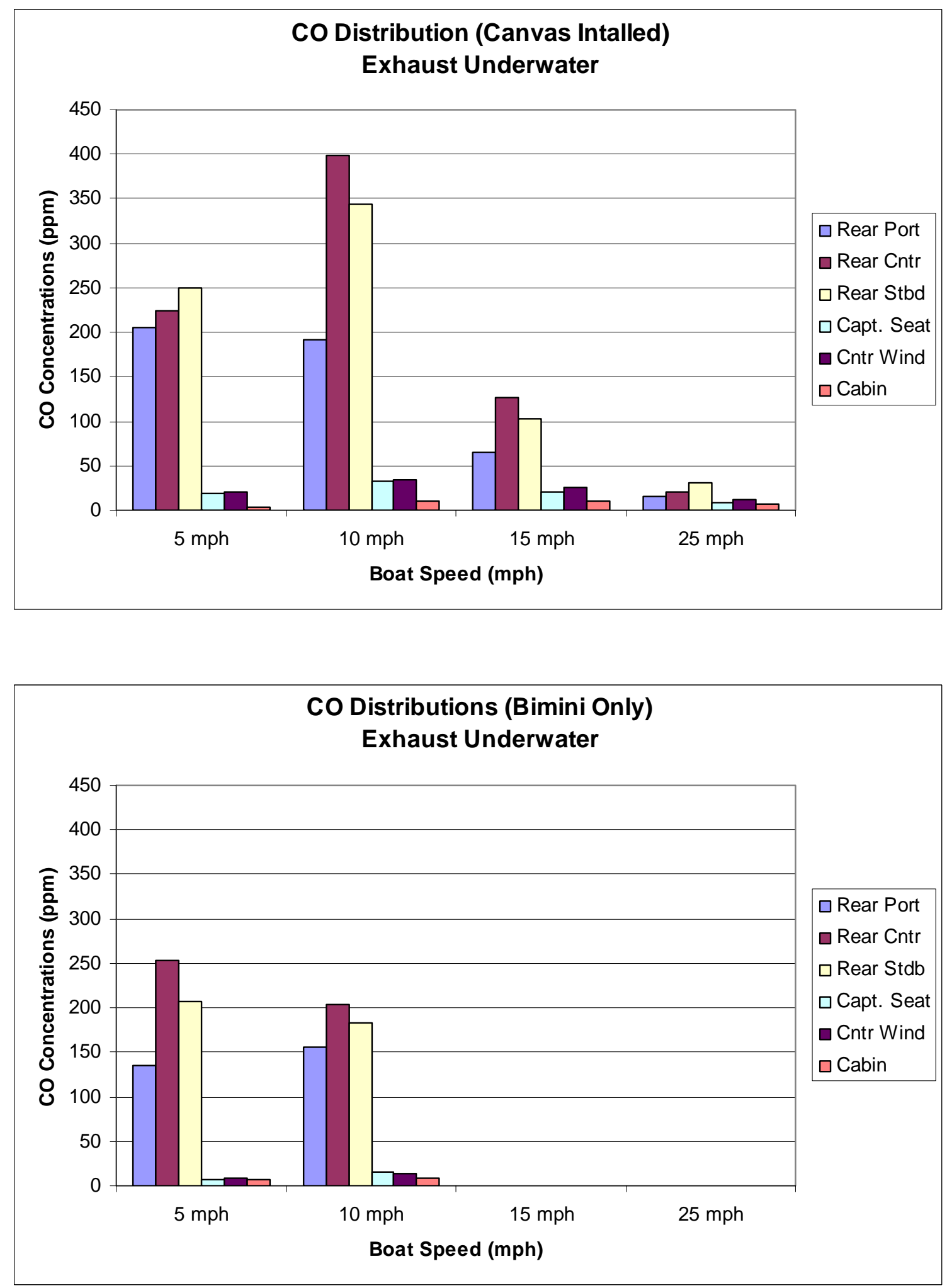


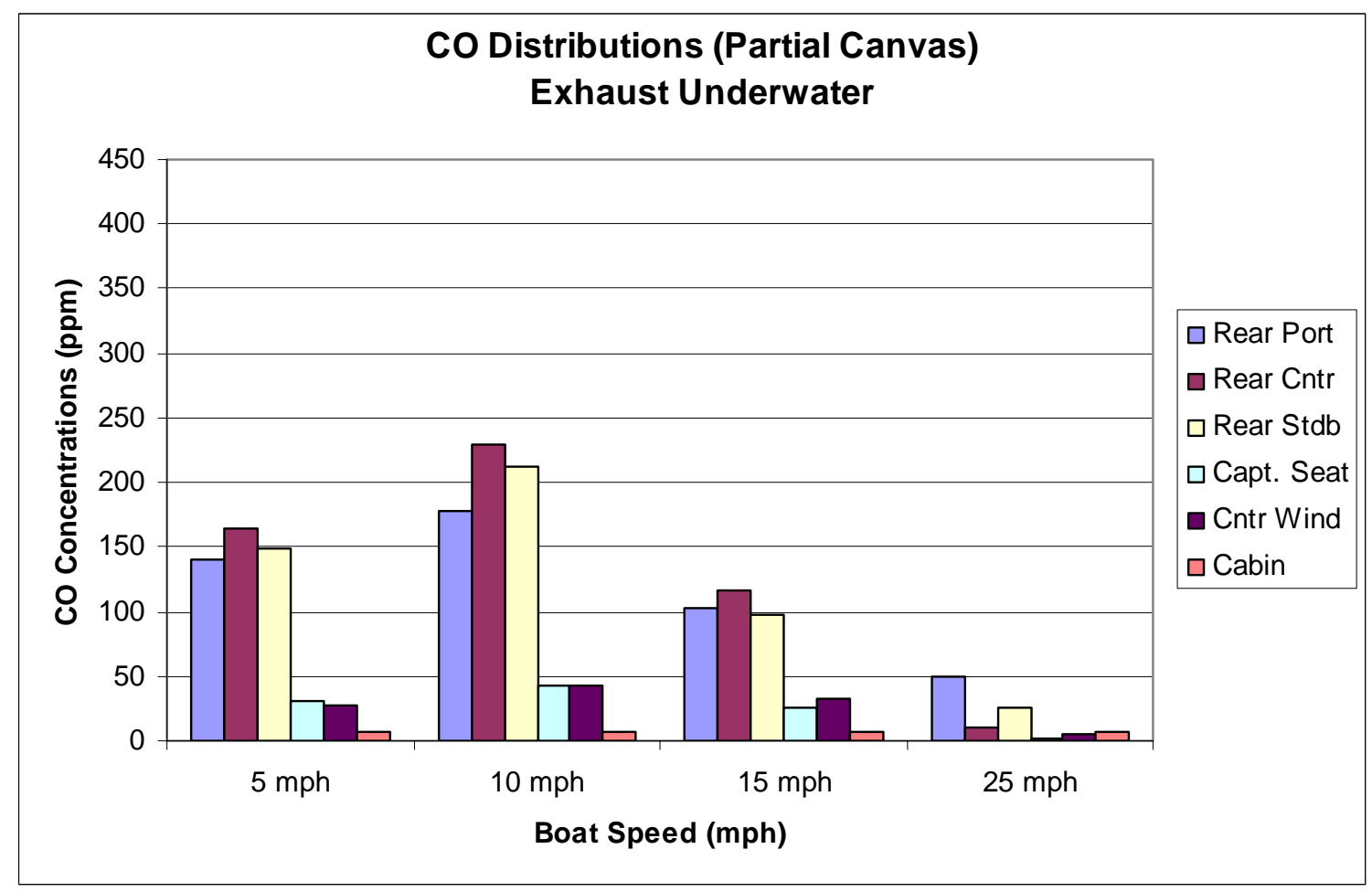


Figure 14: Boat 10 (35’) Motor Yacht Twin Crusaders 8.1L Exhaust Underwater.
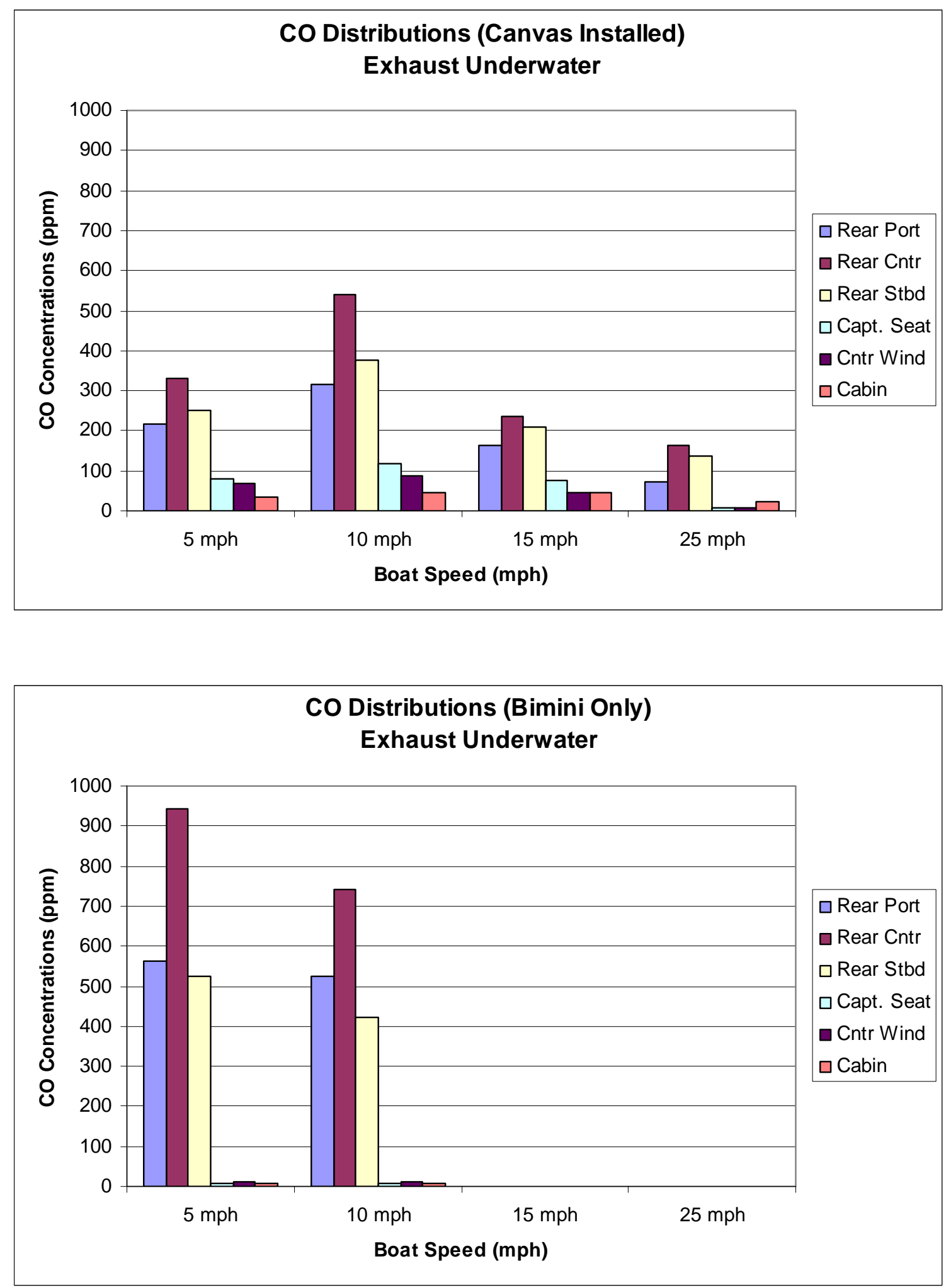


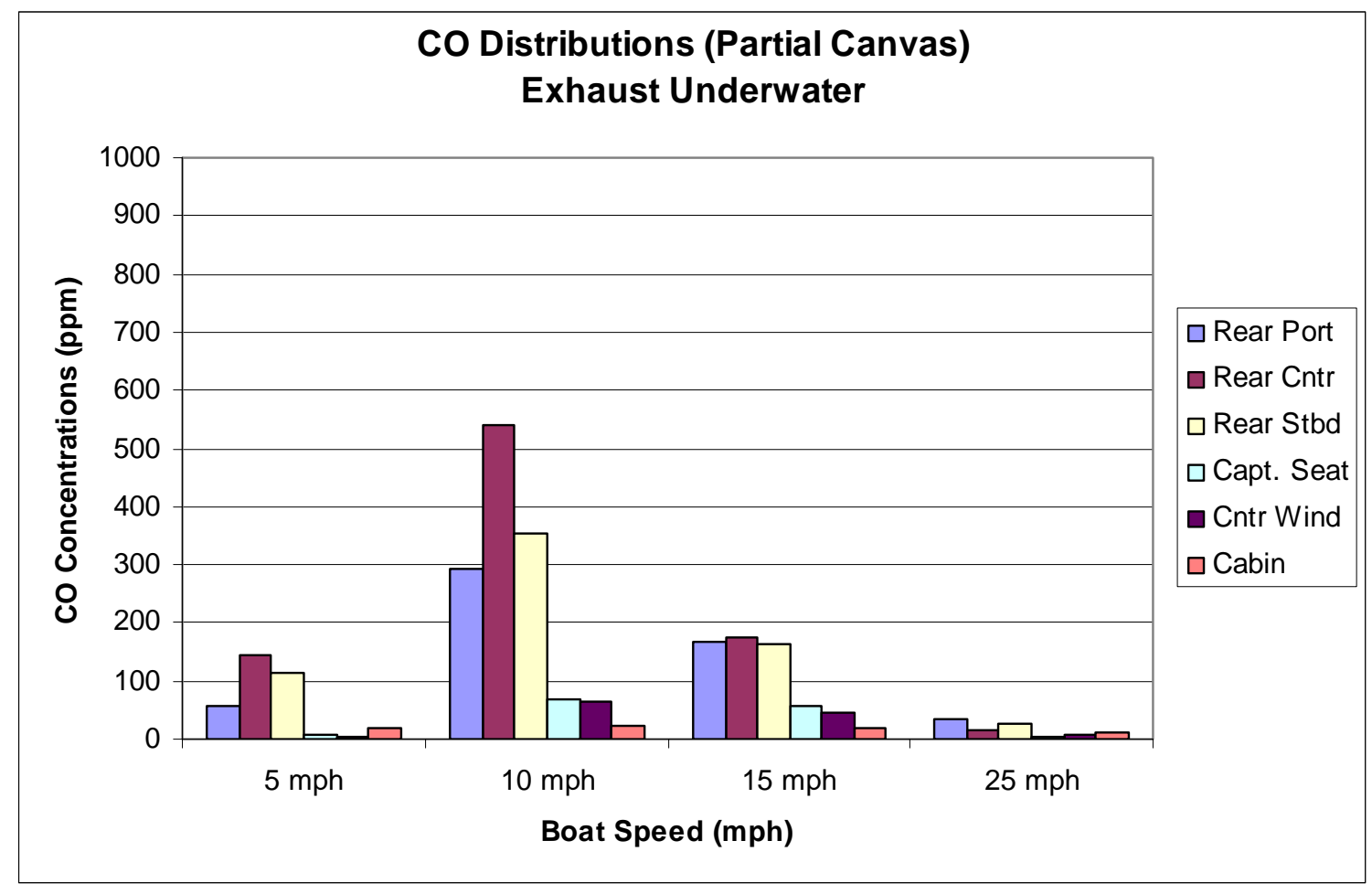

